\title{
Personality and Daily Alcohol Use Across University: Interactions with Academically Intense Events Predicting Alcohol Use Problems
}

\author{
by
}

Sean Alexander

A thesis submitted to the Faculty of Graduate and Postdoctoral Affairs in partial fulfillment of the requirements for the degree of

Master of Arts

in

Psychology

Carleton University

Ottawa, Ontario

(C) 2018

Sean Alexander 


\begin{abstract}
Extraversion and neuroticism are associated with alcohol use problems in university. Students higher in extraversion have heavier alcohol use, while neuroticism is not consistently associated with alcohol use. This study examined the hypothesis that students higher in neuroticism may drink in anticipation of stressors, namely tests and assignments, using archival data taken from the University Life Study, a longitudinal study assessing alcohol use across four years of university, with daily diary bursts each semester. Students higher in extraversion had heavier alcohol use and had increased alcohol use problems. Neuroticism was not associated with drinking outcomes, drinking before a test or assignment, or alcohol problems. Students lower in extraversion, or higher in introversion, who consumed relatively more alcohol before tests and assignments had more alcohol use problems at the end of university. Drinking alcohol in anticipation of stressors can increase alcohol dependence risk for students lower in extraversion.
\end{abstract}

Keywords: psychology, alcohol, personality, university, development 
Table of Contents

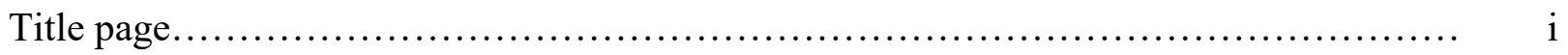

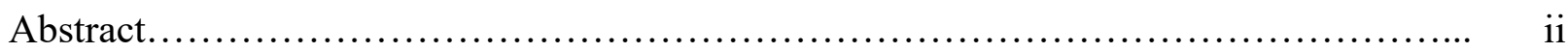

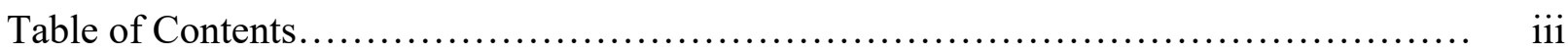

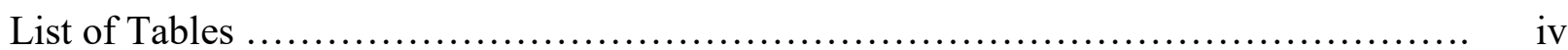

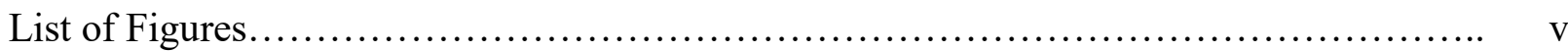

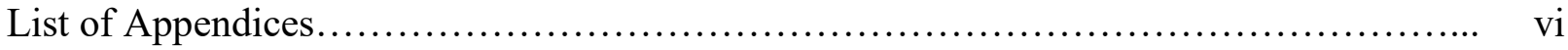

Introduction .............................................................. 1

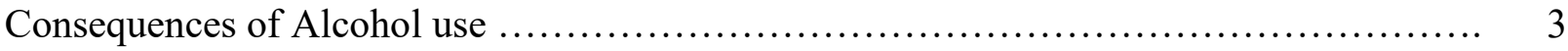

Development of Alcohol use ................................................. 5

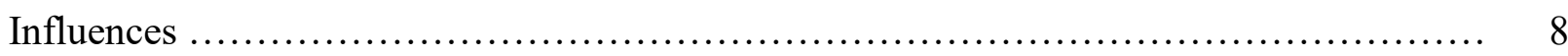

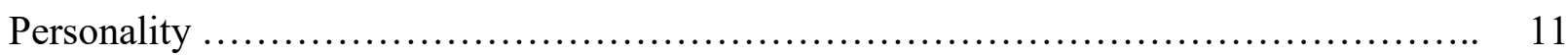

Neuroticism and Behavioural Confirmation ..................................... 16

Methodological Concerns ..................................................... 21

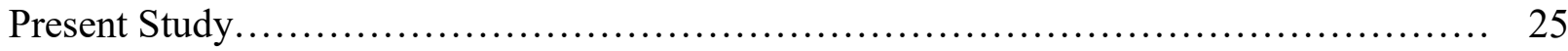

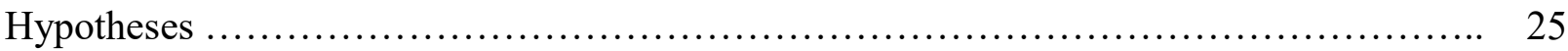

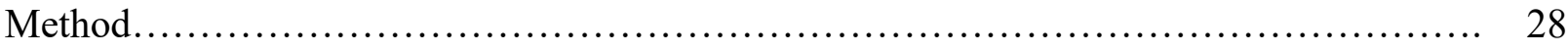

Participants.......................................................... 28

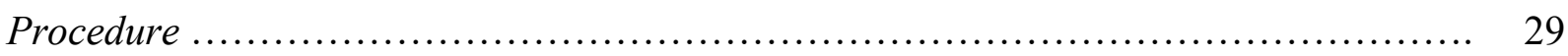

Measures ............................................................... 30

Data Management and Analysis Strategy ..................................... 33

Results .................................................................... 40

Descriptives............................................................. 40

Daily Drinking ......................................................... 45

Daily Drinking Quantity .................................................... 47

Daily Binge Drinking ....................................................... 49

Alcohol Use Problems .......................................................... 51

Summary ............................................................ 59

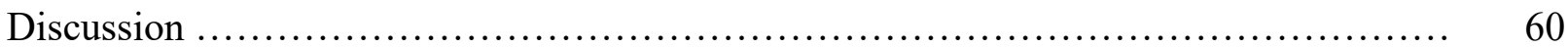

Personality and Daily Alcohol Use ............................................... 61

Academically Intense Events and Drinking Outcomes............................. 63

Predictors of Alcohol Use Problems ............................................. 66

Noteworthy Covariates .................................................... 73

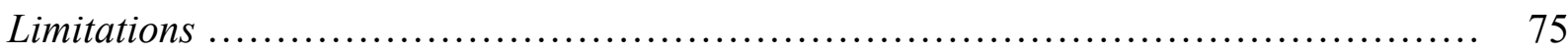

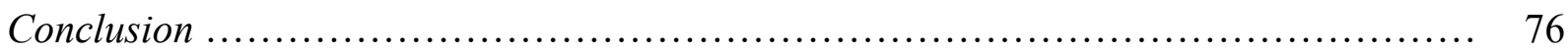

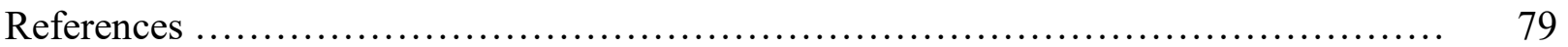




\section{List of Tables}

Table 1: Frequency and descriptive statistics for drinking contexts.................... 42

Table 2: Descriptive statistics for neuroticism, extraversion alcohol use problems......... 43

Table 3: Multilevel logistic regression model predicting daily drinking odds ............. 46

Table 4: Multilevel negative binomial regression predicting drinking quantity ............ 48

Table 5: Multilevel logistic regression model predicting daily binge drinking .............. 50

Table 6: Drinking/AIE negative binomial model predicting AUDIT score ............... 54

Table 7: Drinking/AIE logistic regression model predicting AUDIT high risk status ........ 54

Table 8: Quantity/AIE negative binomial model predicting AUDIT score ................. 56

Table 9: Quantity/AIE logistic regression model predicting AUDIT high risk status ....... 56

Table 10: Binge/AIE negative binomial model predicting AUDIT score ................... 58

Table 11: Binge/AIE logistic regression model predicting AUDIT high risk status .......... 58 


\section{List of Figures}

Figure 1: Hypothesized model between neuroticism and daily drinking before stressor.....

Figure 2: Hypothesized model between extraversion and daily drinking................. 27

Figure 3. Hypothesized model between neuroticism, extraversion, alcohol use problems... 28

Figure 4: Timeline of the proposed study.................................... 30

Figure 5: Example restructured dataset ...................................... 41

Figure 6: Histogram of drinking quantity frequency ............................... 43

Figure 7: Boxplot of drinks consumed across semesters.......................... 44

Figure 8: Interaction plot between extraversion and time predicting daily drinking odds .... 47

Figure 9: Interaction plot between extraversion and time predicting drinking quantity ..... 49

Figure 10: Interaction plot between extraversion and time predicting binge drinking ....... 51

Figure 11: Histogram of AIE slopes for daily drinking, quantity, and binge drinking ........ 52

Figure 12: Interaction plot between drinking/AIE slope, extraversion, AUDIT risk ........ 55

Figure 13: Interaction plot between quantity/AIE slope, extraversion, AUDIT score ........ 57

Figure 14: Interaction plot between binge/AIE slope, extraversion, AUDIT score.......... 59 


\section{List of Appendices}

Appendix A: International Personality Item Pool Lexical Markers.................... 112

Appendix B: Alcohol Use Disorders Identification Test........................... 113 
Personality and Daily Alcohol Use Across University: Interactions with Academically Intense Events Predicting Alcohol Use Problems

Alcohol use is ubiquitous on university and college campuses, with $84 \%$ of college students reporting consumed alcohol in Canada, and 35\% of students reporting they engaged in binge drinking in a two-week period (American College Health Association, 2016). 81\% of students at United States colleges and universities drink alcohol per year, with between $31 \%$ reporting they engaged in binge drinking in the previous week (American College Health Association, 2017). Being a part of a heavy drinking university culture is associated with increased negative consequences during university, such as damage to relationships and inability to function in daily responsibilities (Johnsson, Leifman, \& Berglund, 2008; Huckle, Pledger, \& Casswell, 2005). These alcohol-related problems and behaviours are likely to persist beyond graduation (Casswell, Pledger, \& Pratap, 2002). Students who engage in binge drinking are much more likely to have alcohol-related consequences, such as missing classes, selfinjury, and getting into trouble with police, when compared to individuals who do not engage in binge drinking (Wechsler, Dowdall, Maenner, Gledhill-Hoyt, \& Lee, 1998). Even with the prevalence of heavy alcohol use on campus, the vast majority of students decrease their alcohol use after university (Staff, Greene, Maggs, \& Schoon, 2013). Most of these students do not go on to develop an alcohol use disorder in adulthood. The prevalence of alcohol use disorders in university students is around $6 \%$ (Knight et al., 2002), and around 5\% in adulthood (Rehm et al., 2015). Many students use alcohol in hazardous ways, but do not necessarily develop an alcohol use disorder. This implies that 
there are fundamental differences between those students who do go on to develop an alcohol use disorder, and those who do not.

Two theorized pathways towards alcohol abuse, the externalizing pathway and internalizing pathway (Hussong, Jones, Stein, Baucom, \& Boeding, 2011), and the potential influences within each of those pathways, will be discussed. These pathways are characterized by particular motivations to drink alcohol, and certain personality traits are more associated with these motivations (Cox \& Klinger, 1988). The effects of the personality traits of extraversion and neuroticism (Costa \& McCrae, 1992) on drinking behaviour in university will be discussed, as these traits consist of drinking motivations and behaviours that align with the externalizing and internalizing pathways respectively. These two personality traits have been linked to hazardous alcohol use (Grekin, Sher, \& Wood, 2006), and differential long-term drinking outcomes (Hakulinen et al., 2015). Specifically, students higher in neuroticism tend to have increased likelihood of developing an alcohol use disorder, but do not consume more alcohol than others (Mezquita, Stewart, \& Ruipérez, 2010). Second, the role of stressful academic events in alcohol use will be discussed, and the role of personality in coping with the stress of academic events.

The proposed research plans to investigate the relationship between personality, academic stressors, daily drinking behaviour and eventual drinking problems. To investigate this relationship, I will be using longitudinal data drawn from the University Life Study, conducted at Pennsylvania State University (Patrick, Maggs, \& Osgood, 2010; Patrick \& Maggs, 2009). This study followed undergraduates for four years, with bursts of 14-day daily diaries in each of seven semesters over their university years. I 
hypothesize that students higher in neuroticism will be more likely to drink alcohol the day before an exam, and this will lead to an increase in alcohol problems at the end of the study, when compared to those low in neuroticism. Students high in extraversion will be more likely to drink alcohol, regardless of whether there is an exam the next day. These results with determine differences between individuals that are within the externalizing or the internalizing pathway.

\section{Consequences of Alcohol Use}

Alcohol is the most used substance among adolescents and adults (Center for Behavioural Health Statistics and Quality, 2016; Spijkerman, Knibbe, Knoops, van de Mheen, \& van den Eijinden, 2007; Gatin, 2005). Alcohol is often the first drug that individuals end up using, due to its social acceptability and widespread availability (Kirby \& Barry, 2012). Alcohol is the most common substance that is indicated in substance use disorders in Canada (Tjepkema, 2004). Alcohol use disorder is defined as a pattern of alcohol use leading to severe impairment, causing distress. Alcohol use disorder is characterized by a cluster of behaviours categorized by impaired control, social impairment, risky alcohol use, increased alcohol tolerance and alcohol withdrawal (American Psychiatric Association, 2013). Clinical diagnosis of alcohol use disorder is not necessarily tied to heavy drinking, but rather to the individual's behaviours in relation to their alcohol use. For example, university students frequently engage in heavy episodic drinking without signs of clinical distress, and most do not meet criteria for an alcohol use disorder diagnosis.

In addition to the well-known negative physiological consequences linked to disordered alcohol use (e.g., liver failure, cardiovascular disease, cancer; Hensing, 2012; 
Anderson \& Baumberg, 2006; Babor et al., 2003; Rehm et al., 2009; Rehm et al., 2003), alcohol consumption is associated with depression and anxiety (Alati et al., 2004), with evidence supporting that heavy alcohol involvement increases the likelihood of acquiring a major depressive disorder (Boden \& Fergusson, 2011). Alcohol dependence is comorbid with a variety of mental illnesses, such as obsessive-compulsive disorders, anxiety disorder, affective disorders, schizophrenia, and suicide (Regier et al., 1990; Roy \& Linnoila, 1986). Due to the large number of negative health consequences that result from heavy alcohol use, research into the reasons and risks for long term alcohol use is needed to limit the economic and health costs to the public.

Alcohol use is strongly related to many antisocial, criminal, or self-harming behaviours. Early alcohol use is associated with antisocial behaviours, aggression, decreases in mood, and poor social functioning (Johnson, Cloninger, Roache, Bordnick, \& Ruiz, 2000). Increases in alcohol use are associated with a decrease in academic performance, such as poorer grades and missing classes (Perkins, 2002a). Early onset of alcohol use is associated with increased likelihood of future alcohol dependence, and adolescent delinquency (Mason et al., 2010). Alcohol dependence is associated with suicide; alcohol use often precedes a suicide attempt (Kaplan et al., 2014), and is associated with an increased likelihood to attempt suicide (Gonzalez \& Hewell, 2012), even in adolescence (Schilling, Aseltine, Glanovsky, James, \& Jacobs, 2009). Alcohol use is also a factor in violent crimes, such as assault, homicide, burglary, and sexual assault (Martin, 2001). The behavioural consequences of heavy alcohol use are severe, especially in the university context. Given the numerous health and social problems 
caused by hazardous alcohol use, determining the factors that increase the likelihood of students' hazardous alcohol use is an important research target.

Aside from the long-term health consequences of heavy alcohol use, there are acute consequences that most people will experience from alcohol use. These consequences are usually a direct result of intoxication, rather than symptoms of dependence. The direct consequences are typically physiological, such as nausea, memory loss, and hangovers (Kuntsche, Kuntsche, Thrul, \& Gmel, 2017). Other behavioural consequences occur either directly or indirectly to alcohol use. These negative alcohol use consequences are impairments in regular functioning due to alcohol use but are not necessarily caused by symptoms of dependence (White \& Labouvie, 1989). Some examples of negative alcohol use consequences are being unable to keep up with responsibilities, noticing a change in personality, or being told by friends and family to cut down on drinking behaviour. These sorts of consequences are considered precursors to potential future alcohol dependence (White \& Labouvie, 1989). Even though these consequences are immediate, they do not seem to deter users from heavy alcohol use.

\section{Development of alcohol use}

The transition to problematic drinking for most people is likely to be during the transition to adulthood. While earlier onset of first and regular drinking is predictive of future panic disorder, psychotic symptoms, alcohol use problems (Tanaree, Assanangkornchai, \& Kittirattanapaiboon, 2017), and illegal drug and alcohol use problems (Newton-Howes \& Boden, 2016), regular drinking is extremely rare in children (Donovan, 2013). During adolescence, there is a significant increase in alcohol use, but is 
still significantly less alcohol use when compared to university samples (Donovan, 2007;

Bonomo et al., 2001). In university, the prevalence of alcohol use disorders increases sharply (Knight et al., 2002). In longitudinal twin studies, those who attend college consumed significantly more alcohol than their non-college attending sibling (Slutske et al., 2004). Alcohol use begins to drop on average once people have left college or university (Staff et al., 2013). More university-aged students drink, and in greater quantities, than any other age group (Chen, Dufour, \& Yi, 2004). This increase is partly due to the availability of alcohol, and largely due to the normalization and drinking culture that exists on campus (Osberg et al., 2010). Young adults often engage in supportive behaviour regarding each other's dangerous drinking behaviours, such as encouraging or glorifying (Hebden, Lyons, Goodwin, \& McCreanor, 2015). Due to the sharp increase and normalization of heavy drinking behaviours when entering college and university, this developmental period is likely important in the formation of alcohol use disorders.

Given the pervasiveness of the health and social risks of alcohol use, what are the reasons for excessive drinking on university campuses? The National Advisory Council on Alcohol Abuse and Alcoholism (2002) in the United States has stated that there is a culture of normalization of alcohol use on university campuses. Adolescents from highrisk populations will begin rating those risk factors, such as poor relationships with parents, as less influential to their drinking behaviours when entering university (Sznitman et al., 2013). Students entering university suddenly feel that whatever drinking behaviours they engage in are less severe, even when their drinking behaviours are held constant. University students' behaviours are primarily influenced by their peers, and 
what their peers deem to be acceptable (Perkins, 2002b). University students who believe that certain drinking behaviours are normal are more likely to feel that they identify with the student body (Lewis et al., 2010). Undergraduates tend to drastically overestimate the amount of alcohol that their peers consume (Baer, 1994). In the American College Health Association National College Health Assessment (2016), most Canadian students report using alcohol on two or fewer days per month and drinking an average of 3.89 drinks per session. However, they believe that most students drink at least ten days a month and consume an average of 5.68 drinks per session. University students also believe that alcohol is more positively accepted than it actually is (McAlaney et al., 2015). Alcohol is often used as a form of social bonding; the experiences shared between those who engaged in hazardous alcohol use give a sense of belonging, and strengthened social bonds (Workman, 2001). Even extreme cases of alcohol intoxication, such as losing consciousness or being hospitalized, allows for bonding between friend groups (Griffin, Bengry-Howell, Hackley, Mistral, \& Szmigin, 2009). However, even though there is more alcohol consumed in university, those who attend are less likely to develop an alcohol use disorder than their non-attending peers (Slutske et al., 2004). This implies that there are certain features specific to certain students that make them more likely to acquire an alcohol use disorder, independent of actual alcohol consumption.

The transition into university is considered to be a culmination of multiple developmental milestones occurring at the same time. While entering university, adolescents are suddenly given a wide amount of independence and separation from their families. There are multiple conceptual models for the transition into health behaviour risks during university (see Schulenberg \& Maggs, 2002). The university transition leads 
to an overload of developmental milestones occurring together, which increases risky behaviour as a way of coping with the overload. The transition to university opens new experiences and situations, such as new social scenarios and more opportunities for substance use and sexual experiences. Young adults are not necessarily prepared to navigate these novel situations. For example, many students may not have been to fraternity gatherings, and the availability of alcohol may not be a situation they have previously encountered. While most young adults successfully manage the cumulative and simultaneous stresses related to the university transition, some have an increased sensitivity to the potential negative effects of the university transition, increasing their likelihood to engage in risky behaviours (Graber \& Brooks-Gunn, 1996). Risky behaviours, such as heavy alcohol use, are seen as a way to negotiate these developmental transitions as part of a normative developmental trajectory (Schulenberg \& Maggs, 2002). If alcohol is a normal part of navigating the university transition, there are unanswered questions about what separates those who develop an alcohol use disorder compared to those who do not. The actual pathway between university drinking and eventual problematic alcohol use has not been fully determined.

\section{Influences}

There are three types of influences on drinking behaviour: distal, proximal, and situation specific. Distal influences are personal experiences or situations occurring during development that change an individual's likelihood to engage in a particular behavior (Martin \& Martin, 2002). Distal influences can be seen as general risk factors that do not occur close in time to a person's present situation, but that have impacted their development leading to the situation, such as trauma or personality traits. For example, 
low parental socioeconomic status is associated with an increased likelihood of alcohol problems in university (Harrell, Huang, \& Kepler, 2013). There are also differences in racial likelihood to binge drink in university (Wechsler, Dowdall, Davenport, \& Castillo, 1995). These influences are outside of the person's control, and often occurred many years earlier, but can set in motion a series of events that increase the likelihood of exposure to situations that make risky behaviour more likely. Proximal influences are risk factors for drinking that occur within a particular developmental window. For example, being white increases the odds of engaging in binge drinking (Weschler et al., 1995), but those odds decrease if attending a university with a higher percentage of minorities (Wechsler \& Kuo, 2003). The proximal influence of university interacts with the distal influence of ethnicity within the emerging adulthood developmental window to change drinking patterns. Situation specific influences are contexts occurring at the moment of a drinking decision that increase the likelihood of using alcohol (Marlatt \& Gordon, 1980). These influences cause a certain response in the individual, such as unpleasant emotions after conflict with peers (Annis \& Martin, 1985) that motivate individuals to use alcohol for a desired outcome (Cox \& Klinger, 1988). There has been limited research into the effects of situation specific drinking influences, primarily focusing on the significance of major drinking events (Carey, 1995; Carey, 1993) or the effects of global events that occur to the majority of students, such as spring break (Smeaton, Josiam, \& Dietrich, 1998), a student's $21^{\text {st }}$ birthday (Neighbors, Spieker, Oster-Aaland, Lewis, \& Bergstrom, 2005), or drinking games (Borsari, Bergen-Cico, \& Carey, 2003). Students perceive their peers to drink more during these situations (Pedersen \& LaBrie, 2008; Neighbors, OsterAaland, Bergstrom, \& Lewis, 2006), suggesting that certain situations are considered to 
be acceptable and normal to engage in heavy drinking. Each of these influences interact in each drinking decision. Proximal and situation specific influences have differential effects on students with varying distal influences. One of these distal influences is their developmental pathway towards alcohol use.

There are two hypothesized pathways towards alcohol use problems; the externalizing and internalizing pathway (Hussong et al., 2011). The externalizing pathway is conceptualized as a broad spectrum of heritable traits that predisposes an individual to substance abuse (Iacono, Malone, \& McGue, 2008). The externalizing pathway begins as a temperament problem in infancy and early childhood, where outward behavioural problems such as aggression and conduct problems become evident. This leads to an increase in antisocial behaviour during adolescence, such as illegal activity and early substance use and experimentation (Ghosh, Malhotra, \& Basu, 2016; Farmer, Compton, Burns, \& Robertson, 2002). The increase in antisocial behaviour is due to a decrease in behavioural inhibition, which is an inability to inhibit certain undesirable behaviours (Hussong et al., 2011). For example, children of alcoholics are lower in behavioural inhibition and higher in substance use problems than children of non-alcoholics (Sher, Walitzer, Wood, \& Brent, 1991). These externalizing behaviour patterns are uniquely predictive of adolescent drinking behaviour (Steele, Forehand, Armistead, \& Brody, 1995). Externalizing behaviour is reinforced through multiple factors; however, a strong behavioural factor is a peer network that supports this problematic behaviour. During college or university, problematic substance use is encouraged through a peer network that supports partying and binge drinking and is 
characterized by drinking motivated by enhancement or social goals (such as using alcohol to get drunk, or to improve social gatherings; Cooper, 1994).

The internalizing pathway is not as well researched, as it is not as common as the externalizing pathway (Hussong et al., 2011). The internalizing pathway is characterized by negative affect, depression and anxiety throughout development. The self-medication hypothesis states that some individuals use substances to combat psychological distress, and that the substance choice in substance-use disorders is not random (Khantzian, 1997; Khantzian, 1985). Due to alcohol's depressant and stimulant effects (Pihl, Paylan, Gentes-Hawn, \& Hoaken, 2003; Newlin \& Thomson, 1990; Phorecky, 1977), alcohol can be used to combat many negative internal states (Holdstock, King, \& de Wit, 2000; Holdstock \& de Wit, 1998). During college or university, this pathway should manifest as an increase in drinking motivated by a desire to cope with these negative affective states (such as drinking alcohol after a stressful situation; Cooper, 1994), with students being more likely to drink in solitude in response to interpersonal stressors (Mohr et al., 2001; Cooper, Frone, Russell, \& Mudar, 1995). It is likely that these two pathways are not fully independent. It is likely that some externalizing behaviour can be produced as a method to rid the individual of internalizing symptoms, and vice versa (Hussong et al., 2011). However, an individual should fit more strongly into either pathway; while an individual with internalizing symptoms may exhibit partying and binge drinking, they should be more likely to endorse drinking to cope motivations and drink more often alone. Each of these pathways leads to a similar outcome; alcohol abuse and substance use disorder.

\section{Personality}


Each of the developmental pathways are hypothesized to begin in early childhood and continue into adulthood. This suggests that there are specific personality factors that should potentially lead individuals into either pathway. In order to be representative of each developmental pathway, personality factors need to share important facets of each pathway's respective drinking motivation and behaviours. Personality has long been thought to be a potential cause of alcohol use problems. Early personality research into the development of alcohol problems was focused around the concept of the "alcoholic personality"; that people who abuse alcohol have personality traits that are fundamentally different from those who do not abuse alcohol (Sutherland, Schroeder, \& Tordella, 1950). Alcoholism was listed as a personality disorder in the first edition of the American Psychiatric Association's Diagnostic and Statistical Manual of Mental Disorders (DSMI; American Psychiatric Association, 1952). However, research has shown that there is limited similarity in personality between alcoholics and pre-alcoholics (Barnes, 1979). While there is no set personality type that leads individuals to alcohol use disorders, it is commonly accepted that certain personality traits increase the likelihood of engaging in problematic alcohol use behaviours, mediated or moderated by factors such as motivations and situations (see Sher, Trull, Bartholow, \& Vieth, 1999, for review). Two personality variables that have the strongest associations to problematic alcohol use that are characterized by the problematic motivations to use alcohol: extraversion and neuroticism.

Extraversion is a generally adaptive personality trait that is characterized by high sociability, sensitivity to positive reinforcement, and a focus on external stimuli (Jung, 1921; Costa \& McCrae, 1992). Individuals higher in extraversion have an increased focus 
on positive stimuli (Noguchi, Gohm, \& Dalsky, 2006). Individuals higher in extraversion tend to have greater job satisfaction, higher well-being and typically engage in healthier behaviours (Harris, English, Harms, Gross, \& Jackson, 2017; Blickle et al., 2015; Otonari et al., 2012; Lucas, Le, \& Dyrenforth, 2008; Williams, O’Brien, \& Colder, 2004). While there is no evidence that those with alcohol use disorders are higher in extraversion than non-disordered controls (Cox, 1985), evidence suggests that extraversion may play a role in the development of alcohol use disorders. Certain facets of extraversion have been linked to drinking frequency but not alcohol problems in young adults (Ruiz, Pincus, \& Dickinson, 2003). High extraversion is predictive of an earlier first onset of drinking alcohol (Hill, Shen, Lowers, \& Locke, 2000). Higher extraversion is related to an increase in heavy drinking quantity, and an increase in likelihood of becoming a heavy drinker over time (Hakulinen et al., 2015). Higher extraversion has been linked to increased likelihood of future alcohol dependence (Kilbey, Downey, \& Breslau, 1998). Extraversion is a predictor of alcohol use in preadolescents and adolescents (Merenäkk et al., 2003). Individuals who are high in extraversion experience greater mood enhancement from a dose of alcohol in laboratory settings compared to those who are lower in extraversion, measured by facial coding of Duchenne smiles (Fairbairn et al., 2015), as well as other positive facial emotions when given alcohol (Ruch, 1994).

College students who are higher in extraversion are more likely to engage in hazardous drinking behaviours (Raynor \& Levine, 2009; Martsh \& Miller, 1997). College or university students may be more likely to take advantage of opportunities to go out to parties, engage in binge drinking behaviours, and experience a greater reward from that experience than their less extraverted peers. 
Extraversion is likely an important personality dimension within the externalizing pathway. Extraversion in young children is associated with externalizing behaviours, such as aggression and hyperactivity (Berdan, Keane, \& Calkins, 2008). In adolescents, facets of extraversion are linked with externalizing behaviours (DeYoung, Peterson, Séguin, \& Tremblay, 2008). Extraversion is associated with increased outward aggression in university students (Edmunds, 1977). Meta-analysis shows that extraversion is most commonly associated with enhancement motives for drinking (Kuntsche, Knibbe, Gmel, \& Engels, 2006). Combined with earlier evidence suggesting that those with alcohol use disorders are not higher in extraversion than non-disordered controls (Cox, 1985), but that increased extraversion is related to hazardous drinking behaviours, high extraversion in young and emerging adulthood may play a crucial role in the etiology of alcohol use problems. However, all students high in extraversion are not uniformly at risk for developing an alcohol use disorder. Extraversion is generally considered to be a positive personality trait (Stopfer, Egloff, Nestler, \& Back, 2014). There are likely behavioural components to alcohol use that is unique to those higher in extraversion.

The second personality trait that has been hypothesized to be important in alcohol use problems is neuroticism. Neuroticism is characterized by high emotional instability, increased negative affect and sensitivity to negative reinforcement and negative outcomes (Costa \& McCrae, 1992). Neuroticism is linked to an increased vulnerability to mental illnesses, such as depression, anxiety, eating disorders, and somatoform disorders (Weinstock \& Whisman, 2006; Malouff, Thorsteinsson, \& Schutte, 2005; Krueger, 1999; Krueger, Caspi, Moffitt, Silva, \& McGee, 1996). Neuroticism is also a common link 
between internalizing behaviours and disorders (Griffith et al., 2010). University students who are high in neuroticism report more interpersonal stressors when compared to students who are low in neuroticism (Gunthert, Cohen, \& Armeli, 1999). Individuals who are high in neuroticism experience a greater negative reactivity to stressors when compared to those who are lower in neuroticism (Tong, 2010). Over the life span, people with high levels of neuroticism are more likely to experience negative life events and poorer quality of life (Jeronimus, Riese, Sanderman, \& Ormel, 2014). Individuals higher in neuroticism are more likely to focus on negative information (Noguchi et al., 2006). Given the high rates of comorbidity between alcohol abuse and psychiatric disorders (Regier et al., 1990), and the link between neuroticism and psychiatric disorders, there is a strong likelihood that neuroticism is important in the etiology of alcohol use disorders. The relationship between neuroticism and substance use is not clear. Rates of alcoholism are higher in individuals who are higher in negative emotionality, a key feature of neuroticism (McGue, Slutske, Taylor, \& Iacono, 1997). Neuroticism has been linked to heavy drinking in cross-sectional designs (Hakulinen et al., 2015), but other studies have shown mixed results. When other potential influences of drinking behaviour are controlled, neuroticism has not been found to be directly related to drinking quantity or frequency. Students higher in neuroticism are more likely to drink alcohol to fit in, making them more susceptible to the influence of peer alcohol use culture on campus than students higher in extraversion (Stewart \& Devine, 2000). Neuroticism has been found to predict drinking to cope motivations, which in turn predicts alcohol problems (Kuntsche, Stewart, \& Cooper, 2008; Stewart, Loughlin, \& Rhyno, 2001; Loukas, Krull, Chassin, \& Carle, 2000). These results suggest that neuroticism may also be important in 
the etiology of alcohol use problems, however research into the role of neuroticism in the development of alcohol use problems has not been straightforward.

In one two-year longitudinal study, neuroticism was uniquely predictive of individuals' symptoms of alcohol use dependence at each specific time point, controlling for other personality variables and dependence on other substances (Grekin et al., 2006). Cross-sectional research shows a correlation between neuroticism and alcohol problems (Goldstein \& Flett, 2009). In both of these studies, neuroticism was at no point significantly linked to alcohol consumption. Similarly, a study of undergraduate students found no relationship between neuroticism and alcohol use quantity (Mezquita et al., 2010). People high in neuroticism are then more likely to have alcohol use problems, and an increased likelihood of becoming alcohol dependent, but this mechanism is not exclusively related to alcohol use frequency alone. Common belief would hold that the most obvious path towards substance abuse would be excessive and problematic use of that substance. However, there may be behavioural risk factors that are unaccounted for in previous models. The context surrounding individuals with high neuroticism's alcohol use may be an important factor in predicting alcohol use problems. If those higher in neuroticism are not using alcohol in greater quantities, what are the behavioural factors that increase the likelihood of alcohol dependence?

\section{Neuroticism and behavioural confirmation}

Those with high negative emotionality tend to behave in ways that confirm their negative beliefs about themselves and the world around them. In social theories, behavioural confirmation or self-fulfilling prophecies are when a person has an expectation of a social interaction that influences the responses of the second person they 
are interacting with (Marcus \& Nardone, 1992; Jussim, 1986). For example, people who experience high levels of dysphoria are more likely to elicit responses of rejection from peers (Alloy, Fedderly, Kennedy-Moore, \& Cohan, 1998). Negative expectations or appraisals of current state can also affect an individual's performance on a particular task that confirms their beliefs. People higher in neuroticism may have more negative life outcomes due to their own behavioural influence on situations. For example, individuals higher in neuroticism experience less relationship satisfaction (Caughlin, Huston, \& Houts, 2000), they have more negative interactions in relationships (Donnellan, Conger, \& Bryant, 2004), and they appraise these interactions as more negative (McNulty, 2008; McNulty \& Karney, 2001). Those higher in neuroticism may be more likely to engage in negative behaviours that confirm their negative expectations by unconsciously manipulating the situation to increase the likelihood that their expectancies are confirmed.

A possible explanation for individuals higher in neuroticism having more alcohol-related problems despite drinking in similar quantities to peers lower in neuroticism more may lie in the times that the individuals choose to drink. Hazardous alcohol use, or alcohol use that is more likely to bring negative consequences, is perceived to be more acceptable in certain situations. Solitary drinking, which in college students is associated with higher alcohol-related problems and alcohol dependence (Keough, O’Connor, \& Stewart, 2018; Gonzalez \& Skewes, 2012), is viewed as unacceptable by other students in most situations (Grønkjær, Curtis, de Crespigny, \& Delmar, 2013). A possible moderating variable is the anticipation of a stressful event. Cognitive theories of stress suggest that individuals make appraisals of current and future 
stressors, and estimate the cognitive resources that will be required to cope with those stressors. Without perceived or actual cognitive resources available for coping, other forms of coping mechanisms are required (Lazarus \& Folkman, 1984). Individuals who experience more stressful events during their life are more likely to develop an alcohol use disorder (Boden, Fergusson, \& Horwood, 2014). Individuals are more likely to consume alcohol on days with higher stress, with an increase to daily drinking with more stressors in their work life (Liu, Wang, Zhan, \& Shi, 2009). According to the motivational model of alcohol use (Cox \& Klinger, 1988), these individuals are drinking alcohol in response to these stressors in order to cope with the increased stress. University students are also more likely to drink alcohol on days that have more stressors (Russell, Almeida, \& Maggs, 2017), but daily negative affect itself is not a significant direct predictor of increased drinking likelihood (Howard, Patrick, \& Maggs, 2015). Students who use alcohol to reduce stress tend to drink more heavily in response to stressors at the end of university (Rutledge \& Sher, 2001). People higher in neuroticism are more likely to experience negative affect, but whether negative affect associated with anticipating stressful events predicts alcohol consumption in undergraduates is an open question.

Some common sources of stress for university students are academically intense events, such as exams and assignments. Test anxiety is also a common response to future and current exams (Spielberger \& Vagg, 1995). Exams have been shown to increase physiological measures of stress, such as heart rate and cortisol level (Spangler, 1997), and epinephrine levels (Sherman, Bunyan, Creswell, \& Jaremka, 2009). Exams also increase reported levels of anxiety before and after the examination (Cohen \& Khalaila, 
2014; Spangler, 1997), as well as depression levels (Zunhammer, Eberle, Eichhammer, \& Busch, 2013). University exams create a similar stress response to validated experimental manipulations of stress and negative emotions (Henze et al., 2017). Students with high neuroticism experience more anxiety in anticipation of testing than any other big five personality trait (Borghans, Duckworth, Heckman, \& ter Weel, 2008). Academically intense events allow for investigation into stressful events that have immediate negative consequences for poor performance. Typical students reduce their alcohol use in response to academic requirements (Wood, Sher, \& Rutledge, 2007). Student who drink heavily have reduced academic performance (An, Loes, \& Trolian, 2017). Memory performance is significantly worsened the day after a drinking session (Verster, van Duin, Volkerts, Schreuder, \& Verbaten, 2003). If certain students drink to cope with the stress of future academically intense events, the positive punishment from their performance should immediately cease the behaviour. However, for those students high in neuroticism, this punishment may not outweigh the negative reinforcement given by the mood-elevating properties of alcohol.

When it comes to coping mechanisms for stress, differences between personality variables are related to different coping strategies. Individuals higher in extraversion are more likely to engage in healthy coping mechanisms, while those higher in neuroticism are more likely to engage in problematic coping mechanisms. Individuals higher in neuroticism are more likely to engage in avoidant coping, which is attempting to deal with negative emotions by avoiding or suppressing them (Connor-Smith \& Flachsbart, 2007). While those higher in neuroticism are higher in stress reactivity (Jonassaint et al., 2009), this is not true for those higher in extraversion (Evans et al., 2016). This suggests 
that there may be different patterns of alcohol consumption depending on different personality types.

The first difference in drinking behaviour patterns between personality types may lie in the social setting where drinking occurs. While most drinking occurs in a social setting, a small percentage of students drink in solitary contexts (O’Hare, 1990). Solitary drinking is the most hazardous of drinking contexts. Individuals who drink alone report more alcohol use consequences, increased motivations to use alcohol, and increased depression (Christiansen, Vik, \& Jarchow, 2002). Those who drink more when alone are also more prone to suicide ideation and have more previous suicide attempts (Gonzalez, 2012). There are personality differences in drinking contexts: individuals higher in extraversion are more likely to drink away from home for positive reasons, while those higher in neuroticism are more likely to drink alone at home for negative reasons (Mohr et al., 2001). Solitary drinking leads to worse alcohol use consequences in comparison to similar heavy alcohol use in social contexts (Keough, O’Connor, \& Colder, 2016). Individuals higher in neuroticism may be more likely to engage in hazardous drinking behaviours in solitude, while those higher in extraversion may be more likely to drink hazardously in social contexts.

The second difference in drinking behaviour patterns between personality types may lie in the situations surrounding drinking decisions. For individuals higher in neuroticism, they may be more likely to have negative expectancies of their performance on future academically intense events. In order to cope with the negative affect this expectancy creates, they may be more likely to consume alcohol. However, physiological and psychological consequences of overconsumption likely hampers students' 
performance on exams and assignments (Verster et al., 2003), leading to negative consequences linked back to alcohol use. This pattern would be reinforced by the preferential focus on negative reinforcement in those with high neuroticism (Noguchi et al., 2006), where the removal of negative mood by alcohol use would be strongly attended to, and the negative consequences of alcohol suppressed or ignored. Alcohol use becomes part of their behavioural confirmation, as the negative consequences of engaging in problematic alcohol use would confirm their expectancies of their inabilities. Not all drinking before exams is conscious or unconscious self-sabotage; some drinking at inappropriate times may be caused by neurotic students overvaluing the desire to drink to cope without thinking of future academically intense events. Students higher in impulsivity, a facet of neuroticism, drink more often in response to alcohol cues (Rubenking \& Lang, 2015), and this alcohol use impulse may be strong enough to overshadow future academically intense events. Individuals high in extraversion would not engage in this pattern, but rather would increase their likelihood of experiencing negative alcohol use consequences through heavy and hazardous usage. Due to their focus of attention on positive reinforcement (Smillie, Cooper, Wilt, \& Revelle, 2012), and the social rewards received from heavy drinking in university, individuals higher in extraversion would be more focused on the mood elevation provided by alcohol, rather than the negative consequences that their consumption would lead to.

\section{Methodological concerns}

Much of the previous research has suggested that proximal factors interact with personality in the decision to use alcohol. However, previous research into the proximal influences of drinking behaviour makes inferences about these influences using primarily 
cross-sectional methods, missing opportunities to examine effects close in time to when drinking actually occurs. Daily diaries, in contrast, are small surveys that are completed each day within the subject's natural context (Shiffman, Stone, \& Hufford, 2008; Bolger, Davis, \& Rafaeli, 2003). The primary benefit of using daily diaries is the reduction of retrospection, so there is less distance between the event of interest and the period of assessment. Larger distance between assessment and the event causes bias by the subject using a prototypical assessment of the average situation. When assessing daily drinking, typical frequency measures used in longitudinal studies underestimate the amount of hazardous drinking that an individual engages in. Diaries with shorter time windows give higher reported estimates of binge drinking and other hazardous drinking behaviors (O’Hare, 1991). During self-reports of alcohol consumption, daily diaries estimate a larger amount of alcohol consumption compared to retrospective, regardless of environment or setting (Monk, Heim, Qureshi, \& Price, 2015). This bias arises from participants' prototypes of their drinking behavior; individuals do not drink or engage in heavy drinking all of the time. There are also the memory impairments that are present with heavy alcohol use that can cause an underreporting of how many drinks were consumed while heavily intoxicated. Diaries can capture the large amount of daily variance present in proximal influences on drinking behaviours (Armeli, Todd, \& Mohr, 2005). Finally, daily dairies allow for the investigation of individual differences in alcohol use patterns, and the segregation of within-persons and between-persons variance in alcohol use likelihood.

Daily diaries however are unable to show whether daily variations are meaningful by themselves. A single day's increase in likelihood of alcohol consumption due to 
numerous factors is not necessarily meaningful information in isolation. There are two implicative questions that need to be answered by any daily diary: is a particular pattern continuous and reinforcing, and does this pattern have an impact on future outcomes? If individuals higher in neuroticism are more likely to drink on days before academically intense events, the direct consequences are not meaningful if they do not represent a pattern that repeats itself across the university years. Individuals higher in neuroticism may engage in a pervasive pattern of problematic drinking that resists being extinguished by the immediate consequences. This pattern is reinforced by the immediate removal of negative mood that alcohol provides for those higher in neuroticism. A longitudinal methodology is necessary to determine that this pattern leads to the development of negative alcohol consequences. For extraversion, a pattern of heavy drinking must be shown to lead to negative alcohol consequences that does not extinguish over time, due to the immediately reinforcing mood elevation caused by alcohol.

Given the lack of relationship between neuroticism and drinking quantity, an outcome variable of drinking quantity may not be sufficient to capture problematic drinking behaviour. Studies that include multiple measures of drinking behaviour, such as drinking quantity, frequency, and the presence of binge drinking, are associated with different motivations for alcohol use that are not uniformly hazardous (Grant, Stewart, \& Mohr, 2009). While the average alcohol consumption per occasion for students is between four and five drinks (Nealis, Collins, Lee-Baggley, Sherry, \& Stewart, 2017), it is hypothesized that those students within the internalizing pathway (Hussong et al., 2011) may not drink as much as their peers in the externalizing pathway. Even using standard definitions of what constitutes a single alcoholic drink, university students tend 
to underestimate their alcohol consumption. When creating alcoholic beverages, students overestimate the amount of alcohol required to make a single drink, leading to overconsumption and underreporting (White, Kraus, McCracken, \& Swartzwelder, 2003). Estimating the odds of any alcohol consumption, as well as any heavy or binge drinking, may reveal problematic drinking patterns exhibited by students higher in neuroticism. Negative alcohol use consequences increase linearly with increased alcohol consumption and can even occur from small amounts of alcohol use (Barnett et al., 2014). Each individual drink increases risk of negative alcohol consequences, as much as a 13\% increase in likelihood of negative consequences per drink (Scaglione et al., 2014). Measures of drinking behaviours differ greatly across studies. Using a single measure of drinking behaviour may not accurately represent the actual drinking behaviour that certain students engage in. For instance, a student could drink alcohol nearly every day, but if there is only one drink, one could argue that this does not constitute hazardous drinking behaviour. In order to get an accurate understanding of the specific drinking behaviours that students with differing personality traits engage in, multiple measures of drinking behaviour should be used.

There are also demographic differences in drinking behaviours, drinking outcomes, and personality. Men typically drink more than women; however this gender difference is getting smaller over time (Ragsdale et al., 2012; Clapp et al., 2008). Men are also at a higher risk of developing alcohol use problems (Stewart, Gavric, \& Collins, 2009). Women tend to be higher in neuroticism than men, and both genders are similar in levels of extraversion (Lynn \& Martin, 1997). There are also racial differences in alcohol 
use trends over time (Costanzo et al., 2007). These demographic differences need to be accounted for in any drinking model in university.

\section{Present study}

In order to investigate the development of the externalizing and internalizing pathway towards problematic alcohol use, I will use archival data taken from the University Life Study (ULS) conducted at Pennsylvania State University (Patrick et al., 2010; Patrick \& Maggs, 2009). The ULS was a four year, seven-wave longitudinal study with 14-day daily survey bursts every semester conducted in undergraduate students through their full university career. The study's original aim was to track development and changes in substance use and sexual behaviours throughout university, as well as during university events and milestones. Participants' personality variables were measured at baseline, and their drinking behaviours were measured daily during the seven semesters. The participants' school activities, such as exams and assignments, were also measured during the daily bursts each semester. Baseline personality measurements of neuroticism and extraversion will be used to predict different drinking behaviours in response to stressors encountered during university. These drinking patterns should be different for those who are higher in extraversion when compared with those higher in neuroticism.

\section{Hypotheses}

The first set of hypotheses examines whether baseline personality predicts increased odds of daily drinking throughout university. Neuroticism will not be predictive of a daily drinking quantity but will be predictive of daily drinking odds. Higher extraversion will lead to an increased odds of daily drinking, drinking quantity and binge 
drinking odds. There is little to no previous research investigating the potential interactions between the two personality traits and their relation to daily drinking odds. As there could be differential daily drinking and drinking patterns for those reporting high levels of both personality traits, an exploratory investigation into this relationship will be conducted.

The second set of hypotheses test differential patterns of daily drinking odds in response to future academically intense events due to personality traits. Students who are higher in neuroticism will have increased odds of daily alcohol consumption and drinking quantity on days that precede an exam or assignment. Since students with high levels of neuroticism will find the negative reinforcement of alcohol use more salient than the negative outcomes caused by their alcohol use, this pattern will be consistent throughout university. The hypothesized relationship between neuroticism and alcohol use is shown in Figure 1. Anticipation of a test or assignment will not increase daily drinking odds or drinking quantity for students high in extraversion. Since students higher in extraversion experience the positive reinforcement of alcohol use as more salient than the negative outcomes caused by alcohol use, this pattern will be consistent over the course of university. The hypothesized relationship between extraversion and alcohol use is shown in Figure 2. Similar to the first set of hypotheses, interactions between neuroticism and extraversion will be tested. 
Figure 1. Hypothesized model showing the association between neuroticism and daily drinking odds, moderated by a future academically intense event. There will be no association between neuroticism and daily drinking odds, but daily drinking odds will increase on days preceding academically intense events.

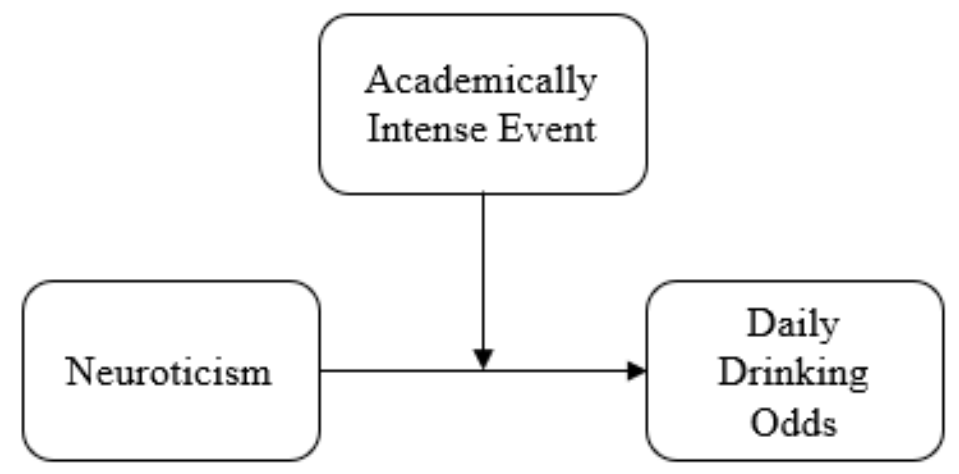

Figure 2. Hypothesized model showing the relationship between extraversion and daily drinking odds. Extraversion will be positively associated with daily drinking odds.

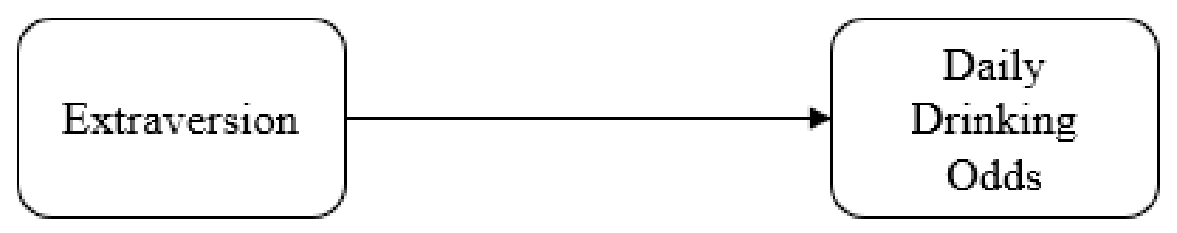

The third set of hypotheses tests whether these patterns of daily drinking lead to an increase in alcohol use problems at the end of university. Students higher in neuroticism and who are more likely to drink on days preceding exams or assignments will have more alcohol use problems at the end of university. Students higher in extraversion who are also more likely to drink and to drink heavily will be more likely to have alcohol use problems at the end of university. The hypothesized model is shown in Figure 3. Students who are high in both neuroticism and extraversion will be investigated to determine if their specific pattern of daily drinking leads to increased alcohol use problems. 
Figure 3. Hypothesized model showing association between neuroticism, extraversion, drinking before an academically intense event, and alcohol use problems. Extraversion will be directly related to alcohol use problems, while neuroticism's relationship to alcohol use problems will be moderated by anticipation of academically intense events.

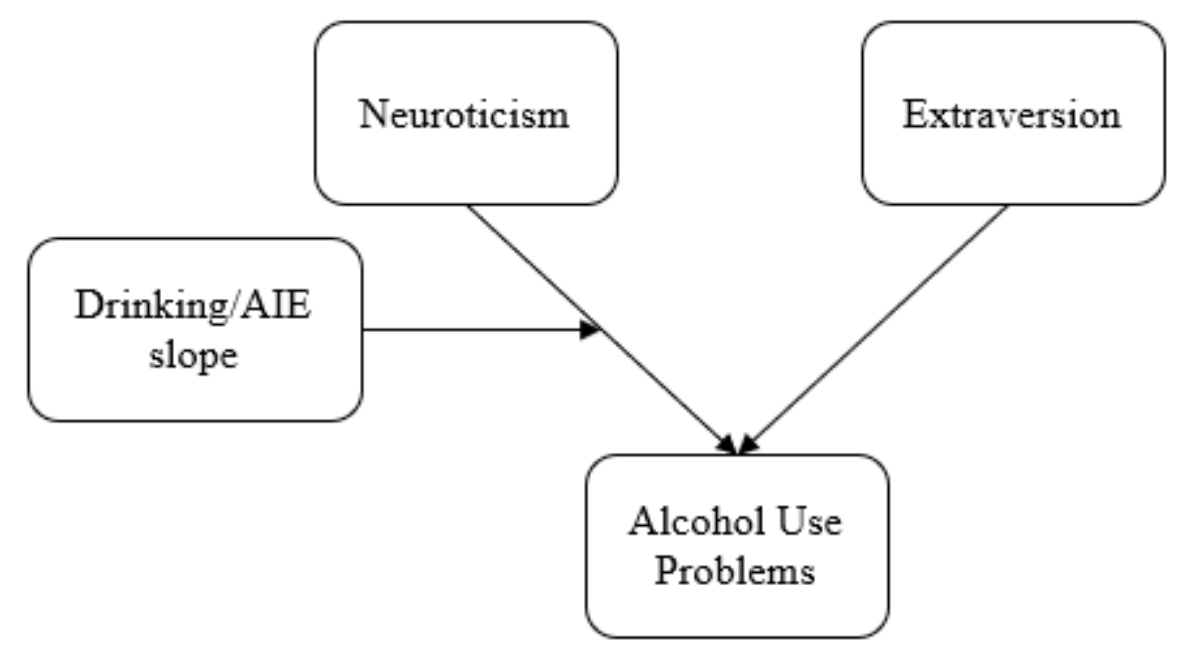

\section{Method}

\section{Participants}

Participants were $N=744$ first-time college students recruited from Pennsylvania State University during their first year to take part in the University Life Study (ULS; Patrick, Maggs, \& Osgood, 2010; Patrick \& Maggs, 2009). The ULS used a longitudinal measurement burst design, with measurement occurring once per semester for four years (seven semesters, from fall of 2007 to winter of 2011). Each burst consisted of 14 days of daily sampling during each of the four semesters, from their first year of college to their fourth year. The timing of each burst of measurement, and what was measured at each time point, is shown in Figure 4. A stratified random sampling procedure was used with respect to gender and ethnicity in order to over-represent minority populations relative to the ethnic makeup of the university. The ethnic makeup of the sample was $25.1 \%$ Hispanic/Latino, 27.4\% Caucasian, 23.3\% Asian American, 15.7\% Black, and 8.5\% 
multiracial. The sample was $49.2 \%$ male, with an average age of 18.4 , with ages ranging between 16.9 and 20.8 years. Students were eligible if they were United States citizens or United States permanent residents, were under the age of 21, and lived with 25 miles of the Pennsylvania State University.

\section{Procedure}

Eligible students were sent a letter containing information about the study, a pen, and a five-dollar cash incentive. Five days later, these students were sent an email with a link directing them to an online baseline survey, containing demographics, personality measures, and a variety of survey instruments assessing student drinking, sexual behaviour, and other health-related risk and protective factors. The following day, students who completed the baseline survey were invited to begin 14 daily surveys over consecutive days, measuring the participants' daily drinking behaviours, their school activities, mood, and daily stressors. Each daily survey was phrased to ask about the previous day and was available to be completed for two days. Each semester followed a similar pattern, with an online link to a larger survey sent to each participant asking about the semester, and smaller daily surveys for 14 days each semester being completed in the same way. This procedure continued for seven semesters, leading to a maximum of 98 days for each participant. Participants had an average daily diary completion rate of $77.8 \%$ over the course of the study, meaning each participant on average completed 76.2 of the possible 98 daily diaries over the course of the study. Overall retention ranged from $96.2 \%$ in the first semester, to $79.4 \%$ in the fall of year four. 
Figure 4. Timeline of the study. First column shows each wave and what was measured during each semester. The second column shows what was measured daily during the 14day daily diary burst. IPIP: International Personality Item Pool (Goldberg, 1999), AUDIT: Alcohol Use Disorders Identification Test (Babor et al., 2003).

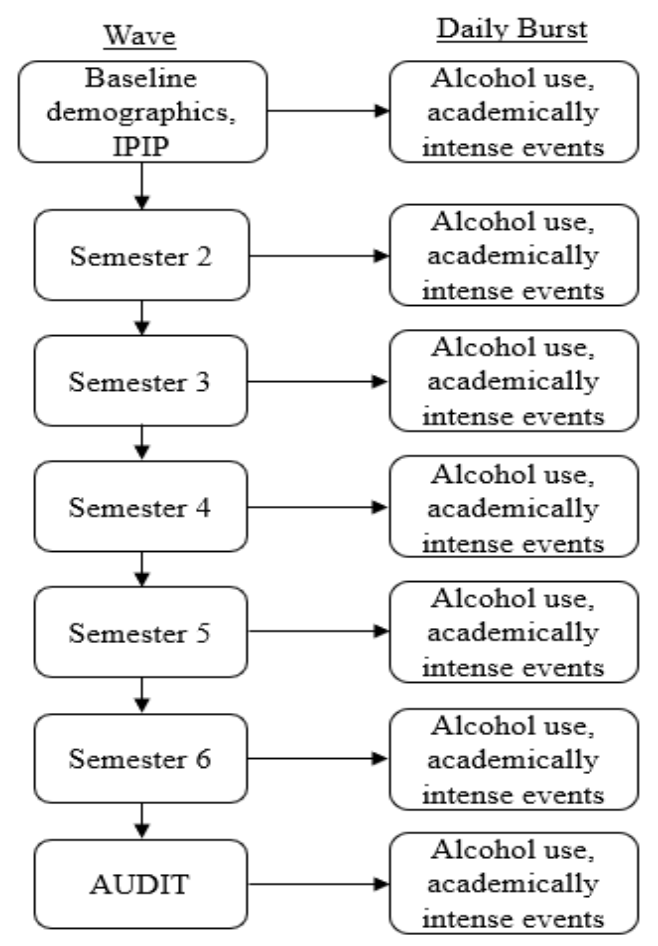

\section{Measures}

Neuroticism and extraversion. Personality variables were measured with items taken from the International Personality Item Pool (IPIP; Goldberg et al., 2006;

Goldberg, 1999). The IPIP is an internet-based collection of open free access personality items from a variety of questionnaires, with reliability information and correlations between each scale. This allows for users to choose the personality inventory that works best with their research and be able to directly relate that information to other well-known personality inventories. The personality inventory used to measure neuroticism and extraversion was derived from a lexical factor markers scale created by Goldberg (1992). Lexical factor markers are abbreviated sentences that describe features of a personality trait, derived from descriptions from subjects or semantic similarity to each trait 
(Norman, 1963). Participants were prompted to rate statements about their characteristics in relation to their peers. Neuroticism was measured by 10 items (e.g., "get stressed out easily") on a scale from $0=$ very inaccurate to $4=$ very accurate. Extraversion was also measured by 10 items on a similar scale (e.g., "am the life of the party"). The lexical factor markers used correlate highly with the lexical factor markers originally derived from the big five personality traits (Goldberg et al., 2006; Costa \& McCrae, 1992). Other personality subscales from the big five were not included. Personality was assessed at baseline. The internal consistency of the neuroticism scale was measured with Cronbach's alpha at $\alpha=0.86$, and the internal consistency of the extraversion scale was $\alpha$ $=0.88$.

Daily alcohol use. Alcohol use was measured each day during each 14-day burst each semester, with a question asking participants "How many drinks of alcohol did you drink yesterday?” A definition of a single drink was posed as one 12-ounce glass of beer or cooler, a 5-ounce glass of wine, or a drink containing one shot of liquor or half an ounce of absolute alcohol. This definition was written and visually shown to participants. This definition followed the National Institute on Alcohol Abuse and Alcoholism questionnaire guidelines (NIAAA, 2003). The range of responses available was zero to 26 drinks. This was split into three variables: whether drinking occurred $(0=n o$, and $1=$ yes), how many drinks were consumed, and whether or not binge drinking occurred $(0=$ no, and $1=y e s)$. Binge drinking was defined as drinking 5 or more drinks during a drinking session. Self-reported alcohol consumption is generally considered to be accurate when paired with confidentiality (Sobell \& Sobell, 1990). 
Drinking context. Drinking context was measured each day during each 14-day daily diary burst each semester, with a question asking participants "Where were you and who were you with when you drank alcohol?" Social settings options consisted of alone, with friends, with a romantic partner, a large group, and their parents. Locations included residence hall, bar or restaurant, a fraternity house, their apartment or home, a major entertainment event, or somewhere else. Participants were asked to select all locations and social settings that applied. As only drinking alone or drinking with others was of interest, all contexts were condensed into a single variable, where $0=$ any location while alone and 1 = any location with others. If no drinking was reported, drinking context was set to missing.

Stressful academic events. Daily academic experiences were measured using a three-item questionnaire (Galambos, Dalton, \& Maggs, 2009). The first item asked whether the students had attended all of their classes, if they had any, the previous day. The second item asked whether the students had an exam or quiz the previous day, and the third item asked whether students had an assignment due the previous day. The presence of an academically intense event (exam/quiz or assignment due) was coded as $0=$ no, and $1=$ yes. Since each question refers to whether the students had an exam the previous day, a new variable was created to represent daily anticipation of academically intense events. For example, if a student answers on a Wednesday that they had an exam the previous day (Tuesday), then they anticipated the exam on Monday. Drinking behaviour on Monday would be linked in the dataset to having an exam on Tuesday.

Alcohol problems. Alcohol use problems were measured using the Alcohol Use Disorders Identification Test (AUDIT; Babor, Higgins-Biddle, Saunders, \& Monteiro, 
2001). The AUDIT is a 10-item questionnaire with items measuring the frequency of different hazardous drinking behaviours at the time of measurement. The AUDIT contains questions about drinking quantity and frequency, and different negative consequences that can result from hazardous drinking (e.g., "How often during the last year have you needed a first drink in the morning to get yourself going after a heavy drinking session"). Higher scores suggest more alcohol use problems and indicate higher risk for developing an alcohol use disorder. The AUDIT has been validated in university students (Fleming, Barry, \& Macdonald, 1991) and cross-culturally in multiple countries (Saunders, Aasland, Amundsen, \& Grant, 1993; Saunders, Aasland, Babor, de la Fuente, \& Grant, 1993). Alcohol use problems were measured once, in semester seven (Fall of students' fourth year). Internal reliability was measured using Cronbach's alpha, $\alpha=$ 0.82. A variable for high-risk for alcohol use disorders was created, where any student who scored an eight or higher on the AUDIT was given a value of one.

\section{Data Management and Analysis Strategy}

The first step was to replicate previous findings, showing that neuroticism is not significantly linked to drinking quantity, but is significantly linked to future alcohol problems. A replication of previous findings is necessary to add validity to each hypothesis test. To account for the clustered data and dependency between variables, a logistic multilevel regression model was used for analysis. Typical ordinary least squares (OLS) regression can only accurately estimate parameters when observations are independent. The dataset used in this study is clustered; multiple observations are available from each participant. Any individual observation within any cluster (i.e., a single repeated measure within a person) is likely to be more similar to other observations 
in the same cluster than to observations in other clusters (Galbraith, Daniel, \& Vissel, 2010). This dataset contains three levels of clustering: the individual, each semester, and each 14-day daily diary burst. Since observations within each cluster are dependent, traditional OLS regression overestimates the amount of unique information contained in the data, leading to smaller standard errors and more Type I errors (Nezlek, 2008). Multilevel modelling, or hierarchical modelling, allows for separate estimation of both within-person and between-person variance included in clustered data, leading to more accurate standard errors and parameter estimation. This method is particularly useful for any research that contains daily diaries, which are clustered within an individual. Multilevel models have fixed effects as predictors, and multiple error terms estimated as random effects (de Leeuw \& Meijer, 2008; Nezlek, 2003; Nezlek, 2001). Multilevel model estimation procedures essentially estimate a unique regression equation for each person, allowing for longitudinal data, which often contains large amounts of missing data, to be analyzed without losing entire individuals due to listwise deletion, and allowing for accurate parameter estimates with all variables. For this study, analysis was split into three levels: days (level 1) are nested within semesters (level 2) which are nested within students (level 3). Variation during each day is modelled within each semester, which is modelled within each individual.

In creating each model, control variables and predictors are added to the model at each level that it applies to; the individual, the semester, or the day. Person-level neuroticism and extraversion measures will be set as predictors at level 3. Anticipation of an academically intense event is entered as a dummy-coded predictor at level 1. Demographic control variables are added to the model at level 3. Whether or not testing 
occurred on a weekday or weekend are added to the model at level 1. Model selection is determined with a forward stepwise procedure, with each addition to the model assessed for goodness of fit. Main effects of all variables remain in the model. Previous research involving alcohol use over time within this sample and visual inspection of the longitudinal data suggests potential quadratic and cubic relationships (Howard et al., 2015). Polynomial time trends are added individually and are retained if a significant improvement in model fit is detected, measured by the difference in -2log likelihood scores as a $\chi^{2}$ test with a single degree of freedom.

Categorical control variables were coded using unweighted effects coding. Ethnicity was divided into categories based on largest categories of self-identification: Caucasian, Black, Asian, Hispanic, and “other" representing mixed ethnicities. Gender and weekend control variables were also coded using unweighted effects coding. Neuroticism and extraversion scores were created using the mean response of the ten items, while AUDIT scores were the sum of coded values corresponding to the Babor et al. (2001) guidelines. Continuous variables, including neuroticism, extraversion, and age, were each mean-centered to help make intercepts of models have more straightforward interpretations.

Parameter estimates in multilevel models are compared to an unconditional means model for hypothesis testing, similar to OLS regression (Kutner, Nachtsheim, Neter, \& Li, 2005). The unconditional means model is a three-level model with no predictors entered (Raudenbush \& Bryk, 2002), and is expressed as follows:

\section{Level 1:}

$$
g\left(Y_{i j k}\right)=\pi_{0 j k}+e_{i j k}
$$


where

$g$ is the logit function, or the inverse of the natural logarithm of the odds of $Y_{i j k}$;

$Y_{i j k}$ is the probability of consuming alcohol on day $i$ within semester $j$ for

individual $k$;

$\pi_{0 j k}$ is the average log odds of daily alcohol consumption in semester $j$ for

individual $k$; and

$e_{i j k}$ is the random deviation of an individual day from the average in semester $\mathrm{j}$ for person $\mathrm{k}$.

The indices $i, j$, and $k$ represent days, semesters, and individuals, where there are

$i=1,2, \ldots I_{j k}$ days within $j$ semesters in individual $k$;

$j=1,2, \ldots J_{k}$ semesters within individual $k$; and

$k=1,2, \ldots K$ individuals.

In this level of the model, the odds of consuming alcohol is dependent on the average daily odds of consuming alcohol for each individual, plus random daily error.

\section{Level 2:}

$\pi_{0 j k}=\beta_{00 k}+r_{0 j k}$

where

$\pi_{0 j k}$ is as defined above;

$\beta_{00 k}$ is the average log odds of daily drinking for individual $k$; and

$r_{0 j k}$ is the random deviation of each semester from average daily drinking for

person $\mathrm{k}$.

This level of the model estimates the average probability of consuming alcohol on any given day within a given semester. 


\section{Level 3:}

$$
\beta_{00 k}=\gamma_{000}+u_{00 k}
$$

where

$\beta_{00 k}$ is the average log odds of daily alcohol use for individual $k$;

$\gamma_{000}$ is the grand mean log odds of daily drinking across all students;

and

$u_{00 k}$ is the random deviation of person $k$ from the grand mean.

This level of the model estimates the overall average probability of consuming alcohol on any given day in any semester. Together, these three levels of analysis can be expressed more simply in a reduced single equation:

$$
g\left(Y_{i j k}\right)=\gamma_{000}+e_{i j k}+r_{0 j k}+u_{00 k}
$$

This model allows for predictions of variance due to each day (level 1), each semester (level 2), and each individual (level 3) to be accounted for separately.

Conditional Means Models. Each personality variable is entered into a conditional model, including all predictors and control variables. The reduced hypothesized model is as follows:

$$
\begin{aligned}
& g\left(Y_{i j k}\right)=\gamma_{000}+\gamma_{100}(\text { academically intense event })+\gamma_{010}(\text { time })+\gamma_{001}(\text { neuroticism })+ \\
& \gamma_{002}(\text { extraversion })+\gamma_{101}(\text { neuroticism } X \text { academically intense event })+ \\
& \gamma_{102}(\text { extraversion } X \text { academically intense event })+e_{i j k}+r_{0 j k}+u_{00 k}
\end{aligned}
$$

This models the log odds of daily drinking as a product of the presence of a future academically intense event, neuroticism, extraversion and interactions between them. The academically intense event variable models differences in the log odds of daily drinking the day before a test or assignment occurs. The neuroticism and extraversion variables 
model changes in the log odds of daily drinking predicted by mean individual-level neuroticism and extraversion. The interaction term between neuroticism and academically intense event models whether students higher in neuroticism will have higher odds of drinking on the day before an academically intense event, while the extraversion and academically intense event models the same concept but for extraversion. Similar models are created predicting daily drinking quantity and binge drinking odds. Covariates are included in the model but are not shown in the equation.

Semester Seven Alcohol Use Problems. In order to test whether daily drinking on days preceding an academically intense event predicts increased alcohol use problems, in essence, a person-level regression for each student is created modelling their individual average daily relationship between a future academically intense event and each of the three drinking outcomes. Individual daily drinking slopes for each student is saved (i.e., predicted scores; following Russell et al., 2017) and used as a predictor variable for alcohol use problems. For each drinking outcome, its relationship to academically intense events will be labelled:

Daily drinking odds before an academically intense event (AIE) $=$ Drinking/AIE slope

Daily drinking quantity before an academically intense event (AIE) $=$ Quantity/AIE slope

Daily binge drinking odds before an academically intense event $(\mathrm{AIE})=$ Binge/AIE slope

The mean fixed slope between future academically intense events and all three drinking outcomes was added to each individual student's slope to reduce collinearity 
between students (Russell et al., 2017). Each slope was multiplied by one hundred to make odds ratios and regression coefficient interpretation more straightforward. These individual slopes for each student were then used as predictors for alcohol use problems at semester seven. A negative binomial regression was used to predict AUDIT scores at semester seven, while a logistic regression was used to predict high-risk AUDIT status: $Y_{i}=\beta_{0}+\beta_{1}($ drinking $/$ AIE slope $)+\beta_{2}$ (average drinking probability $)+\beta_{3}$ (average academically intense events $)+\beta_{4}($ neuroticism $)+\beta_{5}($ extraversion $)+$ $\beta_{6}($ neuroticism $\mathrm{x}$ drinking/AIE slope $)+\beta_{7}($ extraversion $\mathrm{x}$ drinking/AIE slope $)+e_{i}$ where

$Y_{i}$ is the sum of AUDIT alcohol use problems, or the log odds at being at high risk for alcohol dependence.

The $\beta_{1}$ coefficient represents the change in alcohol use problems for a one-unit increase in the average relationship between daily drinking odds in anticipation of an academically intense event. The $\beta_{4}$ coefficient tests whether there is a change in alcohol use problems for each point change in neuroticism, while the $\beta 5$ coefficient tests the same effect for extraversion. The interaction term between neuroticism or extraversion and drinking/AIE slope allow for testing of how the odds of drinking in anticipation of a test or assignment affects alcohol use problems for students with differing levels of neuroticism or extraversion. The model also accounts for effects of each person's average probability of consuming alcohol and the average number of academically intense events. The error term in this equation captures the random differences between individuals in alcohol use problems. This technique allows judgement on whether students higher in either neuroticism or extraversion have an increase in alcohol use problems uniquely 
predicted by their general tendency to drink before a test or assignment across seven semesters of university (Russell et al., 2017; Mohr et al., 2013).

\section{Results}

\section{Descriptives}

Out of $N=744$ participants recruited, 609 students remained in the study until semester seven. A total of 62,160 daily diaries were recorded out of a possible 72,912 days. Out of the total recorded days, there were 7,633 days on which drinking any amount of alcohol was reported, with $M=5.93, S D=4.10$ drinks reported during each drinking day. This is consistent with previous studies average drinking per session, however the exact number may vary due to number of binge drinkers present in a sample (American College Health Association, 2016; Stahre, Naimi, Brewer, \& Holt, 2006; Greenfield \& Rogers, 1999).

In order to analyze days where academically intense events occurred, and whether drinking occurred the previous day, a new variable was created to represent days where academically intense events occurred. This was done by essentially shifting all data so that each daily observation contained whether an academically intense event occurred that day, and whether drinking occurred the previous day. An example dataset showing how the data was restructured is shown in Figure 5. There was no drinking information for the day before Diary Day 1 of each semester wave, and drinking information from the final diary day was lost. This left a total of 57,720 daily diaries in the final set for analysis. 
Figure 5. Example data showing data restructuring to create variable to represent drinking information for the day preceding an academically intense event.

\begin{tabular}{|c|c|c|c|c|c|c|c|}
\hline \multicolumn{4}{|c|}{ Original Data } & \multicolumn{4}{|c|}{ Restructured Data } \\
\hline ID & $\begin{array}{l}\text { Diary } \\
\text { Day }\end{array}$ & $\begin{array}{l}\text { Test } \\
\text { Today }\end{array}$ & $\begin{array}{l}\text { Drink } \\
\text { Today }\end{array}$ & ID & $\begin{array}{l}\text { Diary } \\
\text { Day }\end{array}$ & $\begin{array}{l}\text { Test } \\
\text { today }\end{array}$ & Drink yest. \\
\hline 1 & 1 & 0 & 1 & 1 & 1 & 0 & - \\
\hline 1 & 2 & 0 & 0 & 1 & 2 & 0 & 1 \\
\hline 1 & 3 & 1 & 1 & 1 & 3 & 1 & 0 \\
\hline 1 & 4 & 0 & 1 & 1 & 4 & 0 & 1 \\
\hline 1 & 5 & 1 & 0 & 1 & 5 & 1 & 1 \\
\hline 1 & 6 & 0 & 0 & 1 & 6 & 0 & 0 \\
\hline 1 & 7 & 1 & 1 & 1 & 7 & 1 & 0 \\
\hline 1 & 8 & 1 & 0 & 1 & 8 & 1 & 1 \\
\hline 1 & 9 & 0 & 1 & 1 & 9 & 0 & 0 \\
\hline 1 & 10 & 0 & 1 & 1 & 10 & 0 & 1 \\
\hline 1 & 11 & 0 & 0 & 1 & 11 & 0 & 1 \\
\hline 1 & 12 & 1 & 0 & 1 & 12 & 1 & 0 \\
\hline 1 & 13 & 0 & 0 & 1 & 13 & 0 & 0 \\
\hline 1 & 14 & 1 & 1 & 1 & 14 & 1 & 0 \\
\hline
\end{tabular}

Note: $0=$ no test/alcohol use, $1=$ yes to test/alcohol use.

The quantity of days in different drinking contexts is shown in Table 1. When drinking alone or on a weekday, there were fewer drinks consumed when compared to drinking on weekends or drinking with others. Over seven semesters, students reported 10,719 days with tests or exams, and 11,778 days with assignments due. There was an inverse relationship between academically intense events and drinking days, where the most drinking occurred on days with the lowest amount of academically intense events. There was still considerable overlap, however, with 2,213 drinking days occurring before an academically intense event. 
Table 1. Frequency and descriptive statistics for number of days and their respective context, with average drinks consumed in each context. Different contexts of the same category are grouped together.

\begin{tabular}{lccc}
\hline Drinking Context & $\begin{array}{c}\text { Frequency }(\% \text { of drinking days, } \\
N=7241)\end{array}$ & M(SD) & Median \\
\hline Drinking alone & $147(2.03 \%)$ & $2.67(3.69)$ & 1.00 \\
Drinking with others & $6834(94.41 \%)$ & $6.02(3.69)$ & 5.00 \\
Drinking alone and with others & $226(3.12 \%)$ & $6.80(4.03)$ & 5.00 \\
\hline Drinking on a weekday & $1193(16.48 \%)$ & $4.79(3.94)$ & 4.00 \\
Drinking on a weekend day & $6048(83.52 \%)$ & $6.21(4.09)$ & 5.00 \\
\hline Day before test & $812(11.21 \%)$ & $5.92(4.05)$ & 5.00 \\
Day before assignment & $996(13.76 \%)$ & $5.73(3.78)$ & 5.00 \\
Day before both test and & $405(5.59 \%)$ & $5.76(4.13)$ & 5.00 \\
assignment & $2213(30.56 \%)$ & $5.97(4.10)$ & 5.00 \\
Any academically intense & $4430(61.18 \%)$ & $6.06(4.15)$ & 5.00 \\
$\quad$ event & Without test or assignment & & \\
\hline
\end{tabular}

Note: Weekends are Thursday-Saturday, weekdays are Sunday-Wednesday.

Mean drinks across different contexts were similar, and consistent with previous samples. Solitary versus social drinking was measured, but there were only 147 exclusively solitary drinking days measured out of a total of 7,241 drinking days. One third of all drinking days occurred before an academically intense event. Men drank more alcohol per drinking session on average $(M=7.20, S D=4.70)$ when compared to women $(M=5.02, S D=3.25)$. However, there were more drinking days for women than men.

Descriptive statistics for neuroticism, extraversion and alcohol use problems are shown in Table 2. Means across these categories are similar to previous samples. Neuroticism and extraversion were significantly negatively correlated $(r=0.22, p<.001)$. There were minimal gender differences in personality. Women were slightly higher in both neuroticism (female $M=1.72, S D=0.74$; male $M=1.33, S D=0.72$ ) and extraversion (female $M=2.45, S D=0.77$; male $M=2.33, S D=0.74$ ). 
Table 2. Descriptive statistics for continuous variables of personality and alcohol use problems.

\begin{tabular}{llll}
\hline & $\mathrm{M}(\mathrm{SD})$ & $\mathrm{N}$ & \multicolumn{1}{c}{ Range } \\
\hline Neuroticism & $1.53(0.76)$ & 743 & $0.00-3.80$ \\
Extraversion & $2.39(0.76)$ & 744 & $0.10-4.00$ \\
AUDIT & $6.89(5.33)$ & 605 & $0.00-30.00$ \\
\hline
\end{tabular}

Note: AUDIT $=$ Alcohol Use Disorders Identification Test.

The frequency of total drinks reported per drinking session is shown in Figure 6. The distribution of alcoholic drinks per day was extremely positively skewed, as most days per participant had no alcohol use reported. On drinking days, there was still an extreme positive skew, with most participants reporting between one and five drinks per drinking session. The majority of drinking occurred on Thursdays, Fridays, and Saturdays, which is consistent with previous samples (Kuntsche \& Gmel, 2013). Drinks per drinking session was consistent across semesters, as shown in Figure 7.

Figure 6. Histogram showing the frequency of number of drinks reported per drinking day across university.

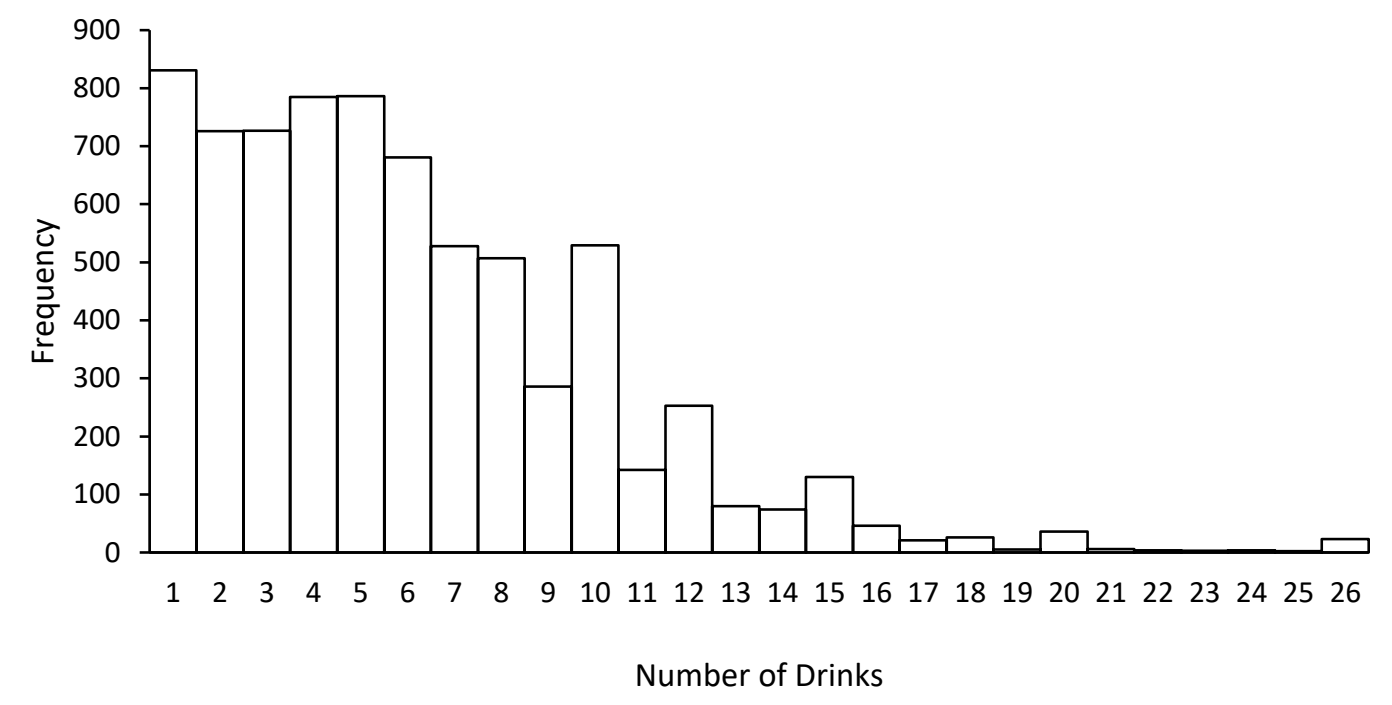


Figure 7. Boxplot showing the distribution of alcoholic drinks consumed per drinking occasion across all semesters in university.

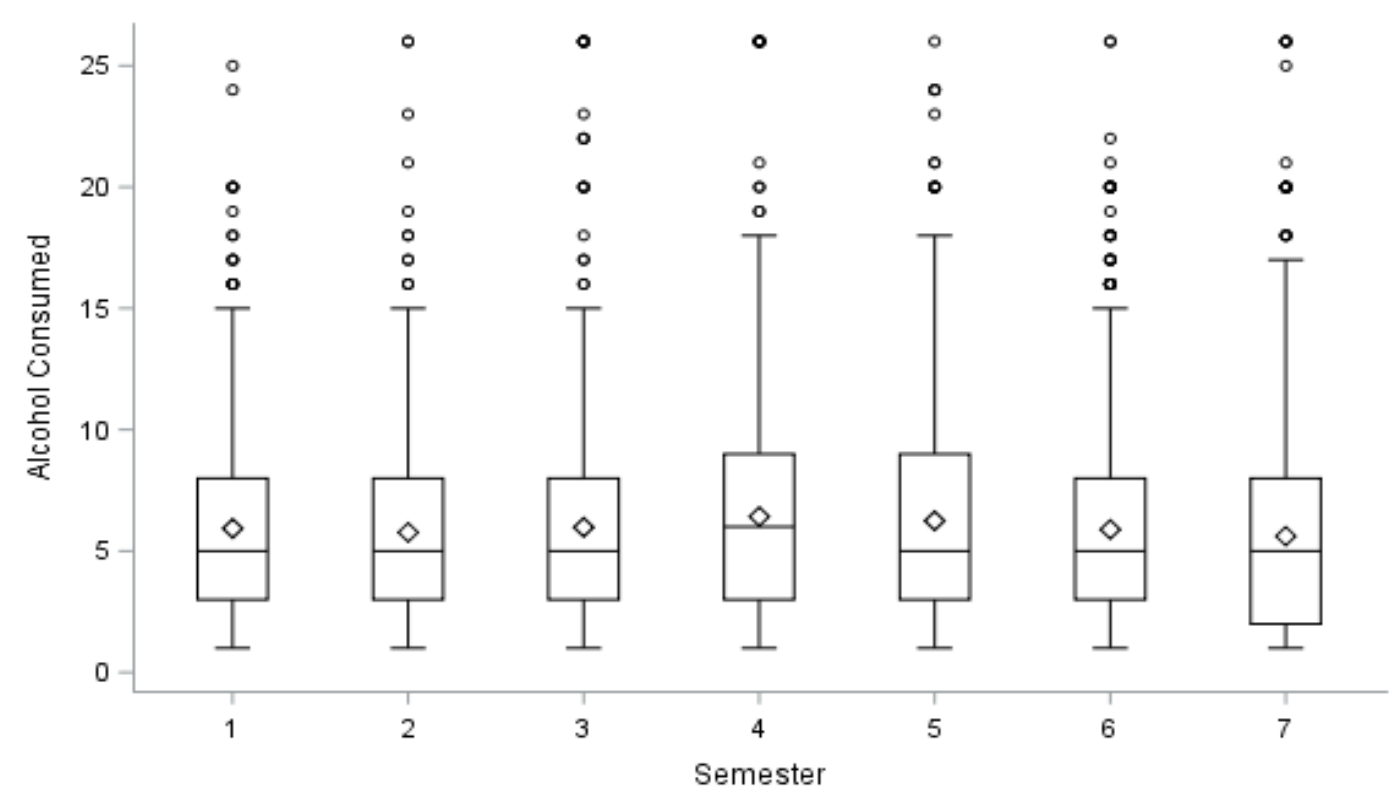

Due to the low number of drinking days that occurred in solitude, drinking context was not included in any models. However, since students higher in neuroticism are more likely to drink in solitude (Kuendig \& Kuntsche, 2013), any potential differences in drinking behaviours could be due to differences between students who drank in solitude compared to students who exclusively consumed alcohol in social settings. Students who had at least one reported drinking day in solitude $(n=91)$ had very similar scores on extraversion $(M=2.36, S D=0.74)$ compared to students who only consumed alcohol in social settings $(n=653)(M=2.40, S D=0.76)$. There were minimal differences in neuroticism between solitary drinkers $(M=1.55, S D=0.76)$ and social drinkers $(M=1.53, S D=0.76)$. Solitary drinkers consumed slightly less alcohol per session $(M=5.66, S D=4.45)$ than social drinkers $(M=6.05, S D=4.01)$. However, solitary drinkers reported a higher number of alcohol use problems $(M=8.33, S D=5.88)$ than social drinkers $(M=6.64, S D=5.16)$. While social drinkers reported using alcohol 
on $11.82 \%$ of days preceding an academically intense event, solitary drinkers reported using alcohol on $18.30 \%$ of days preceding an academically intense event. While solitary drinkers had more drinking days occurring before a test or assignment, there were no characteristic differences in personality or alcohol use behaviour between groups.

All multilevel models contained ethnicity, gender, age, time and potential polynomial time trends, and weekday versus weekend as control variables. Daily drinking and binge drinking were both modelled using a logistic distribution, while drinking quantity was modelled using a negative binomial distribution.

\section{Daily drinking}

Multilevel model parameter estimates predicting daily drinking odds are shown in Table 3. The average probability of drinking on any given day across university was 0.03 , or a $3 \%$ chance of drinking on any given day. The odds of drinking on any given day increased as students progressed through university. Students higher in extraversion had significantly higher odds of drinking on any given day. Students that were one-unit higher in extraversion were over twice as likely to drink on any given day, or a $6.44 \%$ chance of drinking on average. There was no significant main effect of neuroticism. There was a significant negative interaction between extraversion and time, where differences in the odds of daily drinking between students higher in extraversion and students lower in extraversion decreased over the course of university. This interaction is shown in Figure 8. There was no main effect of anticipation of a test or assignment deadline on drinking odds, and there was no relationship between either neuroticism or extraversion on drinking odds before an academically intense event. 
Table 3. Multilevel logistic regression model predicting daily drinking odds.

\begin{tabular}{|c|c|c|c|}
\hline Fixed Effects & $\gamma(S E)$ & OR & $95 \% \mathrm{CI}$ \\
\hline Intercept & $-3.48(0.10)^{* * *}$ & - & - \\
\hline Time & $0.13(0.02)^{* * *}$ & 1.14 & $1.10,1.19$ \\
\hline Academically Intense Event & $0.02(0.04)$ & 1.02 & $0.94,1.11$ \\
\hline Extraversion & $0.73(0.12)^{* * *}$ & 2.09 & $1.66,2.62$ \\
\hline Neuroticism & $-0.03(0.11)$ & 0.98 & $0.78,1.22$ \\
\hline Extraversion $\mathrm{x}$ Time & $-0.09(0.02)^{* * *}$ & 0.92 & $0.88,0.96$ \\
\hline Neuroticism x Time & $0.01(0.02)$ & 1.01 & $0.97,1.05$ \\
\hline $\begin{array}{l}\text { Extraversion x Academically } \\
\text { Intense Event }\end{array}$ & $0.02(0.05)$ & 1.02 & $0.92,1.13$ \\
\hline $\begin{array}{l}\text { Neuroticism x Academically } \\
\text { Intense Event }\end{array}$ & $0.01(0.05)$ & 1.01 & $0.91,1.11$ \\
\hline Extraversion x Neuroticism & $0.18(0.12)$ & 1.20 & $0.95,1.51$ \\
\hline \multicolumn{4}{|l|}{ Covariates } \\
\hline Gender & $-0.06(0.07)$ & 0.95 & $0.83,1.10$ \\
\hline Weekend (Weekend $=1$ ) & $1.36(0.03)$ & 3.91 & $3.71,4.12$ \\
\hline Age & $-0.06(0.04)$ & 0.95 & $0.87,1.02$ \\
\hline \multicolumn{4}{|l|}{ Ethnicity (Caucasian=-1) } \\
\hline Black & $-0.61(0.16)^{* * *}$ & 0.54 & $0.40,0.74$ \\
\hline Hispanic & $0.51(0.13)^{* * *}$ & 1.67 & $1.30,2.14$ \\
\hline Asian & $-0.39(0.14)^{* *}$ & 0.68 & $0.52,0.89$ \\
\hline Other & $0.05(0.19)$ & 1.05 & $0.72,1.53$ \\
\hline
\end{tabular}


Figure 8. Interaction plot showing daily drinking odds trajectories across university for differing levels of extraversion. Students one $S D$ below average extraversion are shown as low extraversion, and students one $S D$ above average extraversion are shown as high extraversion.

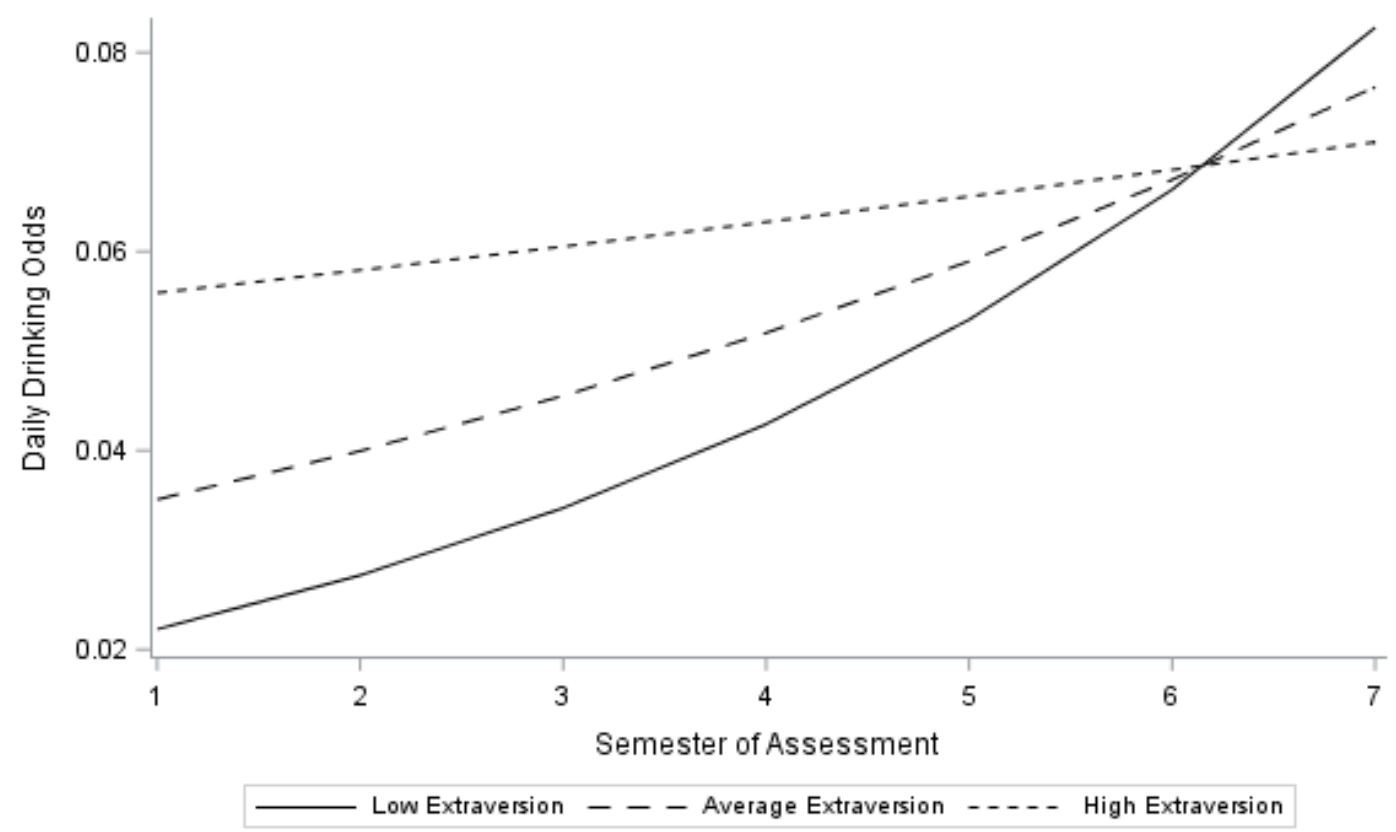

\section{Daily drinking quantity}

Multilevel parameter estimates predicting daily drinking quantity are shown in

Table 4. Students drank significantly more alcohol per drinking session over time during university. On a typical drinking day, the average student consumed one more drink on average per drinking session each passing semester. Similar to drinking odds, students higher in extraversion had significantly higher drinking quantity, where a one-point increase in a student's extraversion score leads to a 2.77 times increase in drinking quantity. Neuroticism was unrelated to drinking quantity. Students higher in extraversion retained a high average quantity of drinking across university, while students lower in extraversion began to have similar average drinking quantity towards the end of university. This interaction is shown in Figure 9. Students drank slightly more alcohol on 
days that preceded academically intense events. This translates to an average increase of 0.48 drinks per drinking session when anticipating a future test or assignment compared to the average alcohol consumption of $M=5.97$ drinks per drinking session. There were no significant interactions of neuroticism or extraversion with academically intense events, so students higher in neuroticism or extraversion's daily drinking quantity did not depend on anticipation of an academically intense event.

Table 4. Multilevel negative binomial regression model predicting daily drinking quantity.

\begin{tabular}{|c|c|c|c|}
\hline Fixed Effects & $\gamma(S E)$ & $e^{y}$ & $95 \% \mathrm{CI}$ \\
\hline Intercept & $-2.83(0.13)^{* * * *}$ & 0.06 & $-3.08,-2.57$ \\
\hline Time & $0.21(0.05)^{* * *}$ & 1.23 & $0.11,0.30$ \\
\hline Time $^{2}$ & $-0.01(0.01)$ & 0.99 & $-0.02,0.01$ \\
\hline Academically Intense Event & $0.08(0.04)^{*}$ & 1.08 & $0.00,0.16$ \\
\hline Extraversion & $1.02(0.14)^{* * *}$ & 2.77 & $0.74,1.30$ \\
\hline Neuroticism & $-0.05(0.14)$ & 0.95 & $-0.33,0.23$ \\
\hline Extraversion $\mathrm{x}$ Time & $-0.11(0.03)^{* * *}$ & 0.90 & $-0.16,-0.06$ \\
\hline Neuroticism $\mathrm{x}$ Time & $0.02(0.02)$ & 1.02 & $-0.03,0.06$ \\
\hline $\begin{array}{l}\text { Extraversion x Academically } \\
\text { Intense Event }\end{array}$ & $-0.03(0.06)$ & 0.97 & $-0.14,0.08$ \\
\hline $\begin{array}{l}\text { Neuroticism x Academically } \\
\text { Intense Event }\end{array}$ & $0.08(0.05)$ & 1.08 & $-0.03,0.18$ \\
\hline Extraversion x Neuroticism & $0.23(0.15)$ & 1.26 & $-0.06,0.51$ \\
\hline \multicolumn{4}{|l|}{ Covariates } \\
\hline Gender & $0.03(0.09)$ & 1.03 & $-0.14,0.21$ \\
\hline Weekend (Weekend=1) & $1.42(0.03)^{* * *}$ & 4.14 & $1.36,1.47$ \\
\hline Age & $-0.04(0.04)$ & 0.96 & $-0.13,0.04$ \\
\hline \multicolumn{4}{|l|}{ Ethnicity $($ Caucasian=-1) } \\
\hline Black & $-0.82(0.19)^{* * *}$ & 0.44 & $-1.21,-0.44$ \\
\hline Hispanic & $0.77(0.16)^{* * *}$ & 2.16 & $0.46,1.07$ \\
\hline Asian & $-0.60(0.17)^{* * *}$ & 0.55 & $-0.93,-0.27$ \\
\hline Other & $0.08(0.24)$ & 1.08 & $-0.38,0.55$ \\
\hline
\end{tabular}


Figure 9. Interaction plot showing drinking quantity trajectories across university.

Students one $S D$ below average extraversion are shown as low extraversion, and students one $S D$ above average extraversion are shown as high extraversion.

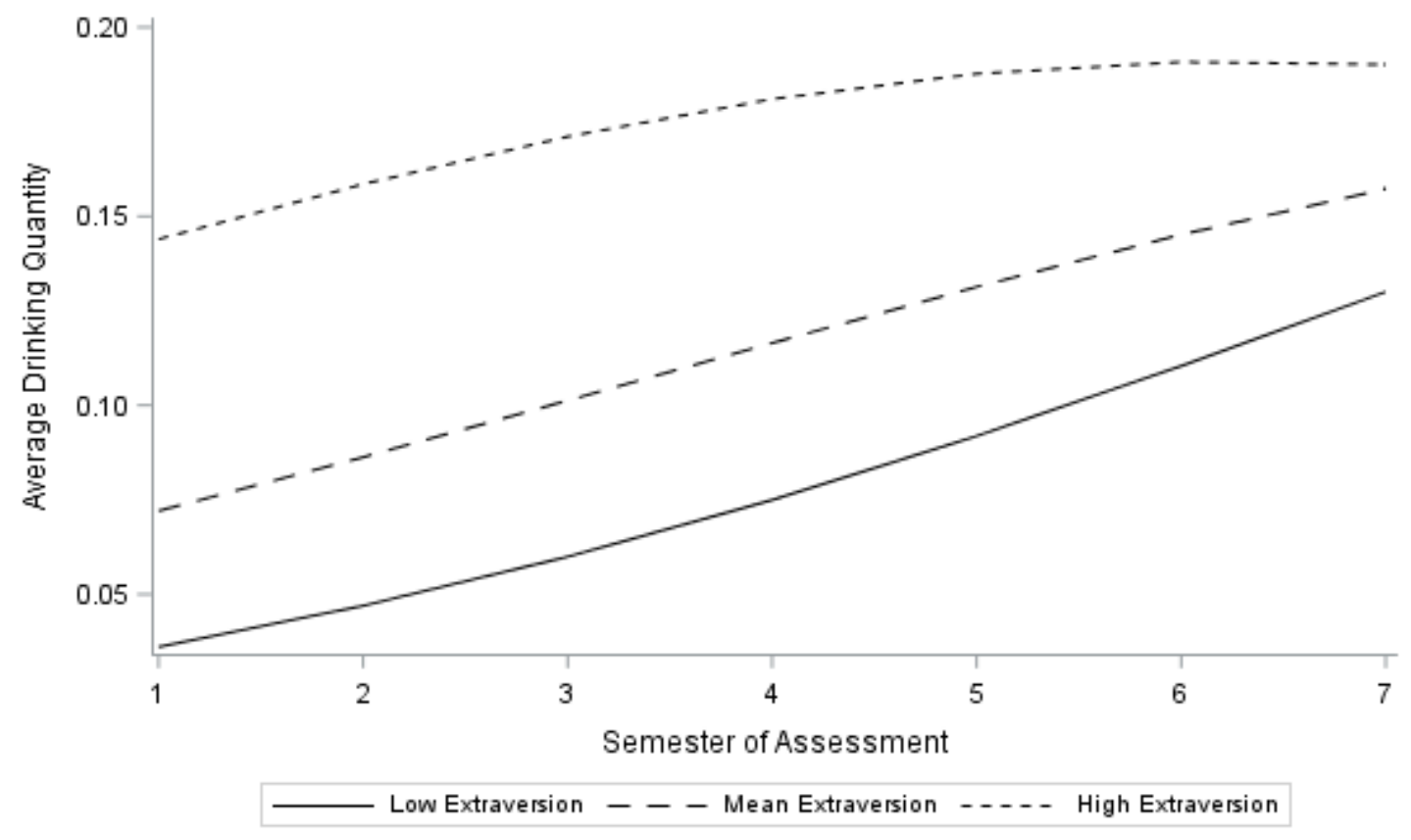

\section{Daily binge drinking}

Multilevel parameter estimates predicting daily binge drinking odds are shown in Table 5. The initial probability of student binge drinking on any given day during the first semester was 0.0098 , or a $1 \%$ chance of binge drinking. Students higher in extraversion were more likely to binge drink. Students higher in extraversion had a higher odds of binge drinking, but the odds decreased sharply over time to match students lower in extraversion, so there were minimal differences in binge drinking odds between students of differing levels of extraversion. The interaction between extraversion and time is shown in Figure 10. There was no effect of neuroticism or academically intense events on binge drinking odds. Students with differing levels of neuroticism had no changes in their daily binge drinking odds, and anticipation of a future test or assignment had no impact 
on binge drinking odds. There were no significant interactions between academically intense events and extraversion, or academically intense events and neuroticism.

Table 5. Multilevel logistic regression model predicting daily binge drinking odds.

\begin{tabular}{|c|c|c|c|}
\hline Fixed Effects & $\gamma(S E)$ & $O R$ & $95 \% \mathrm{CI}$ \\
\hline Intercept & $-4.63(0.14)^{* * *}$ & - & - \\
\hline Time & $0.09(0.11)$ & 1.10 & $0.88,1.36$ \\
\hline Time $^{2}$ & $0.04(0.04)$ & 1.04 & $0.96,1.13$ \\
\hline Time $^{3}$ & $-0.01(0.00)$ & 0.99 & $0.98,1.00$ \\
\hline Academically Intense Event & $0.03(0.06)$ & 1.03 & $0.92,1.15$ \\
\hline Extraversion & $0.88(0.14)^{* * *}$ & 2.40 & $1.83,3.16$ \\
\hline Neuroticism & $-0.01(0.14)$ & 0.99 & $0.76,1.29$ \\
\hline Extraversion $\mathrm{x}$ Time & $-0.05(0.03)^{*}$ & 0.95 & $0.90,1.00$ \\
\hline Neuroticism $\mathrm{x}$ Time & $0.04(0.02)$ & 1.04 & $0.99,1.09$ \\
\hline Extraversion x Academically & $-0.10(0.07)$ & 0.90 & $0.79,1.04$ \\
\hline \multicolumn{4}{|l|}{ Intense Event } \\
\hline Neuroticism x Academically & $-0.04(0.06)$ & 0.96 & $0.84,1.09$ \\
\hline \multicolumn{4}{|l|}{ Intense Event } \\
\hline Extraversion x Neuroticism & $0.17(0.14)$ & 1.19 & $0.90,1.57$ \\
\hline \multicolumn{4}{|l|}{ Covariates } \\
\hline Gender & $0.19(0.08)^{*}$ & 1.21 & $1.02,1.42$ \\
\hline Weekend $($ Weekend $=1)$ & $1.49(0.04)^{* * *}$ & 4.45 & $4.14,4.79$ \\
\hline Age & $-0.03(0.06)$ & 0.97 & $0.87,1.08$ \\
\hline \multicolumn{4}{|l|}{ Ethnicity (Caucasian=-1) } \\
\hline Black & $-1.01(0.20)^{* * *}$ & 0.37 & $0.25,0.54$ \\
\hline Hispanic & $0.63(0.15)^{* * *}$ & 1.88 & $1.40,2.51$ \\
\hline Asian & $-0.58(0.16)^{* * *}$ & 0.56 & $0.41,0.78$ \\
\hline Other & $0.28(0.23)$ & 1.33 & $0.85,2.07$ \\
\hline
\end{tabular}
$* p<.01, * * p<.01, * * * p<.001$. 
Figure 10. Interaction plot showing binge drinking odds trajectories across university. Students one $S D$ below average extraversion are shown as low extraversion, and students one $S D$ above average extraversion are shown as high extraversion.

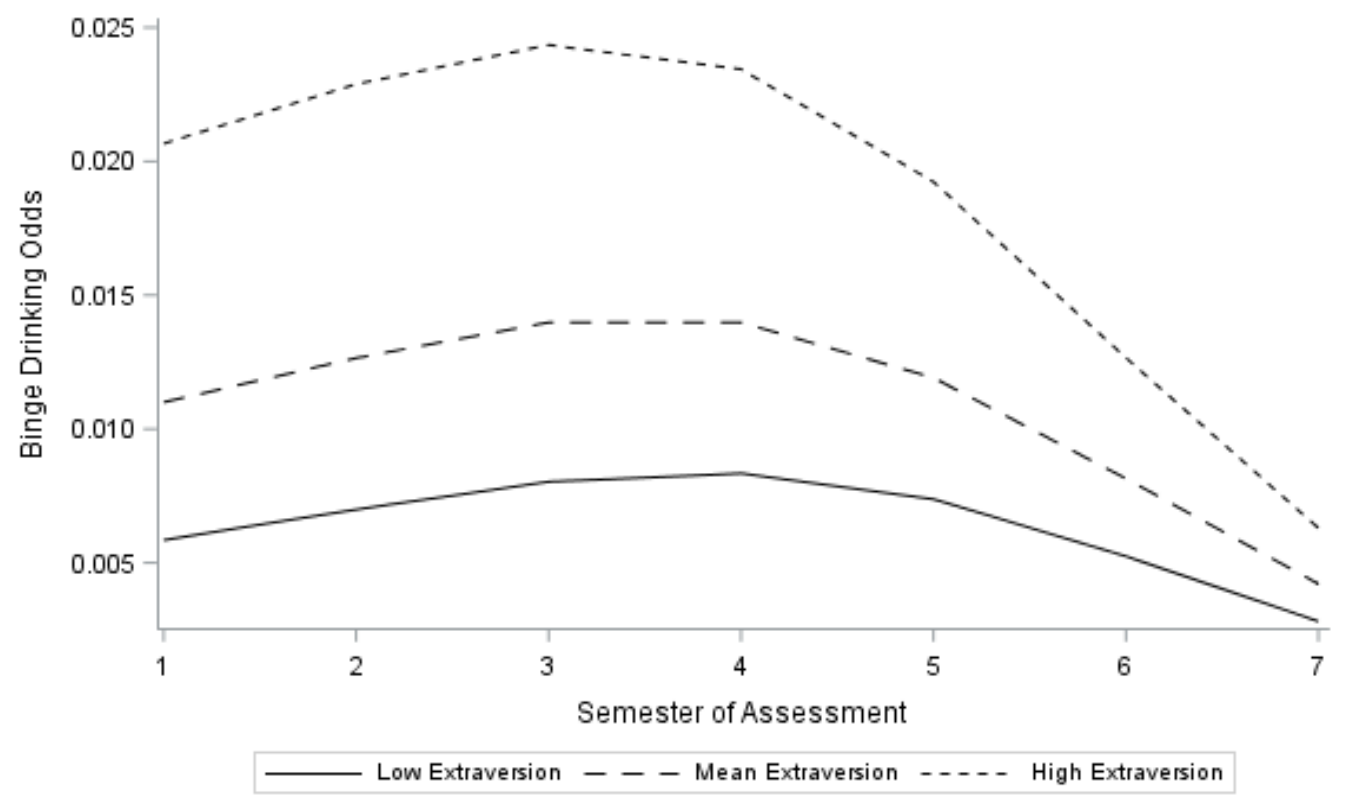

\section{Alcohol use problems}

Distributions of drinking outcomes and academically intense event slopes are shown in Figure 11. There was no student within the sample who was more likely to drink on days that preceded academically intense events compared to days that did not precede academically intense events. Drinking/AIE slope $(M=-16.95, S D=3.83)$ estimates ranged from -37.6 to -1.57 . Average daily drinking quantity before an academically intense event slopes $(M=8.20, S D=2.39)$ ranged from 3.71 to 12.86 , so students drank between 1.04 to 1.13 times more alcohol on days preceding academically intense events. Binge/AIE slope $(M=2.84, S D=0.90)$ estimates ranged from 1.70 to 5.55, so students were between 1.02 and 1.06 times more likely to binge drink before a test or assignment. Students did not have increased odds of drinking in anticipation of a 
test or assignment. If students did drink on days before a test or assignment, they would consume more alcohol than average.

Figure 11. Histograms showing range of AIE slopes for a) daily drinking odds, b) drinking quantity, and c) binge drinking odds.
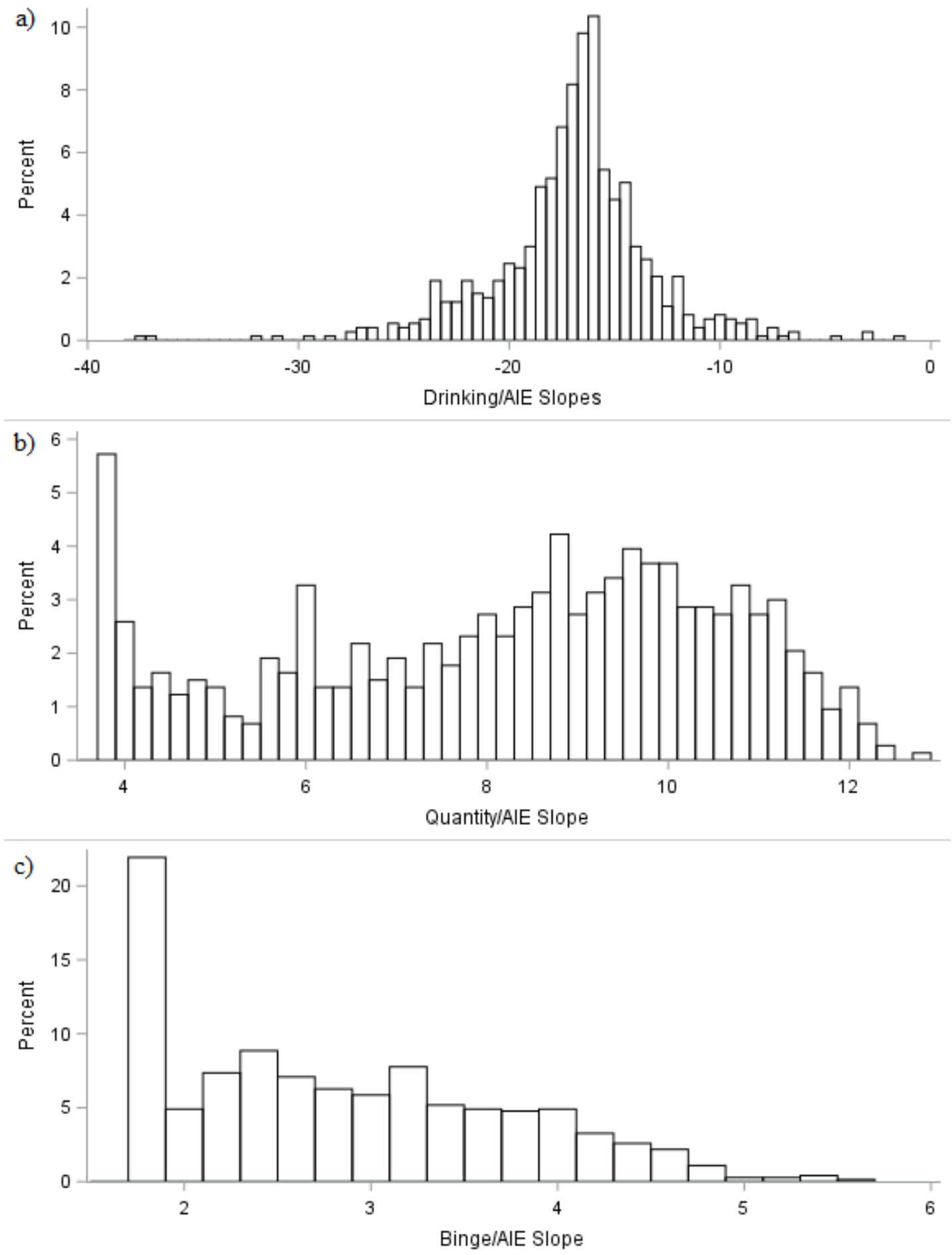
Negative binomial regression parameter estimates for daily drinking odds and academically intense event slopes predicting AUDIT scores are shown in Table 6. There was no significant relationship between individual drinking/AIE slopes and alcohol use problems. There was no significant relationship between extraversion or neuroticism on number of alcohol-use problems. Logistic regression parameter estimates for drinking/AIE slopes and odds of being high risk for alcohol dependence are shown in Table 7. The intercept in this model represents the odds of a student being high risk for developing alcohol dependence when all other predictors equal zero, which is a value not represented in the range of drinking/AIE slopes. Values for drinking/AIE slopes were not centered to correct the intercept, to keep interpretation of coefficients for main effects and interactions less complicated. Importantly, centering does not change the effects present in the model. There was a significant positive relationship between academically intense event drinking slopes and being at high risk for alcohol dependence. Students who had relatively greater odds of drinking before an academically intense event had higher odds of being at high risk for developing alcohol dependence. There was also a significant interaction between extraversion and drinking/AIE slopes, where students higher in extraversion had higher risk of alcohol dependence regardless of how likely they were to drink before a test or assignment. Students lower in extraversion who were relatively more likely to drink before a test or assignment were at greater risk for alcohol dependence. This interaction is shown in Figure 12. Neuroticism had no significant associations with alcohol use problems, odds of being high risk for alcohol dependence, or interactions with daily drinking odds before an academically intense event. 
Table 6. Daily academically intense event and daily drinking odds slope negative binomial regression model predicting total AUDIT score.

\begin{tabular}{lccc}
\hline Predictor & $b(S E)$ & $e^{\gamma}$ & Wald 95\% CI \\
\hline Intercept & $2.14(0.54)^{* * *}$ & 8.50 & $1.05,3.17$ \\
Drinking / AIE slope & $0.00(0.03)$ & 1.00 & $-0.06,0.06$ \\
Extraversion & $0.13(0.16)$ & 1.14 & $-0.18,0.44$ \\
Neuroticism & $0.26(0.17)$ & 1.30 & $-0.08,0.59$ \\
Extraversion x Drinking / AIE slope & $0.00(0.01)$ & 1.00 & $-0.01,0.01$ \\
Neuroticism x Drinking / AIE slope & $0.01(0.01)$ & 1.01 & $-0.1,0.03$ \\
Covariates & & & \\
Average academically intense event & $-0.01(0.00)^{*}$ & 0.99 & $-0.01,0.00$ \\
Average drinking odds & $0.41(0.02)^{* * *}$ & 1.51 & $0.37,0.46$ \\
Gender (Male=1) & $0.26(0.06)^{* * *}$ & 1.30 & $0.15,0.37$ \\
Race (Caucasian=-1) & $-0.08(0.06)$ & 0.92 & $-0.20,0.04$ \\
Black & $0.01(0.05)$ & 1.01 & $-0.08,0.11$ \\
Hispanic & $-0.13(0.05)^{*}$ & 0.88 & $-0.21,-0.03$ \\
Asian & $0.03(0.07)$ & 1.03 & $-0.12,0.17$ \\
Other & & & \\
$\quad * p<.01, * * p<.01, * * * p .001$. & & & \\
$\quad$ AIE = Academically intense event. & $e^{\gamma}$ represents multiplicative constants for average number of alcohol use problems.
\end{tabular}

Table 7. Daily academically intense event and daily drinking odds slope logistic regression model predicting high-risk AUDIT status odds.

\begin{tabular}{lccc}
\hline Predictor & $b(S E)$ & $O R$ & $95 \% \mathrm{CI}$ \\
\hline Intercept & $4.32(2.08)^{*}$ & - & - \\
Drinking / AIE slope & $0.32(0.12)^{* *}$ & 1.37 & $1.09,1.72$ \\
Extraversion & $-1.22(0.63)$ & 0.30 & $0.09,1.02$ \\
Neuroticism & $-0.29(0.63)$ & 0.75 & $0.22,2.57$ \\
Extraversion x Drinking / AIE slope & $-0.10(0.04)^{* *}$ & 0.90 & $0.84,0.97$ \\
Neuroticism x Drinking / AIE slope & $-0.03(0.04)$ & 0.97 & $0.90,1.04$ \\
Covariates & & & \\
Average academically intense event & $0.02(0.01)^{* *}$ & 1.02 & $1.01,1.04$ \\
Average drinking odds & $1.03(0.10)^{* * *}$ & 2.80 & $2.30,3.40$ \\
Gender (Male=1) & $0.68(0.21)^{* *}$ & 1.98 & $1.31,2.99$ \\
Race (Caucasian=-1) & & & \\
Black & $-0.26(0.23)$ & 0.77 & $0.49,1.21$ \\
Hispanic & $-0.01(0.17)$ & 0.99 & $0.70,1.34$ \\
Asian & $-0.65(0.21)^{* *}$ & 0.52 & $0.35,0.80$ \\
Other & $0.62(0.26)^{*}$ & 1.86 & $1.12,3.10$ \\
\hline
\end{tabular}

$* p<.01, * * p<.01, * * * p<.001$.

$\mathrm{AIE}=$ Academically intense event. 
Figure 12. Interaction plot showing AUDIT high risk odds as a product of extraversion and each student's daily drinking odds before an academically intense event relationship. Students one $S D$ below average are Low Extraversion, and students one $S D$ above average are High Extraversion.

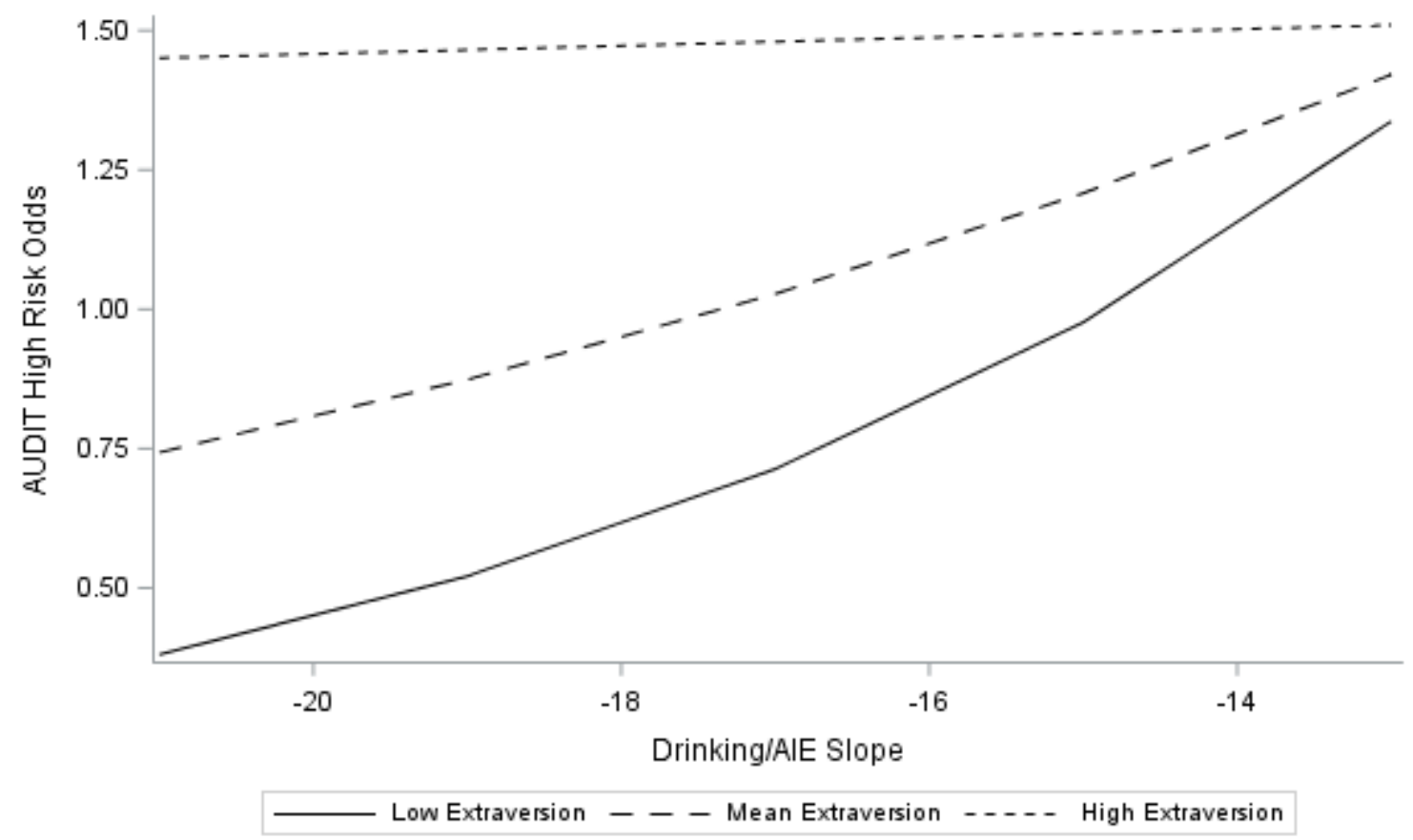

Negative binomial regression parameter estimates for daily drinking quantity and academically intense event slopes predicting alcohol use problems are shown in Table 8, and logistic regression parameter estimates predicting odds of being at high risk for alcohol dependence are shown in Table 9. Students who drank more per drinking session in anticipation an academically intense event had no differences in their alcohol use problems. There was a significant interaction between quantity/AIE slopes and extraversion predicting alcohol use problems, where the differences in alcohol use problems between students of differing extraversion decreased as drinking quantity before a test or assignment increased. This interaction is shown in Figure 13. There were no significant interactions or main effects for neuroticism. 
Table 8. Daily academically intense event and drinking quantity slope negative binomial regression model predicting total AUDIT score.

\begin{tabular}{|c|c|c|c|}
\hline Predictor & $b(S E)$ & $e^{y}$ & Wald $95 \% \mathrm{CI}$ \\
\hline Intercept & $0.20(0.90)$ & 1.22 & $-1.56,1.97$ \\
\hline Quantity / AIE slope & $0.17(0.09)$ & 1.19 & $-0.01,0.35$ \\
\hline Extraversion & $0.48(0.13)^{* * *}$ & 1.62 & $0.22,0.73$ \\
\hline Neuroticism & $0.15(0.13)$ & 1.16 & $-0.11,0.42$ \\
\hline Extraversion x Quantity / AIE slope & $-0.04(0.01)^{* *}$ & 0.96 & $-0.07,-0.01$ \\
\hline Neuroticism x Quantity / AIE slope & $0.00(0.01)$ & 1.00 & $-0.03,0.03$ \\
\hline \multicolumn{4}{|l|}{ Covariates } \\
\hline Average academically intense event & $-0.01(0.00)^{*}$ & 0.99 & $-0.01,0.00$ \\
\hline Average drinking quantity & $0.23(0.11)^{*}$ & 1.26 & $0.02,0.45$ \\
\hline Gender $($ Male $=1)$ & $0.17(0.05)^{* *}$ & 1.19 & $0.07,0.27$ \\
\hline \multicolumn{4}{|l|}{ Race (Caucasian=-1) } \\
\hline Black & $-0.06(0.06)$ & 0.94 & $-0.17,0.05$ \\
\hline Hispanic & $0.00(0.05)$ & 1.00 & $-0.09,0.09$ \\
\hline Asian & $-0.08(0.05)$ & 0.92 & $-0.18,0.02$ \\
\hline Other & $0.02(0.07)$ & 1.02 & $-0.11,0.15$ \\
\hline
\end{tabular}

Table 9. Daily academically intense event and drinking quantity slope logistic regression model predicting high-risk AUDIT status.

\begin{tabular}{lccc}
\hline Predictor & $b(S E)$ & $O R$ & $95 \% \mathrm{CI}$ \\
\hline Intercept & $-3.54(4.06)$ & - & - \\
Quantity / AIE slope & $0.16(0.41)$ & 1.17 & $0.52,2.62$ \\
Extraversion & $0.43(0.80)$ & 1.54 & $0.32,7.42$ \\
Neuroticism & $0.50(0.74)$ & 1.65 & $0.38,7.09$ \\
Extraversion x Quantity / AIE slope & $0.00(0.08)$ & 1.00 & $0.84,1.18$ \\
Neuroticism x Quantity / AIE slope & $-0.02(0.08)$ & 0.98 & $0.84,1.14$ \\
Covariates & & & \\
$\quad$ Average academically intense event & $0.02(0.01)^{*}$ & 1.02 & $1.01,1.04$ \\
Average drinking quantity & $0.79(0.43)$ & 2.20 & $0.94,5.15$ \\
Gender (Male=1) & $0.50(0.21)^{*}$ & 1.65 & $1.09,2.50$ \\
Race (Caucasian=-1) & & & \\
Black & $-0.18(0.21)$ & 0.93 & $0.52,1.33$ \\
Hispanic & $-0.04(0.18)$ & 0.96 & $0.68,1.36$ \\
Asian & $-0.56(0.22)^{* *}$ & 0.57 & $0.37,0.87$ \\
Other & $0.60(0.27)^{*}$ & 1.83 & $1.07,3.12$ \\
\hline
\end{tabular}

$* p<.01, * * p<.01, * * * p<.001$.

AIE $=$ Academically intense event. 
Figure 13. Interaction plot showing differences in alcohol-use problems at the end of university as a product of extraversion score and each student's average drinking quantity before an academically intense event relationship. Students one $S D$ below average are Low Extraversion, and students one SD above average are High Extraversion.

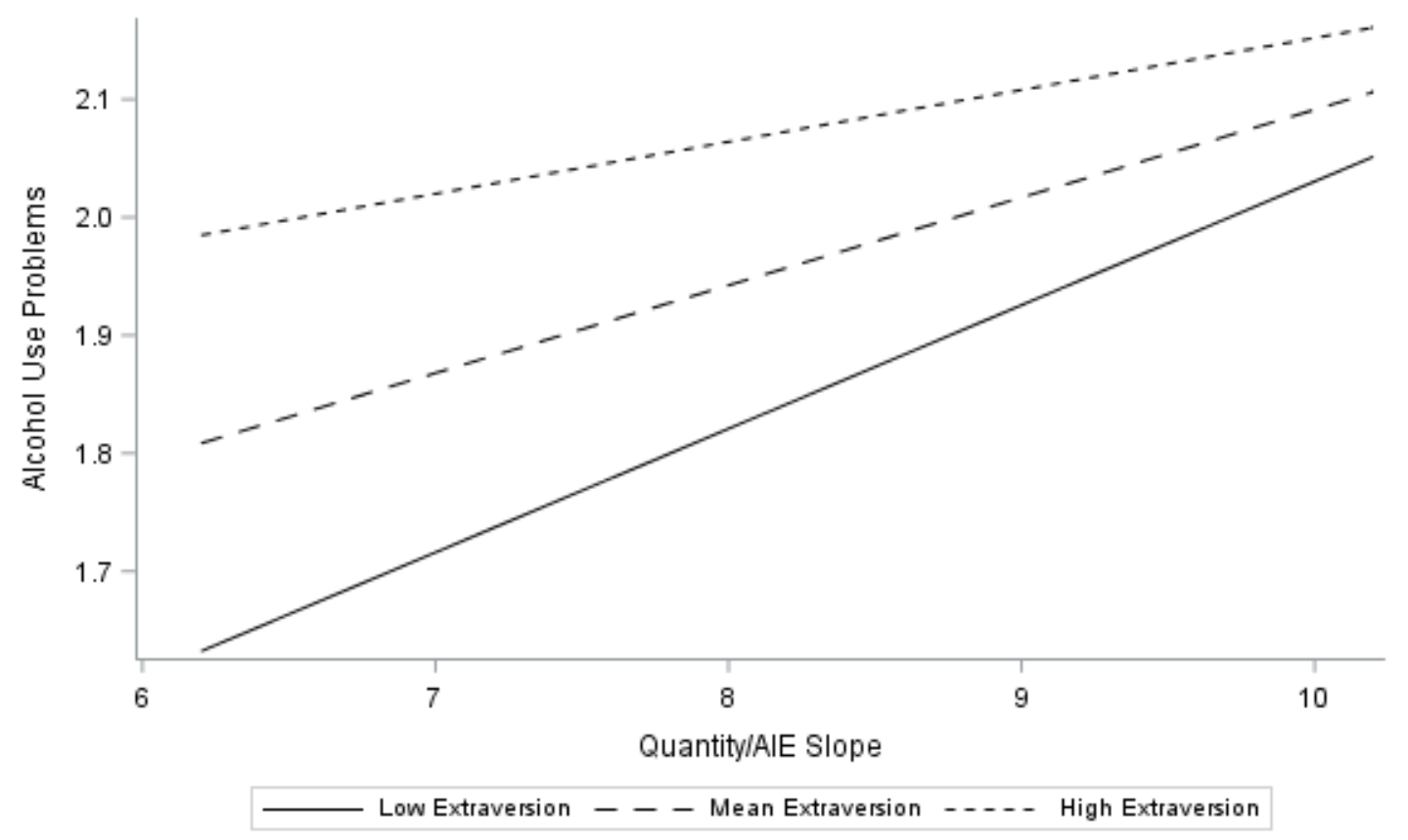

Negative binomial regression parameter estimates for daily binge drinking odds and academically intense event slopes predicting alcohol use problems are shown in Table 10, and logistic regression parameter estimates predicting odds for being at high risk for alcohol dependence are shown in Table 11. Students who were more likely to binge drink before academically intense events had more alcohol use problems but had no difference in their odds of being high risk for alcohol dependence. Extraversion in this model significantly predicted increased alcohol use problems but did not predict changes in the odds of having a high risk of developing alcohol use problems. There was a significant negative interaction between extraversion and daily binge drinking before an academically intense event predicting alcohol use problems, where students who were higher in extraversion had similar alcohol use problems compared to those with higher 
odds of binge drinking before an academically intense event who were lower in extraversion. This interaction is shown in Figure 14.

Table 10. Daily academically intense event and binge drinking odds slope negative binomial regression model predicting total AUDIT score.

\begin{tabular}{|c|c|c|c|}
\hline Predictor & $b(S E)$ & $e^{\gamma}$ & Wald $95 \%$ CI \\
\hline Intercept & $0.86(0.52)$ & 2.36 & $-0.16,1.88$ \\
\hline Binge / AIE slope & $0.43(0.13)^{* *}$ & 1.54 & $0.17,0.70$ \\
\hline Extraversion & $0.49(0.12)^{* * *}$ & 1.63 & $0.26,0.72$ \\
\hline Neuroticism & $0.18(0.12)$ & 1.20 & $-0.05,0.41$ \\
\hline Extraversion x Binge / AIE slope & $-0.11(0.04)^{* *}$ & 0.90 & $-0.19,-0.04$ \\
\hline Neuroticism x Binge / AIE slope & $-0.02(0.04)$ & 0.98 & $-0.10,0.05$ \\
\hline \multicolumn{4}{|l|}{ Covariates } \\
\hline Average academically intense event & $0.00(0.00)$ & 1.00 & $0.00,0.00$ \\
\hline Average binge drinking odds & $0.27(0.05)^{* * *}$ & 1.31 & $0.18,0.37$ \\
\hline Gender $($ Male $=1)$ & $0.15(0.05)^{* *}$ & 1.16 & $0.04,0.25$ \\
\hline \multicolumn{4}{|l|}{ Race (Caucasian=-1) } \\
\hline Black & $-0.02(0.06)$ & 0.98 & $-0.13,0.10$ \\
\hline Hispanic & $0.03(0.05)$ & 1.03 & $-0.07,0.12$ \\
\hline Asian & $-0.11(0.05)^{*}$ & 0.90 & $-0.21,0.00$ \\
\hline Other & $-0.02(0.07)$ & 0.98 & $-0.16,0.12$ \\
\hline
\end{tabular}

Table 11. Daily academically intense event and binge drinking odds slope logistic regression model predicting high-risk AUDIT status.

\begin{tabular}{|c|c|c|c|}
\hline Parameter & $b(S E)$ & $O R$ & $95 \% \mathrm{CI}$ \\
\hline Intercept & $-1.33(2.39)$ & - & \\
\hline Binge / AIE slope & $0.85(0.65)$ & 2.34 & $0.66,8.31$ \\
\hline Extraversion & $0.97(0.61)$ & 2.63 & $0.79,8.79$ \\
\hline Neuroticism & $0.97(0.61)$ & 2.64 & $0.89,7.81$ \\
\hline Extraversion $x$ Binge / AIE slope & $-0.21(0.19)$ & 0.81 & $0.56,1.17$ \\
\hline Neuroticism x Binge / AIE slope & $-0.22(0.17)$ & 0.80 & $0.57,1.12$ \\
\hline \multicolumn{4}{|l|}{ Covariates } \\
\hline Average academically intense event & $0.00(0.01)$ & 1.00 & $0.99,1.02$ \\
\hline Average binge drinking odds & $1.10(0.20)^{* * *}$ & 3.01 & $2.05,4.41$ \\
\hline Gender $($ Male $=1)$ & $0.30(0.22)$ & 1.35 & $0.87,2.07$ \\
\hline \multicolumn{4}{|l|}{ Race (Caucasian=-1) } \\
\hline Black & $-0.10(0.24)$ & 0.90 & $0.65,1.45$ \\
\hline Hispanic & $-0.02(0.18)$ & 0.98 & $0.68,1.40$ \\
\hline Asian & $-0.55(0.23)^{*}$ & 0.58 & $0.37,0.90$ \\
\hline Other & $0.55(0.28)^{*}$ & 1.74 & $1.01,2.99$ \\
\hline
\end{tabular}


Figure 14. Interaction plot showing differences in alcohol-use problems a function of extraversion score and each student's average binge drinking odds before an academically intense event relationship. Students one $S D$ below average are Low Extraversion, and students one SD above average are High Extraversion.

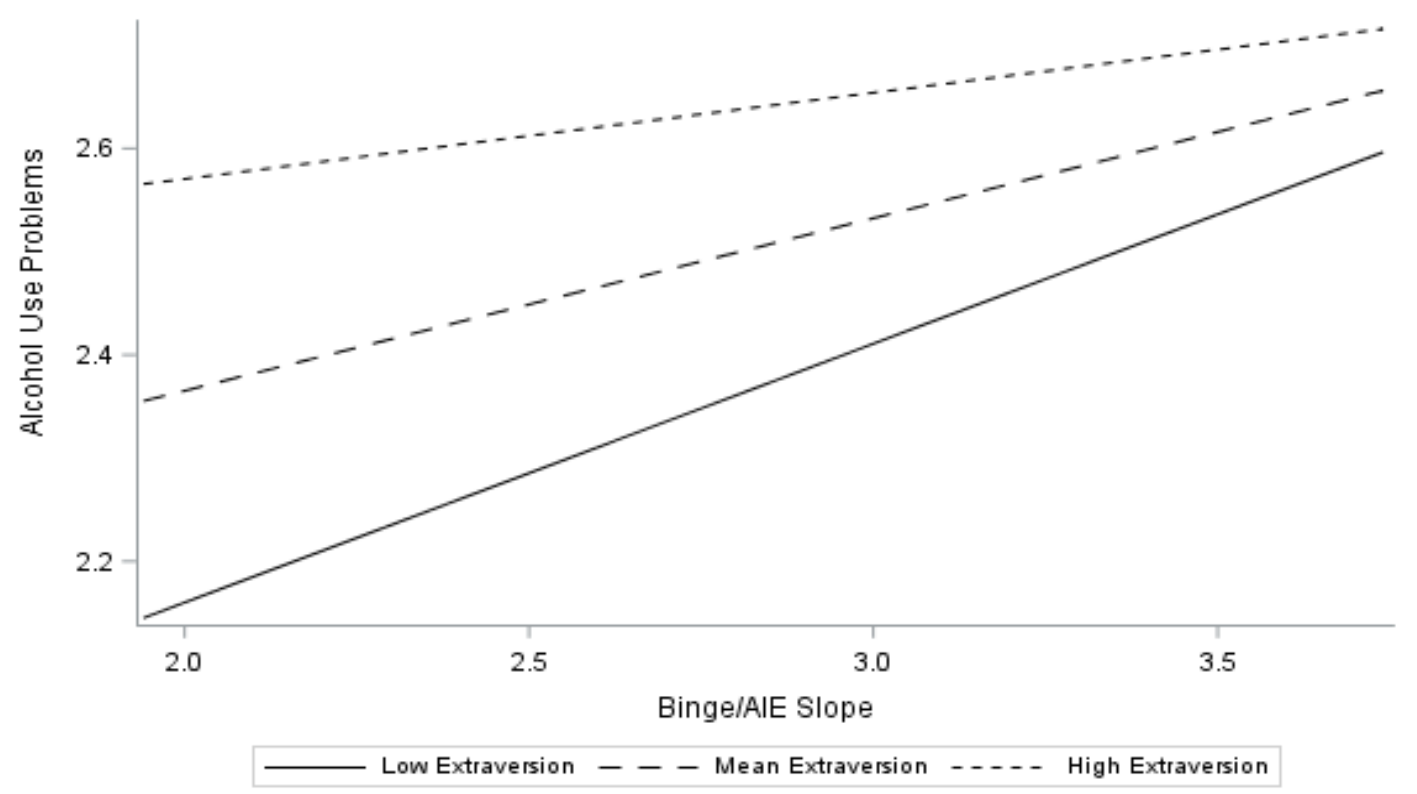

\section{Summary}

Students who were higher in extraversion engaged in more daily drinking than students who were lower in extraversion, across university. There were no associations between neuroticism and daily drinking. Students higher in extraversion were not more likely to drink when anticipating a test or assignment due the following day. Students who were higher in neuroticism were not more likely to drink alcohol on days preceding a test or assignment. Students higher in extraversion had more alcohol use problems at the end of university, and were at a higher risk for alcohol dependence, regardless of their drinking behaviour on days before a test or assignment. However, students lower in extraversion who engaged in more daily drinking before a test or assignment had more alcohol use problems at the end of university. Students higher in neuroticism who 
consumed more alcohol before tests or assignments did not have more alcohol use problems and had no change in their risk for alcohol dependence.

\section{Discussion}

The aim of this study was to investigate the relationship of personality to hazardous alcohol use and alcohol use problems in undergraduates across university. Student's personality traits were measured at the beginning of university, and there was a 14-day daily diary burst each semester measuring daily drinking behaviours. High extraversion was expected to increase daily drinking odds, daily drinking quantity, and binge drinking odds, while neuroticism was not expected to be directly associated with any drinking outcome. Students who were higher in neuroticism would be more likely to drink on days before tests and assignments, while students higher in extraversion would not be more likely to drink on those days. Students higher in neuroticism who were more likely to drink before an academically intense event would have more alcohol use problems at the end of university, while students higher in extraversion would have no association between alcohol use before academically intense events and alcohol use problems.

As expected, extraversion strongly predicted increased drinking odds, drinking quantity, and binge drinking odds. Neuroticism was not associated with daily drinking odds, drinking quantity, or binge drinking odds. There was no interaction between extraversion and the anticipation of an academically intense events on any daily alcohol use outcome, which is consistent with hypothesis two. Contrary to hypothesis two, there was also no association between neuroticism and the anticipation of academically intense events on any daily alcohol use outcome. The level of extraversion or neuroticism of each 
student had no bearing on their odds to consume alcohol, or drink in greater quantities in anticipation of a future test or assignment. Students higher in extraversion had higher alcohol use problems and odds of being high risk of alcohol dependence at the end of university. Neuroticism was not associated with alcohol use but was associated with increased rate of alcohol use problems at the end of university, though less so than students who reported high levels of extraversion. These results are consistent with previous investigations into the relationships between personality and alcohol use. Students who drank more alcohol before an academically intense event had more alcohol use problems at the end of university, but had no effect on students higher in extraversion.

\section{Personality and daily alcohol use}

Students that were higher in extraversion were more likely to drink on any day, drink in higher amounts, and more likely to binge drink across university. These results are consistent with hypothesis one, where students higher in extraversion had higher odds of daily drinking, higher drinking quantity during drinking sessions, and higher odds of binge drinking. This finding is consistent with previous studies into extraversion and alcohol use (Kilbey et al., 1998; Merenäkk et al., 2003; Hakulinen et al., 2015). Students who are higher in extraversion likely have more opportunities to consume alcohol in a socially-acceptable manner, as they may find themselves as a greater part of the campus alcohol culture than other students. Students higher in extraversion would talk to more of their fellow students and would be more likely to attend more of the alcohol-centered events and parties occurring on campus.

The magnitude of the effect of extraversion on daily alcohol use was large. 
Students higher in extraversion were twice as likely to drink on any day, drank twice as much, and were twice as likely to binge drink compared to students with average levels of extraversion. The strength of this relationship is consistent with previous conceptualizations of the externalizing developmental pathway for alcohol use problems. One feature of extraversion is a higher behavioural activation: a tendency to act in ways that maximize the feeling of reward (Gray, 1970). Students that are higher in facets of extraversion, such as positive sensation seeking or gregariousness, have higher desires to engage in whatever activities give them the most positive feelings (Quilty, DeYoung, Oakman, \& Bagby, 2014). Individuals higher in these facets and behavioural activation are also less resistance to peer influence (Stautz \& Cooper, 2014). Students that are higher in extraversion are likely to have more opportunities to drink alcohol and lack the behavioural inhibition to refuse those opportunities. However, while students higher in extraversion were twice as likely to binge drink, this only increased their daily probability of binge drinking to $2 \%$. Compared to other predictors of heavy alcohol use, such as family history of alcohol abuse and age of first drink (Howard et al., 2015), this effect is small.

Neuroticism was not associated with increased drinking odds, drinking quantity or binge drinking odds. These results are mostly consistent with hypotheses one, however we had predicted that students higher in neuroticism would still have increased daily drinking odds, as a function of drinking in anticipation of tests or assignments. This absent main effect is consistent with previous research showing that neuroticism and alcohol use are not related (Grekin et al., 2006; Goldstein \& Flett, 2009). In this sample, neuroticism and extraversion were negatively correlated. If students higher in neuroticism 
tend to be lower in extraversion, and students higher in extraversion drank more alcohol, it is reasonable that students higher in neuroticism would drink less alcohol. Students higher in neuroticism would have fewer social opportunities to engage in the alcoholpositive culture of university, leading them to drink less than students higher in extraversion who do take part in the alcohol culture of university.

\section{Academically intense events and drinking outcomes}

While students were less likely to drink on days before a test or assignment, they would drink a few sips of alcohol more than their average if they were drinking on the day before a test or assignment. There were no personality interactions with future academically intense events on any daily drinking outcome. Neither students higher in extraversion or neuroticism were more likely to drink on the day before a test or assignment. Out of students who did drink in anticipation of a test or assignment, they typically had higher extraversion scores $(M=2.46, S D=0.72)$ than neuroticism scores $(M=1.51, S D=0.74)$, but there is minimal difference in personality scores between those who did drink in anticipation of a test or assignment and those who did not. This result is consistent with the hypothesis that students higher in extraversion would not be more likely to drink before an academically intense event. Students that are higher in extraversion typically do not have the same amount of stress reactivity compared to those higher in neuroticism (Jonassaint et al., 2009; Evans et al., 2016). Students high in extraversion would be less likely to use alcohol to deal with the anticipation of future stressors.

Contrary to our hypothesis, students who were high in neuroticism were not more likely to drink alcohol or drink heavily before an academically intense event. Given that 
students are more likely to drink during days with more stressors (Russell et al., 2017) and that students higher in neuroticism experience greater stress from stressors (Tong, 2010), why was there no relationship between neuroticism and academically intense events?

The first potential factor in the neuroticism and alcohol use relationship lies within the type of stressor chosen for this study. There may not be an association between neuroticism and academically intense events because academically intense events are not stressful enough to warrant using alcohol as a coping mechanism amongst most students higher in neuroticism. While individuals higher in neuroticism experience more stress from stressful situations, it might be those stressors do not pass a threshold required for them to use alcohol. Controlling for personality, the average student only consumed $8 \%$ more alcohol on days preceding academically intense events. Personal stressors, such as relationship problems, parental pressures, financial strain, or the severity of depression or anxiety symptoms, may be more powerful stressors to individuals higher in neuroticism. While students higher in neuroticism appraise stressful situations as more subjectively stressful, these students still view situations that are objectively more stressful as being more stressful (Espejo et al., 2010). These more severe stressors may instigate the drinking to cope mechanism more than academically intense events. Students higher in neuroticism may be drinking in response to these stressors, rather than to the academically intense events chosen for this study. They may still be drinking in response to the anticipation of stressors, and their drinking is causing deficits at these events, but those stressors are not academically intense events. 
The second potential factor may be differential ratings of how stressful each academically intense event is for those higher in neuroticism. Students higher in neuroticism are more likely to drink alcohol when there are stressors, but drinking levels differ in the absence of a stressor (Armeli, DeHart, Tennen, Todd, \& Affleck, 2007). Individuals who are higher in neuroticism change their coping style from adaptive to maladaptive depending on their subjective appraisal of the stressor severity (Boyes \& French, 2012). In the work environment, those higher in neuroticism desire to use alcohol on days with high stress than those lower in neuroticism. However, they desire to drink less than those lower in neuroticism on days with very few stressors (Liu et al., 2009). Alcohol use for those higher in neuroticism may occur more on days that are appraised as stressful, rather than a specific type of stressor. Without accounting for the perceived stress caused by an event, any interaction between neuroticism and daily drinking outcomes may be counted as null.

The third potential factor lies within how students higher in neuroticism actually cope with stressful events. Students higher in neuroticism may not use alcohol in anticipation of stressors, but instead use alcohol after the stressor has occurred. The negative reaction caused by the stressful event may be more salient than the stress caused by the anticipation of that stressor. Those higher in neuroticism may also be more likely to use alcohol after receiving potentially negative feedback for those academically intense events, rather than the anticipation of them. Since students higher in neuroticism are higher in impulsivity, they may be less likely to properly recognize upcoming stressors as negative until after the event has occurred. There may not be enough stress before the academically intense event, but there may be negative affect in response. 


\section{Predictors of alcohol use problems}

Students who were relatively more likely to drink alcohol than others before academically intense events were at higher risk for alcohol dependence, while students who were more likely to binge drink before academically intense events had a higher number of alcohol use problems but were not high risk for alcohol use dependence. Since there were no students who were more likely to drink before an academically intense event than their base probability of daily drinking, this means that students who had a smaller reduction in their daily drinking odds, or students whose drinking/AIE slopes were closer to 0 , are more likely to be at high-risk for developing alcohol use dependence. Students who were more likely to binge drink before academically intense events may just be increasing their likelihood of experiencing some of the negative alcohol use consequences measured by the AUDIT, such as "failing to do what is expected of you", but this behaviour is not necessarily of clinical significance. These results support the original premise of this study, that alcohol use before an academically intense event can be problematic. However, the severity of alcohol use in anticipation of a test or assignment is not as clinically significant as whether students appropriately change their drinking odds in anticipation of a test or assignment.

Students who were higher in extraversion had more alcohol use problems, with minimal differences between students higher in extraversion who were lighter drinkers before a test or assignment and those students who were heavier drinkers. Drinking behaviour before a test or assignment was more impactful for students who were average or lower in extraversion. Students who are higher in extraversion seem to have higher rates of alcohol use problems through heavy and frequent alcohol use, regardless of the 
timing of the alcohol use. Students lower in extraversion who use alcohol in anticipation of a test or assignment appear to be on track for increased alcohol use problems by the end of university.

Students higher in extraversion having higher alcohol use problems through heavy and frequent alcohol use is consistent with hypothesis three. This result is also consistent with conceptualizations of the externalizing pathway (Hussong et al., 2011). Students who are higher in extraversion may be taking part in more drinking situations and be part of more alcohol-positive and deviant peer networks when compared to students lower in extraversion. Students higher in extraversion may have more difficulty refusing social situations involving alcohol (Quilty et al., 2014), which leads to more opportunities for heavy alcohol use. These students higher in extraversion are likely engaging in these heavy drinking behaviours without properly considering the context or the high-risk nature of their heavy drinking, a key component of the externalizing pathway (Zucker, Heitzeg, \& Nigg, 2011).

It is important to note that while extraversion increases the risk of alcohol dependence, extraversion is not necessarily a hazardous personality trait. The vast majority of students who drink heavily in university, primarily consisting of students higher in extraversion, do not go on to form an alcohol use disorder (Staff et al., 2013). Only $2 \%$ of days were binge drinking days for students higher in extraversion. Furthermore, a high AUDIT score does not necessarily indicate alcohol dependence, but rather identifies students at a higher risk of being or becoming higher risk for alcohol dependence. Students can be at high risk for alcohol dependence and not go on to develop alcohol dependence, or can be identified in error (Boschloo et al., 2010). Factors such as 
family history, age of onset, and adolescent mental health issues, are much stronger risk factors for alcohol dependence (Hicks, Iacono, \& McGue, 2010; Kendler, Prescott, Myers, \& Neale, 2003). Students higher in extraversion are nonetheless increasing their risk of becoming alcohol dependent by engaging in the positive alcohol culture of university that is above and beyond these effects.

There was no association between neuroticism and alcohol use problems. Students that were higher in neuroticism did not have increased alcohol use problems or increased odds of being at high risk for developing alcohol dependence. This is consistent from our previous models that showed there was no association between neuroticism and alcohol use but is contrary to previous research into the effects of neuroticism on alcohol use problems. There was also no association between neuroticism and alcohol use before an academically intense event. Students who were higher in neuroticism were not more likely to use alcohol before an academically intense event, and the students who did had no increase in alcohol use problems.

These results are contrary to previous research suggesting that students higher in neuroticism are at greater risk for alcohol dependence (Mezquita et al., 2010) and is at odds with research showing that neuroticism is linked to the most problematic of drinking profiles (Kuntsche et al., 2008). A potential explanation for this result is that a facet of neuroticism that is uniquely predictive of alcohol use is not appropriately identified in our neuroticism measure. There are multiple facets of neuroticism meant to cover the maladaptive features of personality that may result in a clinical personality disorder diagnosis: anxiety, depression, hostility, self-consciousness, impulsivity and vulnerability (Farmer, McGuffin, \& Williams, 2002). Individuals higher in neuroticism tend to have 
higher emotional and fear responses, which in certain situations may be adaptive and appropriate reactions to their environment (Barlow, Ellard, Sauer-Zavala, Bullis, \& Carl, 2014).

One facet of neuroticism that is linked to alcohol use is impulsivity: a general behavioural trait that leads to action without deliberation (Cross, Copping, \& Campbell, 2011). Impulsivity is highly correlated with many psychiatric disorders, including substance abuse (Moeller, Barratt, Dougherty, Schmitz, \& Swann, 2001). Impulsivity is predictive of daily alcohol use, but not predictive of alcohol use problems (Stautz, Dinc, \& Cooper, 2017). However, individual features of impulsivity are predictive of alcohol use disorder (Boschloo et al,. 2012). In the present study, none of the items in our neuroticism measure specifically measured characteristics of impulsivity. Impulsivity may be more predictive of daily drinking before a test or assignment compared to a global measure of neuroticism.

Another potential cause of this discrepancy may by our sampling window of university. Neuroticism may not be a meaningful predictor of alcohol use problems until after university. A large proportion of alcohol-dependence diagnoses occur outside of university (Moffitt et al., 2010), and many alcohol-dependent samples that are higher in neuroticism are in their thirties or higher (Schwandt, Heilig, Hommer, George, \& Ramchandani, 2013). Neuroticism may be an important predictor for alcohol use problems, but just not in this developmental period.

These results suggest that it is possible that neuroticism is not implicated in this stage of the internalizing developmental pathway of alcohol dependence. An increase in alcohol use problems for students who had relatively higher odds of drinking and 
drinking heavily in anticipation of a test or assignment was only accurate in one group: students who were lower in extraversion. Students who were lower in extraversion and who drank heavily in anticipation of a test or assignment had similar alcohol use problems to those higher in extraversion. This type of tension-reduction drinking was not seen in students higher in neuroticism, so this sort of drinking to cope with the anticipation of a stressor may only be important for those who are higher in introversion instead.

Introversion is conceptually opposite to extraversion, characterized by an avoidance of social situations, a preference for autonomy from others, and a tendency to seek reward from sources other than peers (Jung, 1921; Eysenck \& Eysenck, 1975). Individuals who are higher in introversion tend to have lower self-esteem and feel lonelier than those higher in extraversion (Kamath \& Kanekar, 1993). Low extraversion has been found to be associated with similar psychiatric disorders as neuroticism, high emotional instability, and with neuroticism itself (Aron \& Aron, 1997; Bienvenu, Hettema, Neale, Prescott, \& Kendler, 2007; Jylhä, Melartin, Rytsälä, \& Isometsä, 2009). Students higher in introversion, who also have lower self-esteem and higher loneliness, plan to use alcohol during university as a social lubricant to improve their image and reputation (Korn \& Maggs, 2004). Extraversion is negatively correlated with drinking to cope with anxiety and depression motivations, implying that students lower in extraversion are more like to drink in respond to stressors (Stewart \& Devine, 2000).

The internalizing developmental pathway towards alcohol dependence in emerging adulthood may not involve neuroticism at all, but rather some characteristics of introversion. Since students higher in introversion tend to have similar types of 
internalizing problems, introversion is a reasonable candidate for a personality predictor for entering the internalizing pathway. Since students higher in extraversion generally used alcohol more often and in heavier quantities, those lower in extraversion would use less alcohol. While being higher in introversion may not be a risk factor by itself for alcohol use problems, if students are more likely to drink heavily in anticipation of a test or assignment, this pattern of drinking behaviour could increase risk of alcohol use problems at the end of university. The stressor-alcohol link for those low in extraversion is uniquely predictive of alcohol use problems, even though they do not drink as heavily as those higher in extraversion. Future studies can measure introversion independently to confirm introversions role in alcohol use in emerging adulthood.

Within measurement of extraversion and neuroticism in the ULS, potential changes in personality over the course of university were not measured. Both personality types change over time. On average, both extraversion and neuroticism decrease over time within an individual, but the rank order of personality traits within the individual remain relatively stable (Roberts \& DelVecchio, 2000; Scollon \& Diener, 2006). These changes in extraversion and neuroticism over time are largely influenced by a person's environment across the lifespan (Kandler, 2012). Decreases in neuroticism and impulsivity have been associated with reduced alcohol consumption over time (Littlefield, Sher, \& Wood, 2009). Personality measured at the beginning of university may not be the most optimal predictor for future alcohol use problems as drinking behaviour becomes more normative across university.

Due to the prevalence of alcohol use in university, there is a large body of research into which intervention programs are effective at reducing university alcohol 
abuse, and for which students those interventions are the most effective. Interventions targeting first year university students and their drinking behaviours are generally effective (Scott-Sheldon, Carey, Elliott, Garey, \& Carey, 2014). However, interventions targeting alcohol use expectancies and motivations have limited long term effects (ScottSheldon, Terry, Carey, Garey, \& Carey, 2012), and interventions targeting Greek letter organizations, groups generally higher in extraversion (Park, Sher, Wood, \& Krull, 2009), are less effective if the interventions focused on personal high-risk situation identification (Scott-Sheldon, Carey, Kaiser, Knight, \& Carey, 2016). Interventions aimed at harm reduction, or attempting to reduce the consequences of alcohol use (Rosenberg et al., 2011), are generally effective at reducing alcohol use and alcohol use problems in university (Fachini, Aliane, Martinez \& Furtado, 2012). Individual differences in personality come with different coping strategy targets and effectiveness in regards to interventions. Individuals higher in neuroticism are more likely to engage in avoidant coping for tasks that are appraised as being highly stressful, while individuals higher in extraversion engage in proactive coping for stressful events (Boyes \& French, 2012; Straud, McNaughton-Cassill, \& Fuhrman, 2015). Students higher in extraversion are less likely to seek out assistance for alcohol use compared to students higher in introversion, while there is no association with neuroticism and help seeking behaviour (Raynor \& Levine, 2009). Students higher in extraversion are more likely to seek support from their social group (Krause, Pargament, \& Ironson, 2017). While students higher in neuroticism do not seek out more professional help with coping skills, these interventions are effective (Stillmaker \& Kasser, 2013). 
The results of this study may inform university alcohol intervention programs based on individual differences in personality and associated drinking behaviours. When presented with students higher in introversion, given our finding that students higher in introversion engage in hazardous alcohol use by drinking in anticipation of stressors, intervention programs could highlight the potential hazard of this specific type of drinking to cope as a unique form of hazardous alcohol use. Interventions programs that are presented with students higher in extraversion, given our finding that students higher in extraversion engage in more daily drinking and have more alcohol use problems, should focus on harm reduction strategies to reduce their amount of alcohol use problems and negative consequences. Intervention programs should also teach students higher in extraversion how to identify hazardous alcohol use in their peers, and how to refer those peers to intervention services on campus. Since interventions that are tailored to the individual are effective (e.g., Bingham et al., 2010), this study's recommendations can potentially increase efficacy in university student alcohol interventions.

\section{Noteworthy covariates}

Some covariates included in each model had significant effects on drinking outcomes. Gender did not predict daily drinking odds or drinking quantity, but men had $20 \%$ higher odds of binge drinking on any given day. Men also had more alcohol use problems at the end of university and were higher odds of being high risk for alcohol dependence. This finding is consistent with previous research, where men tend to be higher high-risk status for alcohol dependence and have an increased incidence rate of alcohol dependence diagnosis (Gomberg, 1997; Stewart et al., 2009). Men are more likely to drink more heavily and experience more alcohol use problems at earlier ages 
when compared to women, who tend to engage in hazardous drinking later in life (Fillmore et al., 1997; Keyes, Martins, Blanco, \& Hasin, 2010). In the university context, this indicates that more preventative measures and programs should be focused towards men in order to reduce their likelihood of suffering from alcohol dependence during this critical period.

Students who identified as Black or Asian were less likely to drink, drank less alcohol per drinking session and were less likely to binge drink when compared to Caucasian students. Students who identified as Black had no difference in their alcohol use problems, but Asian students had fewer alcohol use problems and a lower probability of being high-risk for alcohol dependence. Students who identified as Hispanic drank more often, drank more alcohol per drinking session and were more likely to binge drink when compared to Caucasian students, but did not differ in alcohol use problems. Previous research typically shows a decrease in alcohol use for students who identify as Black or Hispanic, but an increase in alcohol use problems (Zenmore et al., 2016). However, factors such as ethnic community norms against alcohol use and successful acculturation into predominately Caucasian cultures does show a decrease in alcohol use and alcohol use problems (Caetano \& Clark, 1999; Bryant \& Kim, 2013). Ensuring that minorities are readily accepted into university culture may limit the possibility of hazardous alcohol use and alcohol use problems.

Drinking odds and drinking quantity generally increased over time across university. With each passing semester, students were $14 \%$ more likely to consume alcohol on any given day and would drink one more drink on average per drinking session. This effect was weakened for students higher in extraversion. This is potentially 
due to the effects of alcohol normalization over the course of university. As alcohol use becomes more accepted and normal across university, more students may be starting to use alcohol in heavier amounts as they are exposed to the alcohol-positive campus culture. Personality may be less important of a predictor of alcohol use over time due to the increase in number of students engaging in alcohol use.

\section{Limitations}

A principal limitation lies within the recruitment of participants for this sample. The original ULS sample was recruited to assess daily drinking and sexual behaviours across university for the average student, rather than assessing drinking behaviour specifically. Students who did not drink throughout university, or did not drink regularly, were included in the sample. This resulted in a lower number of drinking days across university compared to what could have been achieved with an equal number of regular drinkers. This leads to a lower power to test the effects of personality and alcohol use timing on alcohol use problems. A key feature of the hypotheses was to determine the factors that cause some students who use alcohol to develop alcohol use problems and not others. Since there are only minimal personality differences between drinkers and nondrinkers (Lac \& Donaldson, 2016), including these drinkers may reduce the power to detect the actual effects of personality on drinking behaviour.

Another limitation lies within the sampling window during each semester. While a feature of the ULS was to assess daily activities such as tests and assignments, daily diary burst sampling occurred exclusively during times when there were no final exams scheduled. While regular tests and assignments did happen, any exam-heavy period on average was avoided. Academically intense events were chosen to represent an event that 
typically requires sobriety beforehand to succeed and has a penalty that is experienced within the sampling window. Most drinks were consumed on weekends, preceding days that do not actually have tests or assignments. These factors led to a generally low number of test and assignments coinciding with drinking days, leading to low power to detect possible deleterious effects of drinking before academically intense events. However, there were a reasonable number of drinking days occurring before academically intense events. Future research could use larger sampling windows, or sample during midterm and exam periods in university to increase power.

\section{Conclusion}

Students who drank more alcohol and were more likely to binge drink before an academically intense event were more likely to have higher alcohol use problems and be at high risk for alcohol-dependence. There were no personality differences in the tendency to drink more before academically intense events. Drinking in inappropriate contexts are universally connected to alcohol use problems, regardless of individual differences in personality. This study highlights the fact that there are forms of hazardous alcohol use that are beyond the alcohol consumed. While heavy alcohol use is one form of hazardous drinking, the context surrounding the alcohol use can be uniquely predictive of alcohol use problems. Students who drank more alcohol before a test or exam are more at-risk for alcohol use problems independent of their average drinking levels.

Preventative programs for hazardous alcohol use in university should highlight the potential risks of using alcohol at inappropriate times, as the context of use can increase the probability of alcohol use problems. 
Students higher in extraversion consumed more alcohol across university and increased alcohol use problems at the end of university. While extraversion is viewed as a universally positive trait, there are downsides when entering the alcohol-positive culture of university. Students that are higher in extraversion may have difficulty refusing the abundant opportunities to consume alcohol in a hazardous manner, leading to eventual alcohol use problems. Since many university students overestimate the normality and severity of alcohol use on campus, they may feel that it is expected of them to use alcohol in these social situations. Students entering university should be informed of the actual amount of drinking that occurs on campus; that alcohol use is not as common and not as heavy as they may believe it is. Students should also be guided towards avoiding drinking in response to stress caused by the anticipation of tests and assignments, and preventative programs at universities should focus on students that are more social than their peers.

If students higher in neuroticism are more likely to drink to cope with depression and anxiety, it is likely that this drinking to cope behaviour is occurring after the stressor has occurred, rather than in anticipation. The stressors chosen for this study may have not been severe enough to warrant coping mechanisms using alcohol in students higher in neuroticism. Future research should investigate how students higher in neuroticism respond to stressors, and their subjective rating of the severity of those stressors, and whether they are more likely to drink alcohol to cope with the negative affect caused by those stressors. Future research should also investigate the role of the facets of neuroticism, such as impulsivity, and determine if those facets are more predictive of drinking in anticipation of stressors. If students higher in neuroticism have increased 
alcohol use problems from drinking after stressors, then resources should be made available at universities to teach healthy coping strategies for new students.

This study identifies a mechanism that is not the explanatory factor for the internalizing developmental pathway towards alcohol dependence. While neuroticism may by implied in a developmental trajectory of alcohol use that is based on coping with internalizing symptoms in emerging adulthood, this coping does not occur in anticipation of set stressors in university. Alcohol use in students higher in neuroticism may be reactionary to these stressors, as opposed to in anticipation of them. Another possibility is that personal stressors may trigger a more intense coping reaction in students higher in neuroticism, rather than tests and assignments that occur in university. Neuroticism itself as a trait may not contain enough internalizing symptoms to be predictive of features of the internalizing developmental pathway towards alcohol dependence. This developmental pathway may have several factors within itself, where neuroticism is too global of a measure that obscures the individual relationships to hazardous alcohol use.

This study supports the later stages of the externalizing developmental pathway towards alcohol dependence. In emerging adulthood, the personality trait of extraversion is strongly linked to heavy and delinquent alcohol use, leading to eventual alcohol use problems. Students lower in extraversion had increased alcohol use problems predicted by drinking in anticipation of a test or assignment, which may be a factor in the internalizing developmental pathway. Personality traits can predict differences in alcohol use patterns that lead of a higher risk of alcohol use dependence, and alcohol use problems are not exclusively caused by globally higher alcohol use. 


\section{References}

Alati, R., Kinner, S., Najman, J. M., Fowler, G., Watt, K., \& Green, D. (2004). Gender differences in the relationships between alcohol, tobacco and mental health in patients attending an emergency department. Alcohol and Alcoholism, 39(5), 463469.

Alloy, L. B., Fedderly, S. S., Kennedy-Moore, E., \& Cohan, C. L. (1998). Dysphoria and social interaction: An integration of behavioral confirmation and interpersonal perspectives. Journal of Personality and Social Psychology, 74(6), 1566-1579.

American College Health Association (2016). American College Health AssociationNational College Health Assessment II: Canadian Reference Group Data Report Spring 2016. Hanover, MD: American College Health Association.

American College Health Association (2017). American College Health AssociationNational college health assessment II: Spring 2017 reference group data report. Hanover, MD: American College Health Association.

American Psychiatric Association. (1952). Diagnostic and statistical manual of mental disorders. Washington, DC: Author.

American Psychiatric Association. (2013). Diagnostic and statistical manual of mental disorders ( $5^{\text {th }}$ ed.). Washington, DC: Author.

An, B. P., Loes, C. N., \& Trolian, T. L. (2017). The relation between binge drinking and academic performance: Considering the mediating effects of academic involvement. Journal of College Student Development, 58(4), 492-508.

Anderson, P., \& Baumberg, B. (2006). Alcohol in Europe. London: Institute of Alcohol Studies. 
Annis, H. M., \& Martin, G. (1985). Inventory of drug-taking stations. Toronto: Addiction Research Foundation of Ontario.

Armeli, S., Todd, M., \& Mohr, C. (2005). A daily diary approach to individual differences in stress-related alcohol use. Journal of Personality, 73(6), 16571686.

Armeli, S., DeHart, T., Tennen, H., Todd, M., \& Affleck, G. (2007). Daily interpersonal stress and the stressor-vulnerability model of alcohol use. Journal of Social and Clinical Psychology, 26(8), 896-921.

Aron, E. N., \& Aron, A. (1997). Sensory-processing sensitivity and its relation to introversion and emotionality. Journal of Personality and Social Psychology, 73(2), 345-368.

Babor, T. F., Higgins-Biddle, J. C., Saunders, J. B., \& Monteiro, M. G. (2001). The Alcohol Use Disorders Identification Test: Guidelines for use in primary care $\left(2^{\text {nd }}\right.$ ed.). Geneva, Switzerland: World Health organization, Department of Mental Health and Substance Dependence.

Babor, T., Caetano, R., Casswell, S., Edwards, G., Giesbrecht, N., Graham, K., ... Rossow, I. (2003). Alcohol: No ordinary commodity. Research and public policy. Oxford: Oxford University Press.

Baer, J. S. (1994). Effects of college residence on perceived norms for alcohol consumption: An examination of the first year in college. Psychology of Addictive Behaviors, 8, 43-50.

Barlow, D. H., Ellard, K. K., Sauer-Zavala, S., Bullis, J. R., \& Carl, J. R. (2014). The origins of neuroticism. Perspectives on Psychological Science, 9(5), 481-496. 
Barnes, G. E. (1979). The alcohol personality: A reanalysis of the literature. Journal of Studies of Alcohol, 40(7), 571-634.

Barnett, N. P., Clerkin, E. M., Wood, M., Monti, P. M., Tevyaw, T. O., Corriveau, D., ... Kahler, C. W. (2014). Description and predictors of positive and negative alcoholrelated consequences $\mathrm{n}$ the first year of college. Journal of Studies on Alcohol and Drugs, 75, 103-114.

Berdan, L. E., Keane, S. P., \& Calkins, S. D. (2008). Temperament and externalizing behavior: Social preference and perceived acceptance as protective factors. Developmental Psychology, 44(4), 957-968.

Bienvenu, O. J., Hettema, J. M., Neale, M. C., Prescott, C. A., \& Kendler, K. S. (2007). Low extraversion and high neuroticism as indices of genetic and environmental risk for social phobia, agoraphobia, and animal phobia. American Journal of Psychiatry, 164, 1714-1721.

Bingham, C. R., Barretto, A. I., Walton, M. A., Bryant, C. M., Shope, J. T., \& Raghunathan, T. E. (2010). Efficacy of a web-based, tailered, alcohol prevention/intervention program for college students: Initial findings. Journal of American College Health, 58(4), 349-356.

Blickle, G., Meurs, J. A., Wihler, A., Ewen, C., Merkl, R., \& Missfeld, T. (2015). Extraversion and job performance: How context relevance and bandwidth specificity create a non-linear, positive, and asymptotic relationship. Journal of Vocational Behavior, 87, 80-88.

Boden, J. M., \& Fergusson, D. M. (2011). Alcohol and depression. Addiction, 106, 906914. 
Boden, J. M., Fergusson, D. M., \& Horwood, L. J. (2014). Associations between exposure to stressful life events and alcohol use disorder in a longitudinal birth cohort studied to age 30. Drug and Alcohol Dependence, 142, 154-160.

Bolger, N., Davis, A., \& Rafaeli, E. (2003). Diary methods: Capturing life as it is lived. Annual Review of Psychology, 54, 579-616.

Bonomo, Y., Coffey, C., Wolfe, R., Lynskey, M., Bowes, G., \& Patton, G. (2001). Adverse outcomes of alcohol use in adolescents. Addiction, 96(10), 1485-1496.

Borghans, L., Duckworth, A. L., Heckman, J. J., \& ter Weel, B. (2008). The economics and psychology of personality traits. The Journal of Human Resources, 43(4), 972-1059.

Borsari, B., Bergen-Cico, D., \& Carey, K. B. (2003). Self-reported drinking-game participation of incoming college students. Journal of American College Health, $41,149-154$.

Boschloo, L., Vogelzangs, N., Smit, J. H., van den Brink, W., Veltman, D. J., Beekman, A. T. F., \& Penninx, B. W. J. H. (2010). The performance of the Alcohol Use Disorders Identification Test (AUDIT) in detecting alcohol abuse and dependence in a population of depressed or anxious persons. Journal of Affective Disorders, $126,441-446$.

Boschloo, L., Vogelzangs, N., van den Brink, W., Smit, J. H., Beekman, A. T. F., \& Penninx, B. W. J. H. (2012). The roloe of negative emotionality and impulsivity in depressive/anxiety disorders and alcohol dependence. Psychological Medicine, $43,1241-1253$. 
Boyes, M. E., \& French, D. J. (2012). The mediating effect of appraisal on the relationship between neuroticism and coping during an anagram-solving task: A goodness-of-fit hypothesis perspective. Personality and Individual Differences, $53,306-311$.

Bryant, A. N., \& Kim, G. (2013). The relation between acculturation and alcohol consumption patterns among older Asian and Hispanic immigrants. Aging and Mental Health, 17(2)., 147-156.

Caetano, R., \& Clark, C. L. (1999). Trends in situational norms and attitudes towards drinking among whites, blacks, and Hispanics: 1984-1995. Drug and Alcohol Dependence, 54, 45-56.

Carey, K. B. (1993). Situational determinants of heavy drinking among college students. Journal of Counseling Psychology, 40(2), 217-220.

Carey, K. B. (1995). Heavy drinking contexts and indices of problem drinking among college students. Journal of Studies on Alcohol, 56, 287-292.

Casswell, S., Pledger, M., \& Pratap, S. (2002). Trajectories of drinking from 18 to 26 years: identification and prediction. Addiction, 97(11), 1427-1437.

Caughlin, J. P., Huston, T. L., \& Houts, R. M. (2000). How does personality matter in marriage? An examination of trait anxiety, interpersonal negativity, and marital satisfaction. Journal of Personality and Social Psychology, 87, 363-383.

Center for Behavioral Health Statistics and Quality. (2016). 2015 National Survey on Drug Use and Health: Detailed Tables. Rockville, MD: Substance Abuse and Mental Health Services Administration, Rockville, MD. 
Chen, C. M., Dufour, M. C., \& Yi, H. (2004). Alcohol consumption among young adults ages 18-24 in the United States: Results from the 2001-2002 NESARC survey. Alcohol Research \& Health, 28(4), 269-280.

Christiansen, M., Vik, P. W., \& Jarchow, A. (2002). College student heavy drinking in social contexts versus alone. Addictive Behaviors, 27, 393-404.

Clapp, J. D., Ketchie, J. M., Reed., M. B., Shillington, A. M., Lange, J. E., \& Holmes, M. R. (2008). Three exploratory studies of college theme parties. Drug and Alcohol Review, 27, 509-518.

Cohen, M., \& Khalaila, R. (2014). Saliva $\mathrm{pH}$ as a biomarker of exam stress and a predictor of exam performance. Journal of Psychosomatic Research, 77, 420-425.

Connor-Smith, J. K., \& Flachsbart, C. (2007). Relations between personality and coping: A meta-analysis. Journal of Personality and Social Psychology, 93(6), 10801107.

Costanzo, P. R., Malone, P. S., Belsky, D., Kertesz, S., Pletcher, M., \& Sloan, F. A. (2007). Longitudinal differences in alcohol use in early adulthood. Journal of Studies on Alcohol and Drugs, 68, 727-737.

Cooper, M. L. (1994). Motivations for alcohol use among adolescents: Development and validation of a four-factor model. Psychological Assessment, 6(2), 117-128.

Cooper, M. L., Frone, M. R., Russell, M., \& Mudar, P. (1995). Drinking to regulate positive and negative emotions: A motivational model of alcohol use. Journal of Personality and Social Psychology, 69, 990-1005.

Costa, P. T., \& McCrae, R. R. (1992). The 5-factor model of personality and its relevance to personality-disorders. Journal of Personality Disorders, 6(4), 343-359. 
Cox, W. M. (1985). Personality correlates of substance abuse. In M. Galizio \& S. A. Maisto (Eds.), Determinants of Substance Abuse (pp 209-246). New York: Plenum.

Cox, W. M., \& Klinger, E. (1988). A motivational model of alcohol use. Journal of Abnormal Psychology, 97(2), 168-180.

Cross, C. P., Copping, L. T., \& Campbell, A. (2011). Sex differences in impulsivity: A meta-analysis. Psychological Bulletin, 137(1), 97-130.

DeYoung, C. G., Peterson, J. B., Séguin, J. R., \& Tremblay, R. E. (2008). Externalizing behavior and the higher order factors of the big five. Journal of Abnormal Psychology, 117(4), 947-953.

Donnellan, M. B., Conger, R. D., \& Bryant, C. M. (2004). The big five and enduring marriages. Journal of Research in Personality, 38, 481-504.

Donovan, J. E. (2007). Really underage drinkers: the epidemiology of children's alcohol use in the United States. Prevention Science, 8, 192-205.

Donovan, J. E. (2013). The burden of alcohol use: Focus on children and preadolescents. Alcohol Research: Current Reviews, 35, 186-192.

Edmunds, G. (1977). Extraversion, neuroticism, and different aspects of self-reported aggression. Journal of Personality Assessment, 41(1), 66-70.

Espejo, E. P., Ferriter, C. T., Hazel, N. A., Keenan-Miller, D., Hoffman, L. R., \& Hammen, C. (2010). Predictors of subjective ratings of stressor severity: The effects of current mood and neuroticism. Stress and Health, 27, 23-33.

Evans, B. E., Stam, J., Huizink, A. C., Willemen, A. M., Westengerd, P. M., Branje, S., ... van Lier, P. A. C. (2016). Neuroticism and extraversion in relation to 
physiological stress reactivity during adolescence. Biological Psychology, 117, 67-79.

Eysenck, H. J., \& Eysenck, S. B. G. (1975). Manual for the Eysenck Personality Questionnaire. London: Hodder \& Stoughton.

Fachini, A., Aliane, P. P., Martinez, M. Z., \& Furtado, E. F. (2012). Efficacy of brief alcohol screening intervention for college students (BASICS): A meta-analysis of randomized controlled trials. Substance Abuse Treatment, Prevention, and Policy, $7(1), 40-50$.

Fairbairn, C. E., Sayette, M. A., Wright, A. G. C., Levine, J. M., Cohn, J. F., \& Creswell, K. G. (2015). Extraversion and the rewarding effects of alcohol in a social context. Journal of Abnormal Psychology, 124(3), 660-673.

Farmer, A., McGuffin, P., \& Williams, J. (2002). Measuring Psychopathology. Oxford: Oxford University Press.

Farmer, E. M. Z., Compton, S. N., Burns, B. J., \& Robertson, E. (2002). Review of the evidence base for treatment of childhood psychopathology: Externalizing disorders. Journal of Consulting and Clinical Psychology, 70(6), 1267-1302.

Fillmore, K. M., Golding, J. M., Leino, E. V., Motoyoshi, M., Shoemaker, C., Terry, H., ... Ferrer, H. P. (1997). Patterns and trends in women's and men's drinking. In R. W. Wilsnack \& S. C. Wilsnack (Eds), Gender and Alcohol: Individual and Social perspectives (pp. 21-48). New Brunswick, NJ: Rutgers Center of Alcohol Studies.

Fleming, M. F., Barry, K. L., \& MacDonald, R. (1991). The Alcohol Use Disorders Identification Test (AUDIT) in a college sample. International Journal of Addictions, 26, 1173-1185. 
Galambos, N. L., Dalton, A. L., \& Maggs, J. L. (2009). Losing sleep over it: Daily variation in sleep quantity and quality in Canadian students' first semester of university. Journal of Research on Adolescence, 19(4), 741-761.

Galbraith, S., Daniel, J. A., \& Vissel, B. (2010). A study of clustered data and approaches to its analysis. The Journal of Neuroscience, 30(32), 10601-10608.

Gatin, D. E. (2005). Adolescent substance use: Current rates and personal impact. North American Journal of Psychology, 7(3), 449.

Ghosh, A., Malhotra, S., \& Basu, D. (2016). Are childhood externalizing disorders the harbinger of early-onset alcohol dependence? Indian Journal of Medical Research, 144(3). 385-392.

Goldberg, L. R. (1992). The development of markers for the Big-Five factor structure. Psychological Assesment, 4, 26-42.

Goldberg, L. R. (1999). A broad-bandwidth, public domain, personality inventory measuring the lower-level facets of several five-factor modes. In I. Mervielde, I. Deary, F. De Fruyt, \& F. Ostendorf (Eds.), Personality Psychology in Europe, Vol. 7 (pp. 7-28). Tilburg, The Netherlands: Tilburg University Press.

Goldberg, L. R., Johnson, J. A., Eber, H. W., Hogan, R., Ashton, M. C., Cloninger, C. R., \& Gough, H. C. (2006). The International Personality Item Pool and the future of public-domain personality measures. Journal of Research in Personality, 40, 8496.

Goldstein, A. L., \& Flett, G. L. (2009). Personality, alcohol use, and drinking motives: A comparison of independent and combined internal drinking motives groups. Behavior Modification, 33(2), 182-198. 
Gomberg, E. S. L. (1997). Alcohol abuse: age and gender differences. In R. W. Wilsnack \& S. C. Wilsnack (Eds.), Gender and Alcohol: Individual and Social Perspectives (pp. 225-244). New Brunswick, NJ: Rutgers Center of Alcohol Studies.

Gonzalez, V. M., \& Skewes, M. C. (2012). Solitary heavy drinking, social relationships, and negative mood regulation in college drinkers. Addiction Research and Theory, 21(4), 285-294.

Gonzalez, V. M. (2012). Association fo solitary binge drinking and suicidal behavior among emerging adult college students. Psychology of addictive behaviors, 26(3), 609-614.

Gonzalez, V. M., \& Hewell, V. M. (2012). Suicide ideation and drinking to cope among college binge drinkers. Addictive Behaviors, 37(8), 994-997.

Graber, J. A., \& Brooks-Gunn, J. (1996). Transitions and turning points: Navigating the passage from childhood through adolescence. Developmental Psychology, 32(4), 768-776.

Grant, V. V., Stewart, S. H., \& Mohr, C. D. (2009). Coping-anxiety and copingdepression motives predict different daily mood-drinking relationships. Psychology of Addictive Behaviors, 23(2), 226-237.

Gray, J. A. (1970). The psychophysiological basis of introversion-extraversion. Behavioural Research and Therapy, 8, 249-266.

Greenfield, T. K., \& Rogers, J. D. (1999). Who drinks most of the alcohol in the U.S.? The policy implications. Journal of Studies on Alcohol, 60(1), 78-89. 
Grekin, E. R., Sher, K. J., \& Wood, P. K. (2006). Personality and substance dependence symptoms: Modelling substance-specific traits. Psychology of Addictive Behaviors, 20(4), 415-424.

Griffin, C., Bengry-Howell, A., Hackley, C., Mistral, W., \& Szmigin, I. (2009). 'Every time I do it I absolutely annihilate myself': Loss of (self-)consciousness and loss of memory in young people's drinking narratives. Sociology, 43(3), 457-476.

Griffith, J. W., Zinbarg, R. E., Craske, M. G., Mineka, S., Rose, R. D., Waters, A. M., \& Sutton, J. M. (2010). Neuroticism as a common dimension in the internalizing disorders. Psychological Medicine, 40, 1125-1136.

Grønkjær, M., Curtis, T., de Crespigny, C., \& Delmar, C. (2013). Drinking contexts and the legitimacy of alcohol use: Findings from a focus group study on alcohol use in Denmark. Scandinavian Journal of Public Health, 41, 221-229.

Gunthert, K. C., Cohen, L. H., \& Armeli, S. (1999). The role of neuroticism in daily stress and coping. Journal of Personality and Social Psychology, 77(5), 10871100.

Hakulinen, C., Elovainio, M., Batty, G. D., Virtanen, M., Kivimäki, M., \& Jokela, M. (2015). Personality and alcohol consumption: Pooled analysis of 72,949 adults from eight cohort studies. Drug and Alcohol Dependence, 151, 110-114.

Harrell, Z. A. T., Huang, J. L., \& Kepler, D. M. (2013). Brief report: Affluence and college problems: The relevance of parent- and child-reported indicators of socioeconomic status. Journal of Adolescence, 36, 893-897. 
Harris, K., English, T., Harms, P. D., Gross, J. J., \& Jackson, J. J. (2017). Why are extraverts more satisfied? Personality, social experiences, and subjective wellbeing in college. European Journal of Personality, 31, 170-186.

Hebden, R., Lyons, A. C., Goodwin, I., \& McCreanor, T. (2015). "When you add alcohol, it gets much better”: University students, alcohol consumption, and online drinking cultures. Journal of Drug Issues, 42(2), 214-226.

Hensing, G. (2012). The health consequences of alcohol and drug abuse. Scandinavian Journal of Public Health. 40(9), 211-228.

Henze, G., Zänkert, S., Urschler, D. F., Hiltl, T. J., Kudielka, B. M., Pruessner, J. C., \& Wüst, S. (2017). Testing the ecological validity of the Trier Social Stress Test: Association with real-life exam stress. Psychoneuroendocrinology, 75, 52-55.

Hicks, B. M., Iacono, W. G., \& McGue, M. (2010). Consequences of an adolescent onset and persistent course of alcohol dependence in men: Adolescent risk factors and adult outcomes. Alcoholism: Clinical and Experimental Research, 34(5), 819-833.

Hill, S. Y., Shen, S., Lowers, L., \& Locke, J. (2000). Factors predicting the onset of adolescent drinking in families at high risk for developing alcoholism. Society of Biological Psychiatry, 48, 265-275.

Holdstock, L., King, A. C., \& de Wit, H. (2000). Subjective and objective responses to ethanol in moderate/heavy and light social drinkers. Alcoholism: Clinical and Experimental Research, 24(6), 789-794.

Holdstock, L., \& de Wit, H. (1998). Individual differences in the biphasic effects of ethanol. Alcoholism: Clinical and Experimental Research, 22(9), 1903-1911. 
Howard, A. L., Patrick, M. E., \& Maggs, J. L. (2015). College student affect and heavy drinking: Variable associations across days, semesters, and people. Psychology of Addictive Behaviours, 29(2), 430-443.

Huckle, T., Pledger, M., \& Casswell, S. (2005). Trends in alcohol-related harms and offences in a liberalized alcohol environment. Addiction, 101(2), 232-240.

Hussong, A. M., Jones, D. J., Stein, G. L., Baucom, D. H., \& Boeding, S. (2011). An internalizing pathway to alcohol use and disorder. Psychology of Addictive Behaviors, 25(3), 390-404.

Iacono, W. G., Malone, S. M., \& McGue, M. (2008). Behavioural disinhibition and the development of early-onset addiction: Common and specific influences. Annual Review of Clinical Psychology, 4, 325- 348.

Jeronimus, B. F., Riese, H., Sanderman, R., \& Ormel, J. (2014). Mutual reinforcement between neuroticism and life experiences: A five-wave, 16-year study to test reciprocal causation. Journal of Personality and Social Psychology, 107(4), 751764.

Johnson, B. A., Cloninger, C. R., Roache, J. D., Bordnick, P. S., \& Ruiz, P. (2000). Age of onset as a discriminator between alcoholic subtypes in a treatment-seeking outpatient population. The American Journal on Addictions, 9, 17-27.

Johnsson, K. O., Leifman, A., \& Berglund, M. (2008). College students' drinking patterns: trajectories of AUDIT scores during the first four years at university. European Addiction Research, 14, 11-18.

Jonassaint, C. R., Why, Y. P., Bishop, G. D., Tong, E. M., Doing, S. M., Enkelmann, H. C., ... Ang, J. (2009). The effects of neuroticism and extraversion on 
cardiovascular reactivity during a mental and an emotional stress task. International Journal of Psychophysiology, 74(3), 274-279.

Jung, C. G. (1921). Psychological types: Collected works. Princeton, NJ: Princeton University Press.

Jussim, L. (1986). Self-fulfilling propheicies: A theoretical and integrative review. Psychological Review, 93(4), 429-445.

Jylhä, P., Melartin, T., Rytsälä, H., \& Isometsä, E. (2009). Neuroticism, introversion, and major depressive disorder - traits, states, or scars? Depression and Anxiety, 26, $325-334$

Kamath, S., \& Kanekar, M. (1993). Loneliness, shyness, self-esteem, and extraversion. Journal of Social Psychology, 133, 855-857.

Kandler, C. (2012). Nature and nurture in personality development: The case of neuroticism and extraversion. Current Directions in Psychological Science, 21(5), 290-296.

Kaplan, M. S., Huguet, N., McFarland, B. H., Caetano, R., Conner, K. R., Giesbrecht, N., \& Nolte, K. B. (2014). Use of alcohol before suicide in the United States. Annals of Epidemiology, 24, 588-592.

Kendler, K. S., Prescott, C. A., Myers, J., \& Neale, M. C. (2003). The structure of genetic and environmental risk factors for common psychiatric and substance use disorders in men and women. Archives of General Psychiatry, 60, 929-937.

Keough, M. T., O’Connor, R. M., \& Colder, C. R. (2016). Testing the implicit and explicit cognitions underlying BIS-related drinking in young adults. Alcoholism: Clinical and Experimental Research, 40(5), 1065-1074. 
Keough, M. T., O’Connor, R. M., \& Stewart, S. H. (2018). Solitary drinking is associated with specific alcohol problems in emerging adults. Addictive Behaviors, 76, $285-$ 290.

Keyes, K. M., Martins, S. S., Blanco, C., \& Hasin, D. S. (2010). Telescoping and gender differences in alcohol dependence: New evidence from two national surveys. American Journal of Psychiatry, 167, 969-976.

Khantzian, E. J. (1997). The self-medication hypothesis of substance use disorders: A reconsideration and recent applications. Harvard Review of Psychiatry, 4, 231244.

Khantzian, E. J. (1985). The self-medication hypothesis of addictive disorders: Focus on heroin and Cocaine Dependence. American Journal of Psychiatry, 142, 12591264.

Kilbey, M. M., Downey, K., \& Breslau, N. (1998). Predicting the emergence and persistence of alcohol dependence in young adults: The role of expectancy and other risk factors. Experimental and Clinical Psychopharmacology, 6(2), 149156.

Kirby, T., \& Barry, A. E. (2012). Alcohol as a gateway drug: A study of US $12^{\text {th }}$ graders. Journal of School Health, 82, 371-379.

Knight, J. R., Wechsler, H., Kuo, M., Seibring, M., Weitzman, E. R., \& Schuckit, M. A. (2002). Alcohol abuse and dependence among U.S. college students. Journal of Studies on Alcohol, 63(3), 263-270. 
Korn, M. E., \& Maggs, J. L. (2004). Why drink less? Diffidence, self-presentation styles, and alcohol use among university students. Journal of Youth and Adolescence, 33(3), 201-211.

Krause, N., Pargament, K. I., \& Ironson, G. (2017). Assessing the relationships among spiritual social support, stress, and anxiety: Does extraversion also play a role in the coping process? Current Psychology, https://doi.org/10.1007/s12144-0179764-8.

Krueger, R. F. (1999). The structure of common mental disorders. Archives of General Psychiatry, 56, 921-926.

Krueger, R. F., Caspi, A., Moffitt, T. E., Silva, P. A., \& McGee, R. (1996). Personality traits are differentially linked to mental disorders: A multitrait - multidiagnosis study of an adolescent birth cohort. Journal of Abnormal Psychiatry, 105(3), 299312.

Kuendig, H., \& Kuntsche, E. (2013). Beyond personality - experimental investigations of the effects of personality traits on in situ alcohol consumption in social and solitary drinking contexts. Addictive Behaviors, 38, 1635-1638.

Kuntsche, E., Knibbe, R., Gmel, G., \& Engels, R. (2005). Why do young people drink? A review of drinking motives. Clinical Psychology Review, 25, 841-861.

Kuntsche, E., Knibbe, R., Gmel, G., \& Engels, R. (2006). Who drinks and why? A review of socio-demographic, personality, and contextual issues behind the drinking motives in young people. Addictive Behaviors, 31, 1844-1857.

Kuntsche, E., Stewart, S. H., \& Cooper, M. L. (2008). How stable is the motive - alcohol link? A cross-national validation of the drinking motives questionnaire revised 
among adolescents from Switzerland, Canada, and the United States. Journal of Studies on Alcohol and Drugs, 69(3), 388-396.

Kuntsche, E., \& Gmel, G. (2013). Alcohol consumption in late adolescence and early adulthood - where is the problem? Swiss Medical Weekly, 143, doi:10.4414/smw.2013.13826.

Kuntsche, E., Kuntsche, S., Thrul, J., \& Gmel, G. (2017). Binge drinking: Health impact, prevalence, correlates, and interventions. Psychology and Health, 32(8), 9761017.

Kutner, M. H., Nachtsheim, C. J., Neter, J., \& Li, W. (2005). Applied linear statistical models $\left(5^{\text {th }}\right.$ ed.). New York, NY: McGraw-Hill.

Lac, A., \& Donaldson, C. D. (2016). Alcohol attitudes, motives, norms, and personality traits longitudinally classify non-drinkers, moderate drinkers, and binge drinkers using discriminant function analysis. Addictive Behaviors, 61, 91-98.

Lazarus, R. S., \& Folkman, S. (1984). Stress, appraisal, and coping. New York: Springer.

de Leeuw, J., \& Meijer, E. (2008). Introduction to multilevel analysis. In J. de Leeuw, E. Meijer (Eds.), Handbook of Multilevel Analysis (pp. 1-75). New York, NY: Springer.

Lewis, M. A., Neighbors, C., Geisner, I. M., Lee, C. M., Kilmer, J. R., \& Atkins, D. C. (2010). Examining the associations among severity of injunctive drinking norms, alcohol consumption, and alcohol-related negative consequences: The moderating roles of alcohol consumption and identity. Psychology of Addictive Behaviors, 24(2), 177-189. 
Littlefield, A. K., Sher, K. J., \& Wood, P. K. (2009). Is the "maturing out" of problematic alcohol involvement related to personality change? Journal of Abnormal Psychology, 118, 360-374.

Liu, S., Wang, M., Zhan, Y., \& Shi, J. (2009). Daily work stress and alcohol use: Testing the cross-level moderation effects of neuroticism and job involvement. Personnel Psychology, 62, 575-597.

Loukas, A., Krull, J. L., Chassin, L., \& Carle, A. C. (2000). The relation of personality to alcohol abuse/dependence in a high-risk sample. Journal of Personality, 68(6), 1153-1175.

Lucas, R. E., Le, K., \& Dyrenforth, P. S. (2008). Explaining the extraversion/positive affect relation: sociability cannot account for extraverts' greater happiness. Journal of Personality, 76(3), 385-414.

Lynn, R., \& Martin, T. (1997). Gender differences in extraversion, neuroticism, and psychoticism in 37 nations. The Journal of Social Psychology, 137(3), 369-373.

Malouff, J. M., Thorsteinsson, E. B., \& Schutte, N. S. (2005). The relationship between the five-factor model of personality and symptoms of clinical disorders: A metaanalysis. Journal of Psychopathology and Behavioral Assessment, 27(2), 101-114.

Marcus, D. K., \& Nardone, M. E. (1992). Depression and interpersonal rejection. Clinical Psychology Review, 12, 433-449.

Marlatt, G. A., \& Gordon, J. R. (1980). Determinants of relapse: Implications for the maintenance of behavior change. In P. O. Davidson \& S. M. Davidson (Eds.), Behavioral medicine: Changing health lifestyles (pp. 410-452). New York: Brunner/Mazel. 
Martin, P., \& Martin, M. (2002). Proximal and distal influences on development: The model of developmental adaptation. Developmental Review, 22, 78-96.

Martin, S. E. (2001). The links between alcohol, crime, and the criminal justice system: Explanations, evidence, and interventions. The American Journal on Addictions, $10,136-158$.

Martsh, C. T., \& Miller, W. R. (1997). Extraversion predicts heavy drinking in college students. Personality and Individual Differences, 23(1), 153-155.

Mason, W. A., Hitch, J. E., Kosterman, R., McCarthy, C. A., Herrenkohl, T. I., \& Hawkins, J. D. (2010). Growth in adolescent delinquency and alcohol use in relation to young adult crime, alcohol use disorders, and risky sex: A comparison of youth from low- versus middle-income backgrounds. The Journal of Child Psychology and Psychiatry, 51(12), 1377-1385.

McAlaney, J., Helmer, S. M., Stock, C., Vriesacker, B., van Hal, G., Dempsey, R. C., ... Mikolajczyk, R. (2015). Personal and perceived peer use of and attitudes toward alcohol among university and college students in seven EU countries: Project SNIPE. Journal of Studies on Alcohol and Drugs, 76, 430-438.

McCabe, S. E. (2002). Gender differences in collegiate risk factors for heavy episodic drinking. Journal of Studies on Alcohol, 63(1), 49-56.

McGue, M., Slutske, W., Taylor, J., \& Iacono, W. G. (1997). Personality and substance use disorders: I. Effects of gender and alcoholism subtype. Alcoholism: Clinical and Experimental Research, 21, 513-520. 
McNulty, J. K., \& Karney, B. R. (2001). Attributions in marriage: Integrating specific and global evaluations of a relationship. Personality and Social Psychology Bulletin, 27(8), 943-955.

McNulty, J. K. (2008). Neuroticism and interpersonal negativity: The independent contributions of perceptions and behaviors. Personality and Social Psychology Bulletin, 34(11), 1439-1450.

Merenäkk, L., Harro, M., Kiive, E., Laidra, K., Eensoo, D., Allik, J., ... Harro, J. (2003). Association between substance use, personality traits, and platelet MAO activity in preadolescents and adolescents. Addictive Behaviors, 28, 1507-1514.

Mezquita, L., Stewart, S. H., \& Ruipérez, M. A. (2010). Big-five personality domains predict internal drinking motives in young adults. Personality and Individual Differences, 49, 240-245.

Moeller, F. G., Barratt, E. S., Dougherty, D. M., Schmitz, J. M., \& Swann, A. C. (2001). Psychiatric aspects of impulsivity. American Journal of Psychiatry, 158, 17831793.

Moffitt, T. E., Caspi, A., Taylor, A., Kokaua, J., Milne, B. J., Polanczyk, G., \& Poulton, R. (2010). How common are common mental disorders? Evidence that lifetime prevalence rates are doubled by prospective versus retrospective ascertainment. Psychological Medicine, 40, 899-909.

Mohr, C. D., Armeli, S., Tennen, H., Carney, M. A., Affleck, G., \& Hromi, A. (2001). Daily interpersonal experiences, context, and alcohol consumption: Crying in your beer and toasting good times. Journal of Personality and Social Psychology, 80(3), 489-500. 
Mohr, C. D., Brannan, D., Wendt, S., Jacobs, L., Wright, R., \& Wang, M. (2013). Daily mood-drinking slopes as predictors: A new take on drinking motives and related outcomes. Psychology of Addictive Behaviors, 27(4), 944-955.

Monk, R. L., Heim, D., Qureshi, A., \& Price, A. (2015). "I have no clue what I drunk last night": Using smartphone technology to compare in-vivo and retrospective selfreports of alcohol consumption. PLoS One, 10(5), DOI:

10.1371/journal.pone.0126209.

Muthén, B. O., \& Muthén, L. K. (2000). The development of heavy drinking and alcoholrelated problems from ages 18 to 37 in a U.S. national sample. Journal of Studies on Alcohol, 61, 290-300.

Nealis, L. J., Collins, J., Lee-Baggley, D. L., Sherry, S. B., \& Stewart, S. H. (2017). One of these things is not like the others: Testing trajectories in drinking frequency, drinking quantity, and alcohol-related problems in undergraduate women. Addictive Behaviors, 66, 66-69.

Neighbors, C., Oster-Aaland, L., Bergstrom, R. L., \& Lewis, M. A. (2006). Event- and context-specific normative misperceptions and high-risk drinking: $21^{\text {st }}$ birthday celebrations and football tailgating. Journal of Studies on Alcohol, 67, 282-289.

Neighbors, C., Spieker, C. J., Oster-Aaland, L., Lewis, M. A., \& Bergstrom, R. L. (2005). Celebration intoxication: An evaluation of $21^{\text {st }}$ birthday alcohol consumption. Journal of American College Health, 54, 76-80.

Newlin, D. B., \& Thomson, J. B. (1990). Alcohol challenge with sons of alcoholics: A critical review and analysis. Psychological Bulletin, 108(3), 383-402. 
Newton-Howes, G., \& Boden, J. M. (2016). Relation between age of first drinking and mental health and alcohol and drug disorders in adulthood: evidence from a 35year cohort study. Addiction, 111(4), 637-644.

Nezlek, J. B. (2001). Multilevel random coefficient analysis of event- and intervalcontingent data in social and personality psychology research. Personality and Social Psychology Bulletin, 27(7), 771-785.

Nezlek, J. B. (2003). Using multilevel random coefficient modelling to analyze social interaction diary data. Journal of Social and Personality Relationships, 20(4), 437-469.

Nezlek, J. B. (2008). An introduction to multilevel modeling for social and personality psychology. Social and Personality Psychology Compass, 2, 842-860. DOI: 10.1111/j.1751-9004.2007.00059.x.

NIAAA (2002). A call to action: Changing the culture of drinking at U.S. colleges. Bethesda. MD: National Institute on Alcohol Abuse and Alcoholism.

NIAAA (2003). Task force on recommended alcohol questions: National Council on Alcohol Abuse and Alcoholism recommended sets of alcohol consumption questions. Bethesda, MD: National Institute on Alcohol Abuse and Alcoholism.

Noguchi, K., Gohm, C. L., \& Dalsky, D. J. (2006). Cognitive tendencies of focusing on positive and negative information. Journal of Research in Personality, 40, 891910.

Norman, W. T. (1963). Toward an adequate taxonomy of personality attributes: Replicated factor structure in peer nomination personality ratings. Journal of Abnormal and Social Psychology, 66, 574-583. 
O'Hare, T. M. (1990). Drinking in college: Consumption patterns, problems, sex differences and legal drinking age. Journal of Studies on Alcohol, 51, 536-541.

O'Hare, T. M. (1991). Measuring alcohol consumption: A comparison of the retrospective diary and the quantity-frequency methods in a college drinking survey. Journal of Studies on Alcohol, 52(5), 500-502.

Otonari, J., Nagano, J., Morita, M., Budhathoki, S., Tashiro, N., Toyomura, N., ... Takayanagi, R. (2012). Neuroticism and extraversion personality traits, health behaviours, and subjective well-being: The Fukuaka Study (Japan). Quality of Life Research, 21(10), 1847-1855.

Osberg, T. M., Atkins, L., Buchholz, L., Shirshova, V., Swiantek, A., Whitley, J., ... Oquendo, N. (2010). Development and validation of the College Life Alcohol Salience Scale: A measure of beliefs about the role of alcohol in college life. Psychology of Addictive Behaviors, 24(1), 1-12.

Park, A., Sher, K. J., Wood, P. K., \& Krull, J. L. (2009). Dual mechanisms underlying accentuation of risky drinking via fraternity/sorority affilitation: The role of personality, peer norms, and alcohol availability. Journal of Abnormal Psychology, 118(2), 241-255.

Patrick, M. E., \& Maggs, J. L. (2008). Profiles of motivations for alcohol use and sexual behaviour among first-year university students. Journal of Adolescence, 33, 755765.

Patrick, M. E., \& Maggs, J. L. (2009). Does drinking lead to sex? Daily alcohol-sex behaviors and expectancies among college students. Psychology of Addictive Behaviors, 23(3), 472-481. 
Patrick, M. E., Maggs, J. L., \& Osgood, D. W. (2010). LateNight Penn State Alcohol-free programming: Students drink less on the days they participate. Prevention Science, 11, 155-162.

Pedersen, E. R., \& LaBrie, J. W. (2008). Normative misperceptions of drinking among college students: A look at the specific contexts of prepartying and drinking games. Journal of Studies on Alcohol and Drugs, 69, 406-411.

Perkins, H. W. (2002a). Surveying the damage: A review of research on consequences of alcohol misuse in college populations. Journal of Studies on Alcohol, 63(2), 91100.

Perkins, H. W. (2002b). Social norms and the prevention of alcohol misuse in collegiate contexts. Journal of Studies on Alcohol, Supplement No. 14, 164-172.

Phorecky, L. A. (1977). Biphasic action of ethanol. Biobehavioral Reviews, 1(4), 231240 .

Pihl, R. O., Paylan, S. S., Gentes-Hawn, A., \& Hoaken, P. N. S. (2003). Alcohol effects executive cognitive functioning differently on the ascending versus descending limb of the blood alcohol concentration curve. Alcoholism: Clinical and Experimental Research, 27(5), 773-779.

Pohorecky, L. A. (1977). Biphasic action of ethanol. Biobehavioural Reviews, 1, 231240.

Quilty, L. C., DeYoung, C. G., Oakman, J. M., \& Bagby, R. M. (2014). Extraversion and behavioral activation: Integrating the components of approach. Journal of Personality Assessment, 96(1), 87-94. 
Ragsdale, K., Porter, J. R., Mathews, R., White, A., Gore-Felton, C., \& McGarvey, E. L. (2012). “Liquor before beer, you're in the clear": Binge drinking and other risk behaviours among fraternity/sorority members and their non-Greek peers. Journal of Substance Use, 17(4), 323-339.

Raudenbush, S. W., \& Bryk, A. S. (2002). Hierarchical linear models: Applications and data analysis methods ( $2^{\text {nd }}$ ed.). Thousand Oaks, CA: Sage Publications.

Raynor, D. A., \& Levine, H. (2009). Associations between the five-factor model of personality and health behaviors among college students. Journal of American College Health, 58(1), 73-81.

Regier, D. A., Farmer, M. E., Rae, D. S., Locke, B. Z., Keith, S. J., Judd, L. L., \& Goodwin, F. K. (1990). Comorbidity of mental disorders with alcohol and other drug abuse: Results from the Epidemiologic Catchment Area (ECA) study. Journal of the American Medical Association, 264(19), 2511-2518.

Rehm, J., Room, R., Graham, K., Monteiro, M., Gmel, G., \& Sempos, C. T. (2003). The relationship of average volume of alcohol consumption and patterns of drinking to burden of disease: an overview. Addiction, 98, 1209-1228.

Rehm, J., Mathers, C., Popova, S., Thavorncharoensap, M, Teerawattananon, Y., \& Patra, J. (2009). Global burden of disease and injury and economic cost attributable to alcohol use and alcohol use disorders. The Lancet, 373, 2223-2233.

Rehm, J., Anderson, P., Barry, J., Dimitrov, P., Elekes, Z., Feijão, F., ... Gmel, G. (2015). Prevalence of and potential influencing factors for alcohol dependence in Europe. European Addiction Research, 21(1), 6-18. 
Roberts, B. W., \& DelVecchio, W. F. (2000). The rank-order consistency of personality from childhood to old age: A quantitative review of longitudinal studies. Psychological Bulletin, 126, 3-25.

Rosenberg, H., Bonar, E. E., Hoffman, E., Kryszak, E., Young, K. M., Kraus, S. W., ... Pavlick, M. (2011). Assessing university students'self-efficacy to employ alcohol-related harm reduction strategies. Journal of American College Health, 59(8), 736-742.

Roy, A., \& Linnoila, M. (1986). Alcoholism and suicide. Suicide and Life-Threatening Behavior, 16(2), 244-273.

Rubenking, B., \& Lang, A. (2015). Appetitive and impulsive: Examining alcohol use via the motivational and self-control systems. The Social Science Journal, 52, 258265.

Ruch, W. (1994). Extraversion, alcohol, and enjoyment. Personality and Individual Differences, 16(1), 89-102.

Ruiz, M. A., Pincus, A. L., \& Dickinson, K. A. (2003). NEO PI-R predictors of alcohol use and alcohol-related problems. Journal of Personality Assessment, 81(3), 226236.

Russell, M. A., Almeida, D. M., \& Maggs, J. L. (2017). Stressor-related drinking and future alcohol problems among university students. Psychology of Addictive Behaviors, 31(6), 676-687.

Rutledge, P. C., \& Sher, K. J. (2001). Heavy drinking from the freshman year into early young adulthood: The roles of stress, tension-reduction drinking motives, gender and personality. Journal of Studies on Alcohol, 62, 457-455. 
Saunders, J. B., Aasland, O. G., Amundsen, A., \& Grant, M. (1993). Alcohol consumption and related problems among primary health care patients: WHO collaborative project on early detection of persons with harmful alcohol consumption I. Addiction, 88, 349-362.

Saunder,s J. B., Aasland, O. G., Babor, T. F., de la Fuente, J. R., \& Grant, M. (1993). Development of the Alcohol Use Disorders Identification Test (AUDIT): WHO collaborative project on early detection of person with harmful alcohol consumption II. Addiction, 88, 791-804.

Scaglione, N. M., Turrisi, R., Mallett, K. A., Ray, A. E., Hultgren, B. A., \& Cleveland, M. J. (2014). How much does one more drink matter? Examining effects of eventlevel alcohol use and previous sexual victimization on sex-related consequences. Journal of Studies on Alcohol and Drugs, 75, 241-248.

Schilling, E. A., Aseltine, R. H., Glanovsky, J. L., James, A., \& Jacobs, D. (2009). Adolescent Alcohol use, suicide ideation, and suicide attempts. Journal of Adolescent Health, 44(4), 335-341.

Schulenberg, J. E., \& Maggs, J. L. (2002). A developmental perspective on alcohol use and heavy drinking during adolescence and the transition to young adulthood. Journal of Studies on Alcohol, 63(2), 54-70.

Schwandt, M. L., Heilig, M., Hommer, D. W., George, D. T., \& Ramchandani, V. A. (2013). Childhood trauma exposure and alcohol dependence severity in adulthood: Mediation by emotional abuse severity and neuroticism. Alcoholism: Clinical and Experimental Research, 37(6), 984-992. 
Scollon, C. N., \& Diener, E. (2006). Love, work, and changes in extraversion and neuroticism over time. Journal of Personality and Social Psychology, 91(6), $1152-1165$

Scott-Sheldon, L. A. J., Terry, D. L., Carey, K. B., Garey, L., \& Carey, M. P. (2012). Efficacy of expectancy challenge interventions to reduce college student drinking: A meta-analytic review. Psychology of Addictive Behaviors, 26(2), 393-405.

Scott-Sheldon, L. A. J., Carey, K. B., Elliott, J. C., Garey, L., \& Carey, M. P. (2014). Efficacy of alcohol interventions for first-year college students: A meta-analytic review of randomized controlled trials. Journal of Consulting and Clinical Psychology, 82(2), 177-188.

Scott-Sheldon, L. A. J., Carey, K. B., Kaiser, T. S., Knight, J. m., \& Carey, M. P. (2016). Alcohol interventions for Greek letter organizations: A systematic review and meta-analysis, 1987-2014. Health Psychology, 35(7), 670-684.

Sher, K. J., Trull, T. J., Batholow, B. D., \& Vieth, A. (1998). Personality and alcoholism: issues, methods, and etiological processes. In K. E. Leonard \& H. T. Blane (Eds.), Psychological theories of drinking and alcoholism: second edition (pp. 54-105). New York, NY: The Guilford Press.

Sher, K. J., Walitzer, K. S., Wood, P, K., \& Brent, E. E. (1991). Characteristics of children of alcoholics: Putative risk factors, substance use and abuse, and psychopathology. Journal of Abnormal Psychology, 100(4), 427-448.

Sherman, D. K., Bunyan, D. P., Creswell, J. D., \& Jaremka, L. M. (2009). Psychological vulnerability and stress: the effects of self-affirmation on sympathetic nervous system responses to naturalistic stressors. Health Psychology, 28(5), 554-562. 
Shiffman, S., Stone, A. A., \& Hufford, M. R. (2008). Ecological momentary assessment. Annual Review of Clinical Psychology, 4, 1-32.

Slutske, W. S., Hunt-Carter, E. E., Nabors-Oberg, R. E., Sher, K. J., Bucholz, K. K., Madden, P. A. F., ... Heath, A. C. (2004). Do college students drink more than their non-college attending peers? Evidence from a population-based longitudinal female twin study. Journal of Abnormal Psychology, 113(4), 530-540.

Smeaton, G. L., Josiam, B. M., \& Dietrich, U. C. (1998). College students’ binge drinking at a beach-front destination during spring break. Journal of American College Health, 46, 247-254.

Smillie, L. D., Cooper, A. J., Wilt, J., \& Revelle, W. (2012). Do extraverts get more bang for the buck? Refining the affective-reactivity hypothesis of extraversion. Journal of Personality and Social Psychology, 103(2), 306-326

Sobell, L. C., \& Sobell, M. B. (1990). Self-report issues in alcohol abuse: State of the art and future directions. Behavioral Assessment, 12, 77-90.

Spangler, G. (1997). Psychological and physiological responses during an exam and their relation to personality characteristics. Psychoneuroendocrinology, 22(6), 423-441.

Spielberger, C. D., \& Vagg, P. R. (1995). Test anxiety: a transactional process model. In: C. D. Spielberger \& P. R. Vagg (Eds.), Test anxiety: Theory, assessment, and treatment (pp.3-14). Washington, DC: Taylor and Francis.

Spijkerman, R., Knibbe, R., Knoops, K., van de Mheen, D., \& van den Eijinden, R. (2007). The utility of online panel surveys versus computer-assisted interviews in obtaining substance-use prevalence estimates in the Netherlands. Addiction, 104, $1641-1645$. 
Staff, J., Greene, K. M., Maggs, J. L., \& Schoon, I. (2013). Family transitions and change in drinking from adolescence to mid-life. Addiction, 109(2), 227-236.

Stahre, M., Naimi, T., Brewer, R., \& Holt, J. (2006). Measuring average alcohol consumption: the impact of including binge drinks in quantity - frequency calculations. Addiction, 101, 1711-1718.

Stautz, K., \& Cooper, A. J. (2014). Brief report: Personality correlates of susceptibility to peer influence in adolescence. Journal of Adolescence, 37, 401-405.

Stautz, K., Dinc, L., \& Cooper, A. J. (2017). Combining trait models of impulsivity to improve explanation of substance use behaviour. European Journal of Personality, 31, 118-132.

Steele, R. G., Forehand, R., Armistead, L., \& Brody, G. (1995). Predicting alcohol and drug use in early adulthood: The role of internalizing and externalizing behaviour problems in early adolescence. American Journal of Orthopsychiatry, 65(3), 380388.

Stewart, S. H., \& Devine, H. (2000). Relations between personality and drinking motives in young adults. Personality and Individual Differences, 29, 495-511.

Stewart, S. H., Loughlin, H. L., \& Rhyno, E. (2001). Internal drinking motives mediate personality domain - drinking relations in young adults. Personality and Individual Differences, 30, 271-286.

Stewart, S. H., Gavric, D., \& Collins, P. (2009). Women, girls, and alcohol. In K. Brady, S. Back, \& S. Greenfield (Eds.), Women and alcohol (pp. 341-359). New York: Guildford. 
Stillmaker, J., \& Kasser, T. (2013). Instruction in problem-solving skills increases the hedonic balance of highly neurotic individuals. Cognitive Therapy Research, 37, $380-382$.

Stopfer, J. M., Egloff, B., Nestler, S., \& Back, M. D. (2014). Personality expression and impression formation in online social networks: An integrative approach to understanding the processes of accuracy, impression management, and metaaccuracy. European Journal of Personality, 28, 73-94.

Straud, C., McNaughton-Cassill, M., \& Fuhrman, R. (2015). The role of the Five Factor Model of personality with proactive coping and preventative coping among college students. Personality and Individual Differences, 83, 60-64.

Sutherland, E. H., Schroeder, H. G., \& Tordella, C. L. (1950). Personality traits and the alcoholic; a critique of existing studies. Quarterly Journal of Studies on Alcohol, 11(4), 547-561.

Sznitman, S. R., Kolobov, T., ter Bogt, T., Kuntsche, E., Walsh, S. D., Boniel-Nissim, M., \& Harel-Fisch, Y. (2013). Exploring substance use normalization among adolescents: A multilevel study in 35 countries. Social Science and Medicine, 97, $143-151$.

Tanaree, A., Assanankornchai, S., \& Kittirattanapaiboon, P. (2017). Pattern and risk of developing alcohol use disorders, illegal substance use and psychiatric disroders after early onset of alcohol use: Results of the Thai National Mental Health Survey 2013. Drug and Alcohol Dependence, 170, 102-111

Tjepkema, M. (2004). Alcohol and illicit drug dependence. Health Reports, 15, 9-18. 
Tong, E. M. W. (2010). Personality influences in appraisal-emotion relationships: The role of neuroticism. Journal of Personality, 78, 393-417.

Verster, J. C, van Duin, D., Volkerts, E. R., Schreuder, A. H., \& Verbaten, M. N. (2003). Alcohol hangover effects on memory functioning and vigilance performance after an evening of binge drinking. Neuropsychopharmacology, 28, 740-746.

Weinberger, D. A., \& Bartholomew, K. (1996). Social-emotional adjustment and patterns of alcohol use among young adults. Journal of Personality, 64(2), 495-527.

Weinstock, L. M., \& Whisman, M. A. (2006). Neuroticism as a common feature of the depressive and anxiety disorders: A test of the revised integrative hierarchical model in a national sample. Journal of Abnormal Psychology, 115(1), 68-74.

Wechsler, H., Dowdall, G. W., Davenport, A., \& Castillo, S. (1995). Correlates of college student binge drinking. American Journal of Public Health, 85, 921-926.

Wechsler, H., Dowdall, G. W., Maenner, G., Gledhill-Hoyt, J., \& Lee, H. (1998). Changes in binge drinking and related problems among American college students between 1993 and 1997: Results of the Harvard School of Public Health College Alcohol Study. Journal of American College Health, 47(2), 57-68.

Wechsler, H., \& Kuo, M. (2003). Watering down the drinks: The moderating effect of college demographics on alcohol use of high-risk groups. American Journal of Public Health, 93, 1929-1933.

White, A. M., Kraus, C. L., McCracken, L. A., \& Swartzwelder, H. S. (2003). Do college students drink more than they think? Use of a free-pour paradigm to determine how college students define standard drinks. Alcoholism: Clinical and Experimental Research, 27(11), 1750-1756. 
White, H. R., \& Labouvie, E. W. (1989). Towards the assessment of adolescent problem drinking. Journal of Studies on Alcohol, 50(1), 30-37.

Williams, P. G., O’Brien, C. D., \& Colder, C. R. (2004). The effects of neuroticism and extraversion on self-assessed health and health-relevant cognition. Personality and Individual Differences, 37(1), 83-94.

Wood, P. K., Sher, K. J., \& Rutledge, P. C. (2007). College student alcohol consumption, day of the week, and class schedule. Alcoholism: Clinical and Experimental Research, 31(7), 1195-1207

Workman, T. A. (2001). Finding the meanings of college drinking: An analysis of fraternity drinking stories. Health Communication, 13(4), 427-447.

Zenmore, S. E., Ye, Y., Mulia, N., Martinez, P., Jones-Webb, R., \& Karriker-Jaffe, K. (2016). Poor, persecuted, young and alone: Toward explaining the elevated risk of alcohol problems among Black and Latino men who drink. Drug and Alcohol Dependence, 163, 31-39.

Zucker, R. A., Heitzeg, M. M., \& Nigg, J. T. (2011). Parsing the undercontroldisinhibition pathway to substance use disorders: A multilevel developmental problem. Child Development Perspectives, 5(4), 248-255.

Zunhammer, M., Eberle, H., Eichhammer, P., \& Busch, V. (2013). Somatic symptoms evoked by exam stress in university: the role of alexithymia, neuroticism, anxiety and depression. PLOS One, 8(12): doi:10.1371/journal.pone.0084911. 
Appendix A: International Personality Item Pool Lexical Markers (Goldberg, 1992).

The following phrases describe people's characteristics. Please indicate how accurately each statement describes you as you generally are now, not as you wish to be in the future. Describe yourself in relation to other people you know who are the same age and sex as you.

Neither

Very Moderately inaccurate Moderately Very Inaccurate Inaccurate or accurate accurate Accurate

\section{Extraversion}

Am the life of the party.

Don't talk a lot.

Keep in the background.

Don't like to draw attention to myself. Don't mind being the center of attention.

Have little to say.

Talk to a lot of different people at parties.

Start conversations.

Feel comfortable around people.

Am quiet around strangers.

$\begin{array}{lllll}1 & 2 & 3 & 4 & 5 \\ 1 & 2 & 3 & 4 & 5 \\ 1 & 2 & 3 & 4 & 5 \\ 1 & 2 & 3 & 4 & 5 \\ 1 & 2 & 3 & 4 & 5 \\ 1 & 2 & 4 & 5 \\ 1 & 2 & 4 & 5 \\ 1 & 2 & 3 & 4 & 5 \\ 1 & 2 & 3 & 4 & 5 \\ 1 & 2 & 3 & 4 & 5\end{array}$

\section{Neuroticism}

Get stressed out

easily.

Have frequent mood swings.

Get irritated easily.

Often feel blue.

Get upset easily.

Am easily disturbed.

Change my mood a

lot.

Worry about things.

Am relaxed most of

the time.

Seldom feel blue.

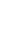 \\ 1}

2

12

2

3


Appendix B: Alcohol Use Disorders Identification Test (Babor, Higgins-Biddle,

Saunders, \& Monteiro, 2001).

Questions that do not have numerical answers have their scoring values in parentheses.

Select the option that best describes your answer to each question.

1. How often do you have a drink containing alcohol?

\begin{tabular}{|c|c|c|c|c|}
\hline Never (0) & $\begin{array}{c}\text { Monthly or } \\
\text { less (1) }\end{array}$ & $\begin{array}{c}\text { 2-4 times a } \\
\text { month (2) }\end{array}$ & $\begin{array}{c}2-3 \text { times a } \\
\text { week (3) }\end{array}$ & $\begin{array}{c}4 \text { or more } \\
\text { times a week } \\
\end{array}$
\end{tabular}

2. How many drinks containing alcohol do you have on a typical day when you are drinking?

\begin{tabular}{|c|c|c|c|c|c|}
\hline $\begin{array}{c}\text { None } \\
\text { (Skip } \\
\text { questions 3-8) }\end{array}$ & $\begin{array}{c}1 \text { or } 2 \\
(0)\end{array}$ & $\begin{array}{c}3 \text { or } 4 \\
(1)\end{array}$ & $\begin{array}{c}5 \text { or } 6 \\
(2)\end{array}$ & $\begin{array}{c}7 \text { to } 9 \\
(3)\end{array}$ & $\begin{array}{c}10 \text { or more } \\
(4)\end{array}$ \\
\hline
\end{tabular}

\begin{tabular}{|l|c|c|c|c|c|}
\hline & Never & $\begin{array}{c}\text { Less than } \\
\text { Monthly }\end{array}$ & Monthly & Weekly & $\begin{array}{c}\text { Daily or } \\
\text { almost } \\
\text { daily }\end{array}$ \\
\hline $\begin{array}{l}3 . \text { How often do } \\
\text { you have six or } \\
\text { more drinks on one } \\
\text { occasion? }\end{array}$ & 0 & 1 & 2 & 3 & 4 \\
\hline $\begin{array}{l}\text { 4. How often during } \\
\text { the last year have } \\
\text { you found that you } \\
\text { were not able to } \\
\text { stop drinking once } \\
\text { you had started? }\end{array}$ & 0 & 1 & 2 & 3 & 4 \\
\hline $\begin{array}{l}\text { 5. How often during } \\
\text { the last year have } \\
\text { you failed to do } \\
\text { what was normally } \\
\text { expected of you } \\
\text { because you were } \\
\text { drinking? }\end{array}$ & 0 & 1 & 2 & 3 & 4 \\
\hline $\begin{array}{l}\text { 6. How often during } \\
\text { the last year have }\end{array}$ & 0 & 1 & 2 & 3 & 4 \\
\hline
\end{tabular}




\begin{tabular}{|l|l|l|l|l|l|}
\hline $\begin{array}{l}\text { you needed a first } \\
\text { drink in the } \\
\text { morning to get } \\
\text { yourself going after } \\
\text { a heavy drinking } \\
\text { session? }\end{array}$ & & & & \\
\hline $\begin{array}{l}7 . \text { How often during } \\
\text { the last year have } \\
\text { you had a feeling of } \\
\text { guilt or remorse } \\
\text { after drinking? }\end{array}$ & 0 & 1 & 2 & 3 & 4 \\
\hline $\begin{array}{l}8 . \text { How often during } \\
\text { the last year have } \\
\text { you been unable to } \\
\text { remember what } \\
\text { happened the night } \\
\text { before because of } \\
\text { drinking? }\end{array}$ & 0 & 1 & 2 & 3 & 4 \\
\hline
\end{tabular}

9. Have you or someone else been injured because of your drinking?

\begin{tabular}{|c|c|c|}
\hline Never (0) & $\begin{array}{c}\text { Yes, but not in the last } \\
\text { year } \\
(2)\end{array}$ & $\begin{array}{c}\text { Yes, during the last year } \\
(4)\end{array}$ \\
\hline
\end{tabular}

10. Has a relative, friend, or doctor, or other health care worker been concerned about your drinking or suggested you cut down?

\begin{tabular}{|c|c|c|}
\hline No (0) & $\begin{array}{c}\text { Yes, but not in the last } \\
\text { year (2) }\end{array}$ & $\begin{array}{c}\text { Yes, during the last year } \\
(4)\end{array}$ \\
\hline
\end{tabular}

